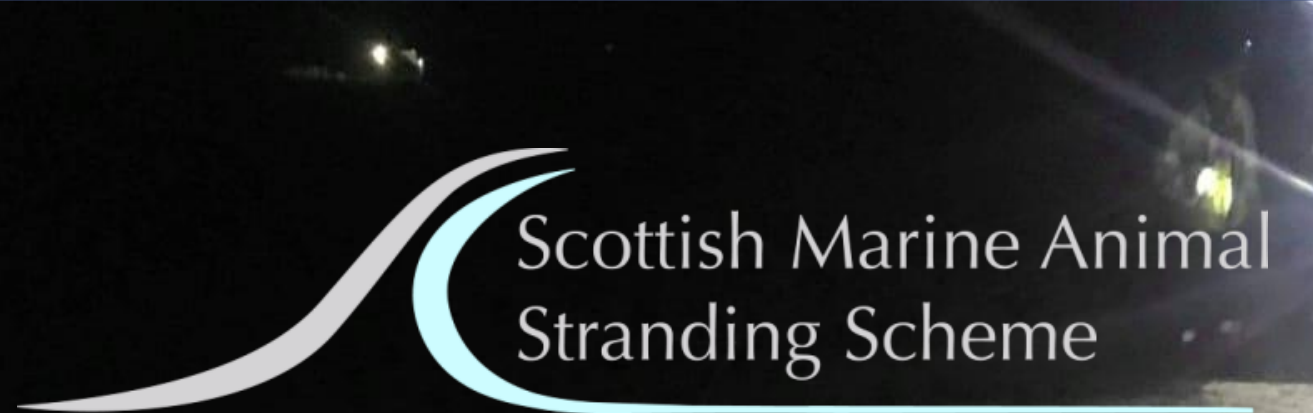

\title{
Annual Report 2018
}

1 January to 31 December 2018

for Marine Scotland, Scottish Government

Andrew Brownlow, Nick Davison and Mariel ten Doeschate SRUC Wildlife Unit

Drummondhill

Inverness

IV2 4JZ

Tel 01463246044 


\section{Contents}

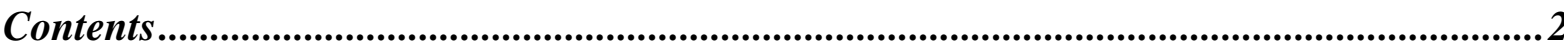

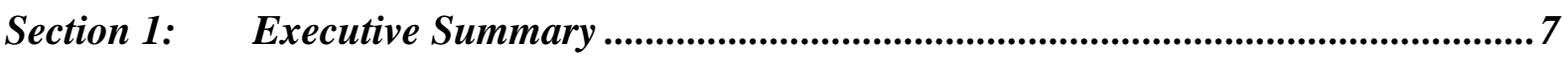

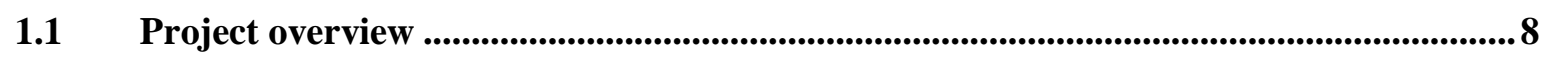

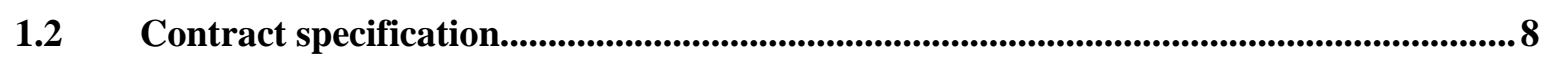

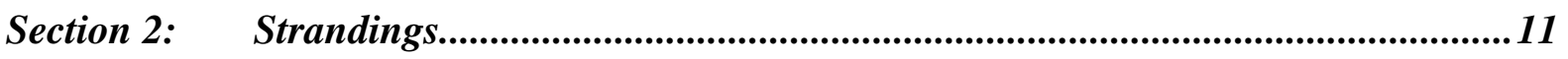

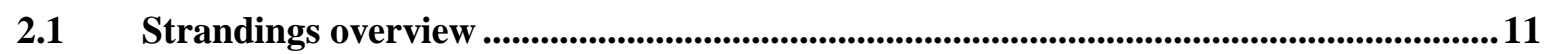

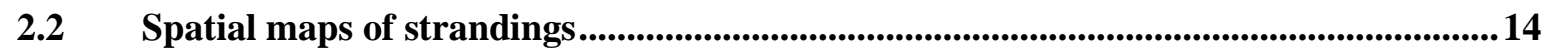

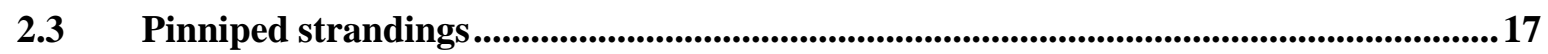

2.3.1 'Corkscrew' or spiral trauma cases ..................................................................................... 18

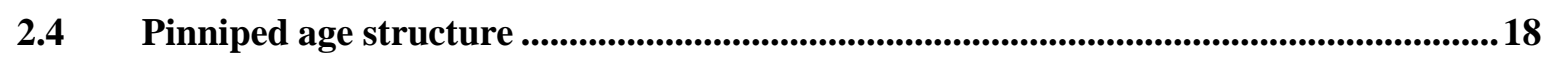

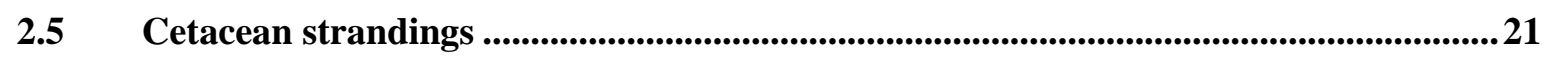

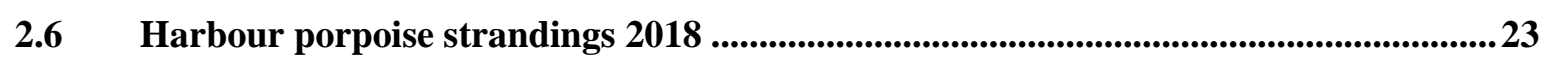

Section 3: Cause of death/findings summary tables ...................................................25

3.1 Cause of death; direct anthropogenic versus other causes of death. .............................27

Section 4: $\quad$ Mass stranding events (MSE's) and Unusual mortality events (UME's).....29

4.1.1 Mass stranding events (MSE's) multiple strandings and unusual mortality events 29

4.2 M193.1- M193.2/18 harbour porpoise (Phocoena phocoena) ...........................................29

4.3 M245.1- M245.2/18 common dolphin (Delphinus delphis) ............................................31

4.4 M245.1- M245.2/18 common dolphin (Delphinus delphis) ................................................32

4.5 M769.1- M769.5/18 long-finned pilot whale (Globicephala melas) ...................................33

4.6 Cuvier's beaked whale (Ziphius cavirorostris) and Northern bottlenose whale (Hyperoodon ampullatus) UME (s) .........................................................................................................35

Section 5: Entanglement cases..........................................................................................39

5.1 Cetacean entanglement cases............................................................................................39

5.1.1 M592/18 - minke whale (Balaenoptera acutorostrata) ......................................... 39

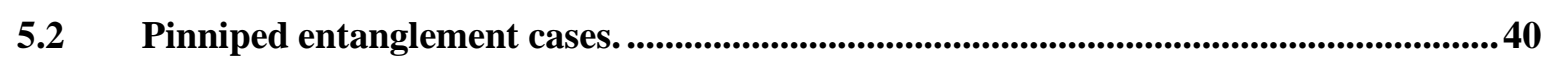

5.2.1 M364/18 - Grey seal (Halichoerus grypus)......................................................... 40

Section 6: Grey seal predation (cetaceans)................................................................41

6.1 Primary trauma cases suspected to be seal predation on harbour porpoise.................42

6.2 Secondary infection possibly due to seal bite lesions on harbour porpoise .................... 44

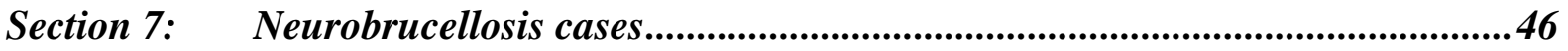

7.1 M129/18 - Atlantic white-sided dolphin (Lagenorhynchus acutus)..................................46

7.2 M391/18 - Sowerby's beaked whale (Mesoplodon bidens) ................................................... 47

7.3 M553/18- striped dolphin (Stenella coeruleoalba) ........................................................48 


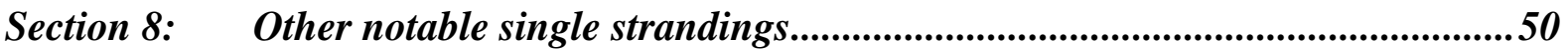

8.1 M59/18- Long-finned pilot whale (Globicephala melas) ..........................................50

8.2 M181/18 - Sperm whale (Physeter macrocephalus) ..............................................................51

8.3 M285/18 - harbour porpoise (Phocoena phocoena) ...............................................................52

8.4 M402/18- Sowerby's beaked whale (Mesoplodon bidens) ...............................................53

8.5 M481/18 - Risso's dolphin (Grampus griseus) ...............................................................54

8.6 M488/18 - white beaked dolphin (Lagenorhynchus albirostris) .....................................55

8.7 M586/18 - minke whale (Balaenoptera acutorostrata) ........................................................56

8.8 M644 /18- sperm whale (Physeter macrocephalus) .............................................................57

8.9 M773/18 - short-beaked common dolphin (Delphinus delphis) .........................................58

8.10 M919/18 - Cuvier's beaked whale (Ziphius cavirostris) ........................................................59

Section 9: Spiral "corkscrew" trauma seal cases.......................................................61

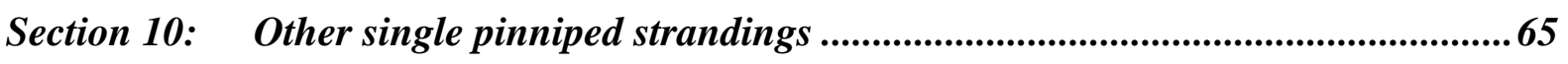

10.1 M6/18- Harbour seal (Phoca vitulina) …...........................................................................65

10.2 M27/18- Harbour seal (Phoca vitulina) .........................................................................65

10.3 M263/18- Harbour seal (Phoca vitulina) ....................................................................................66

10.4 M296/18- harp seal (Pagophilus groenlandicus) ...........................................................67

$10.5 \quad \mathrm{M343/18}$ - grey seal (Halichoerus grypus) ................................................................................68

10.6 M429/18- Harbour seal (Phoca vitulina) ....................................................................69

10.7 M523/18- Harbour seal (Phoca vitulina) …..................................................................... 71

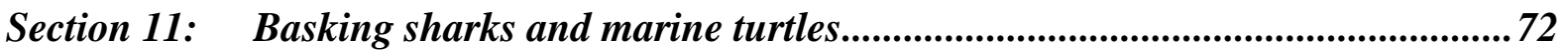

11.1 Basking sharks (Cetorhinus maximus) …....................................................................... 72

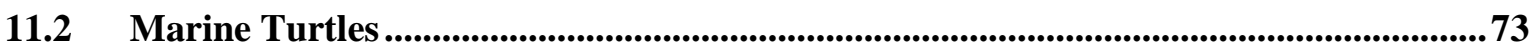

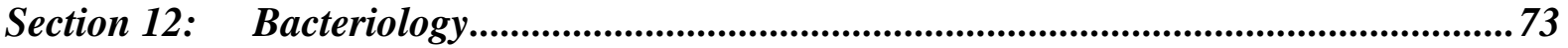

$12.1 \quad$ Brucella sp....................................................................................................................................... 73

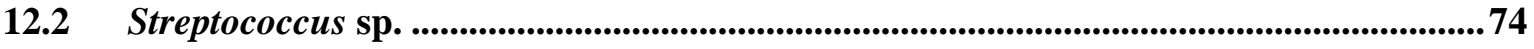

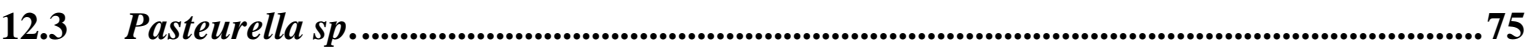

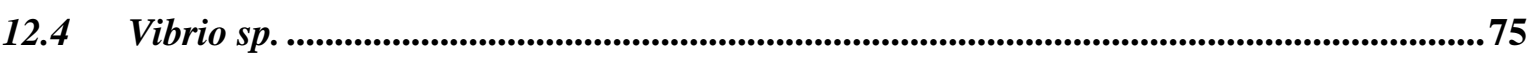

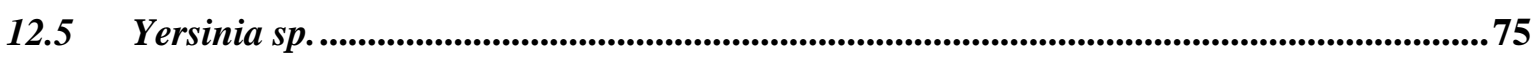

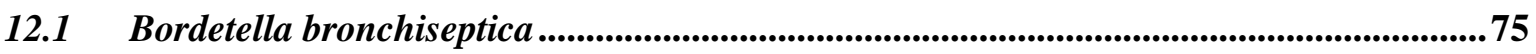

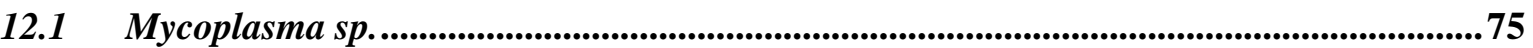

$12.2 \quad$ Fungal isolates................................................................................................................................. 76

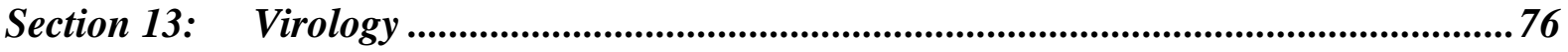

Section 14: Volunteer training courses …...........................................................................76

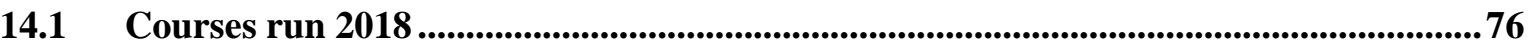

Section 15: Necropsy demonstrations and outreach ................................................. 79

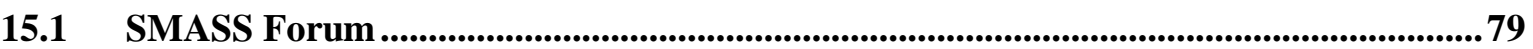




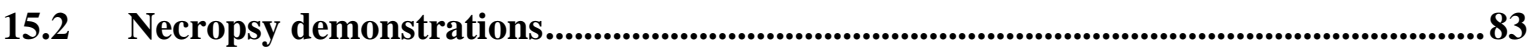

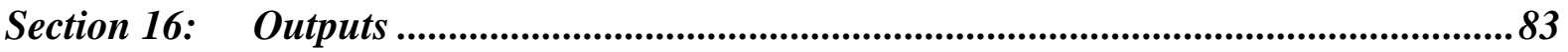

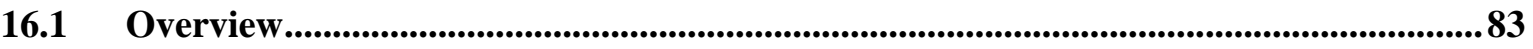

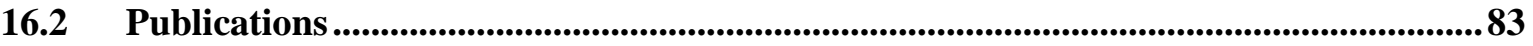

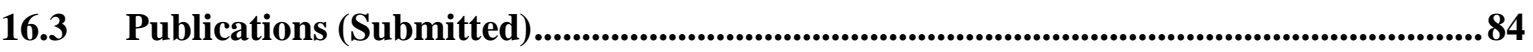

16.4 Conference Presentations.......................................................................................................... 84

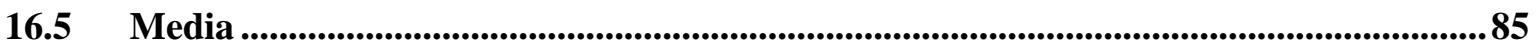

16.6 Conferences/meetings...........................................................................................................8

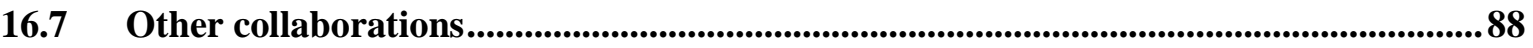

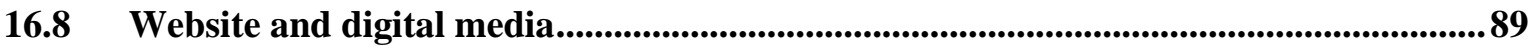

16.9 Data and sample requests .............................................................................................................90

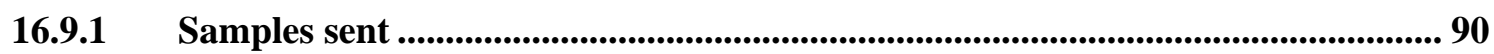

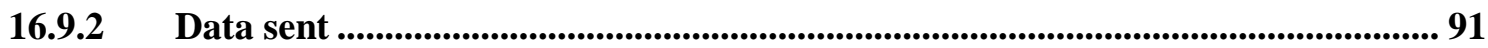

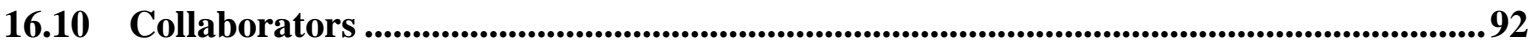

Section 17: Staff and facilities ...............................................................................................93

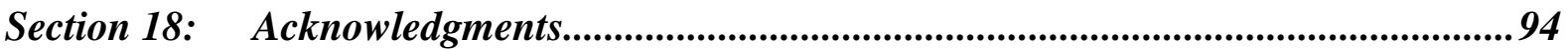

Figure 1: Total number of strandings reported 2009-2018. Red line shows the mean number of strandings over

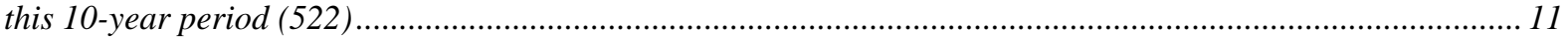

Figure 2: Total number of species reported in 2018, by subclass …............................................................ 13

Figure 3: Cumulative number of cases all species by month for 2014 - 2018.............................................. 13

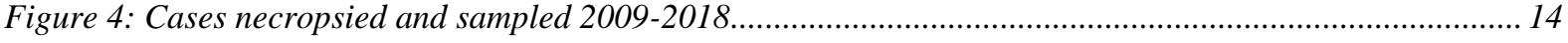

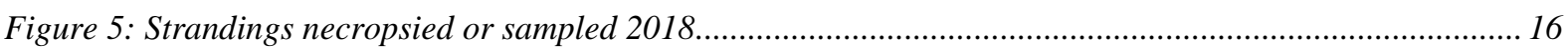

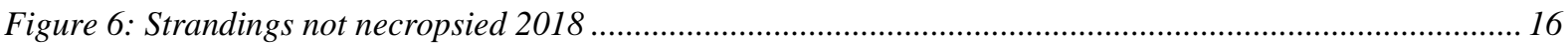

Figure 7: Kernel density plot of all strandings 2017. Colour spectrum from green (low) to red (high) ............. 17

Figure 8: Pinniped strandings (all species) 2014-2018, separated by level of examination ............................... 18

Figure 9:- Age structure of pinniped strandings 2018, by age group and species.......................................20

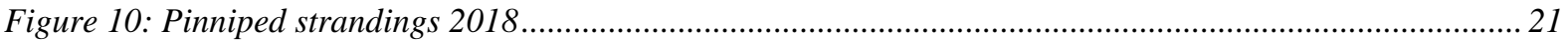

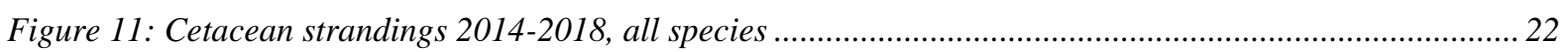

Figure 12: All cetacean strandings excluding harbour porpoise 2018 .........................................................2 23

Figure 13: Spatial distribution of Harbour porpoise strandings, by age class, 2018 .....................................2 24

Figure 14: Cause of death findings per species class. Direct anthropogenic versus other causes of death. ....... 28

Figure 15: M193.1/18 harbour porpoise (Phocoena phocoena) from the Fortrose........................................29

Figure 16: M193.2.2/18 harbour porpoise (Phocoena phocoena) from Fortrose prior to refloat....................... 30

Figure 17: M245.1 \&.2/18 common dolphins (Delphinus delphis) from Cairn Ryan Beach near Stranraer .......31

Figure 18: M251.1/18 common dolphin (Delphinus delphis) from South Uist. ............................................ 32

Figure 19: M251.2/18 common dolphin (Delphinus delphis) from South Uist. ............................................ 33

Figure 20: M769.1- M769.5/18 long-finned pilot whale (Globicephala melas) near Culross, Fife on the Firth of Forth on the 4th of December... 
Figure 23: M769.4/18 long-finned pilot whale (Globicephala melas) showing extent of purulent abscess on tailstock..

Figure 24: Distribution of beaked whale strandings 2018

Figure 25: Distribution of beaked whale strandings 2018, grouped by region.

Figure 26: M592/18 minke whale (Balaenoptera acutorostrata) from Ardeseir, Highland.....

Figure 27: M364/18 grey seal (Halichoerus grypus) from Skaw beach, Unst, Shetland with net entanglement around neck.

Figure 28: M364/18 grey seal (Halichoerus grypus) from Skaw beach, Unst, Shetland showing lesion once net has been removed.

Figure 29: M78/18 harbour porpoise (Phocoena phocoena) Largs, North Ayrshire showing lesions typically associated with grey seal predation.

Figure 30: M78/18 harbour porpoise (Phocoena phocoena) Glackbabuie, Bute,showing lesions typical of grey seal predation with likely post-mortem avianscavenging.

Figure 31: M78/18 harbour porpoise (Phocoena phocoena) showing infected bite wound to right pectoral fin (arrow)......

Figure 32: M78/18 harbour porpoise (Phocoena phocoena) showing lung abscessation.

Figure 33: M129/18 Atlantic white-sided dolphin (Lagenorhynchus acutus) Hoy, Orkney. 46

Figure 34: M129/18 Atlantic white-sided dolphin (Lagenorhynchus acutus) showing severe dilation of lateral ventricles (arrows) of the brain.

Figure 35: M391/18 Sowerby's beaked whale (Mesoplodon bidens) Brue, Lewis. 48

Figure 36: M391/18 Sowerby's beaked whale (Mesoplodon bidens) brain showing enlarged lateral ventricles (yellow arrows)......

Figure 37: M553/18 striped dolphin (Stenella coeruleoalba) from Benderloch, Argyll and Bute. 49

Figure 38: M553/18 striped dolphin (Stenella coeruleoalba) showing dilated lateral ventricles and turbid CSF

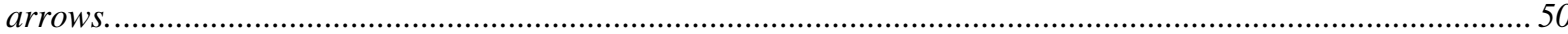

Figure 39: M59/18 long-finned pilot whale (Globicephala melas) on Calgary beach, Mull. .............................51

Figure 40: M181/18 sperm whale (Physeter macrocephalus) from the Tay estuary..................................... 52

Figure 41: M285/18 harbour porpoise (Phocoena phocoena) from Fort George. Photo credit John Hourston. 53

Figure 42: Sowerby's beaked whale (Mesoplodon bidens) from Belhaven beach. ...........................................54

Figure 43: Risso's dolphin (Grampus griseus) nenonte from Aultbea, Highland.......................................... 55

Figure 44: M488/18 white beaked dolphin (Lagenorhynchus albirostris) from Evie beach, Aiterness, Orkney.. 56

Figure 45: M586/18 minke whale (Balaenoptera acutorostrata) from Ardeseir, Highland................................5 57

Figure 46: M447/17 neonate sperm whale (Physeter macrocephalus) East Kilbride beach, South Uist............ 58

Figure 47: M773/18 short-beaked common dolphin (Delphinus delphis) Troon, South Ayrshire...................... 59

Figure 48: M919/18 Cuvier's beaked whale (Ziphius cavirostris) Calgary beach, Mull................................... 60

Figure 49: M324/18 harbour seal (Phoca vitulina) from Jemimaville, Highland showing typical

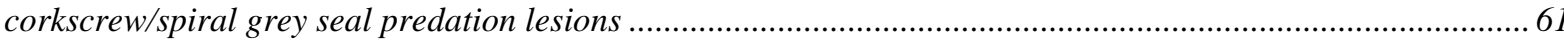

Figure 50: M6/18 harbour seal (Phoca vitulina) from Reiff near Achiltibuie, Highland....................................65

Figure 51: M27/18 harbour seal seal (Phoca vitulina) from Portree, Skye ..................................................66

Figure 52: M263/18 harbour seal (Phoca vitulina) from Fairlie, North Ayrshire. ........................................ 67

Figure 53: M296/18 harp seal (Pagophilus groenlandicus) from near Halistra, Skye.................................... 68

Figure 54: M343/18 grey seal (Halichoerus grypus) from near Melby, Shetland...........................................69

Figure 55: M263/18 harbour seal (Phoca vitulina) from Kylesku, Highland. .............................................. 70 
Figure 56: M523/18 harbour seal (Phoca vitulina) from St. Ninians Isle, Shetland.

Figure 57: M728/18 Basking shark (Cetorhinus maximus) from Elliot beach, Angus

Figure 58: M445/18 leatherback turtle (Dermochelys coriacea), disentangled by fishermen and released alive from creel lines near Barra, Western Isles. 73

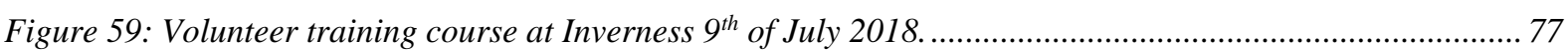

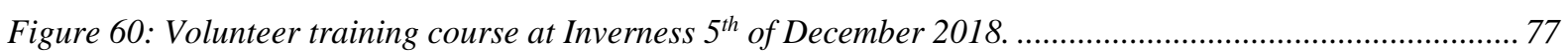

Figure 61: Distribution of stranding volunteers, colours representing the different WhatsApp groups .............. 78

Figure 62: WDC Photographer Charlie Phillips giving a workshop on wildlife photography at the SMASS

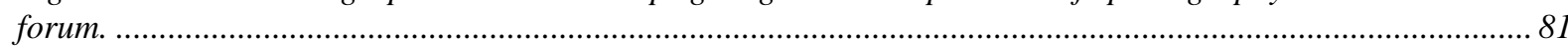

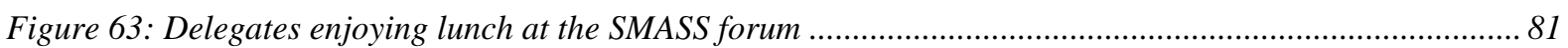

Figure 64: Stephen Marsh Operations Manager for British Diver's Marine Life Rescue (BDMLR) gets volunteers involved in a mock mass stranding workshop at the SMASS forum.

Figure 65: Necropsy Demonstration for Scottish Association for Marine Science (SAMS) undergraduate students at Inverness, $6^{\text {th }}$ of November.

Figure 66: Raquel Puig Lozano from the University of Las Palmas, Grand Canaria during the pilot whale MSE December 2018.

Figure 67: Facebook front page, Jan 2018.

Table 1: Summary of stranded animals 2018.

Table 2: Age structure of pinniped strandings 2014 - 2018........................................................................... 19

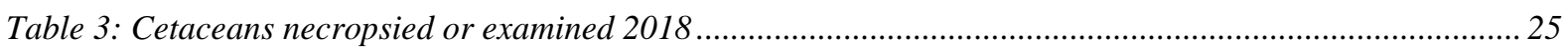

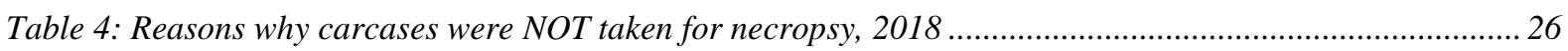

Table 5: Cause of death/findings for pinnipeds, basking sharks and marine turtles reported 2018 ...................227

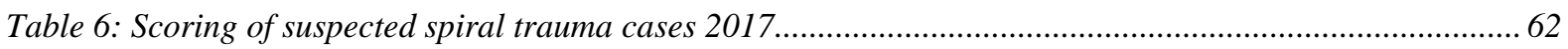




\section{Section 1: $\quad$ Executive Summary}

There were a greater number of strandings reported to the Scottish Marine Animal Stranding Scheme (SMASS) in 2018 than in any year since the project's inception in 1992. This was attributable largely to increased public awareness of the scheme, although a large beaked whale mortality event contributed to this increase in reports. From the 1st January to 31st December 2018, 932 reports of 937 marine animals were reported to SMASS, comprising 499 seals, 435 cetaceans, 2 basking shark and single marine turtle. Of these, 76 cases (8.1\%), comprising 49 cetaceans, 27 seals were necropsied to establish a cause of death. A further 172 (18.3\%) animals, comprising 123 cetaceans, 48 seals and single basking shark were sampled by trained volunteers. In those cases not necropsied, advanced autolysis or carcase accessibility were the most common reasons precluding further examination.

Of most note this period was a globally unprecedented number of beaked whale strandings in August, September and early October, involving mainly Cuvier's beaked whales (Ziphius cavirostris) and later northern bottlenose whales (Hyperoodon ampullatus). This UME is the largest number of beaked whale strandings reported globally, and was characterised by an abnormal increase in incidence of strandings in Ireland, Scotland, Iceland and the Faeroes. Pathological data was limited due to autolysis, however a summary of the work undertaken is detailed in a separate report.

There were five other mass stranding events (MSE), albeit $80 \%$ of these involved only two animals: Harbour porpoise (Phocoena phcoena) at Fortrose, Moray and Clackmannanshire, two short beaked common dolphin MSE's (Delphinus delphis) in Stranraer, Dumfries and Galloway and South Uist. The final MSE of the year involved five long-finned pilot whales on the Firth of Forth in December.

Seals exhibiting lesions consistent with grey seal predation continue to be reported with 67 cases, mostly from Orkney. The majority were grey seal juveniles (weaners) (Halichoerus grypus) reported in the winter months, although harbour seals (Phoca vitulina) were also reported, as were suspected seal attacks on harbour porpoise (Phocoena phocoena). The impact of grey seal predation on sympatric species will be investigated as an upcoming PhD in collaboration with SMRU, St Andrews.

In January SMASS held the first SMASS forum at Inverness Campus- a day-long series of talks and workshops open to the public. This was a sell-out event and, based on the positive feedback, seemed to have been very well received. The volunteer network has continued to expand with two courses being run in 2018; at Inverness SAC. The number of trained volunteers had increased to 212 by the end of 2018 . The volunteer network is proving a significant asset to SMASS, through provision of both photographic and accurate morphometric data and the safe collection of tissues for genetic and toxicological analysis.

Strandings continue to attract significant media attention and effort has been maintained to provide strandings and case updates through social media channels. There was particular media interest in a sperm whale stranding in the Tay Estuary in March, a long-finned pilot whale stranding on Mull and the beaked whale UME. In terms of seals, the rare report of a harp seal pup on Skye and its subsequent necropsy attracted media interest including the National Geographic magazine. 
i. This work is delivered under the Scottish Marine Animal Strandings Research Programme, issued on $28^{\text {th }}$ May 2018 by Scottish Ministers, with work running for between $8^{\text {th }}$ June 2018 and $8^{\text {th }}$ March 2020 . The project is currently managed by SRUC and run from their Veterinary Disease Investigation Centre, Drummondhill, Inverness. The principal aim of the project is to provide a coordinated approach to surveillance of cetacean, seal, basking shark and marine turtle strandings, and to investigate major causes of death of stranded animals in Scotland. Where required, efforts should be made to expand and develop the established volunteer network to improve reporting and strandings investigations. This project therefore has the following objectives:

\subsection{Contract specification}

ii. Collate, analyse and report data for all cetacean, seal, basking shark and marine turtle strandings across the Scottish coast. This will include determination of cause of death and surveillance of the incidence of disease where possible. It will also involve an ongoing review of techniques used to determine the causes of death aimed at improving their accuracy, efficiency and cost-effectiveness.

iii. A small number of priority species should be identified in each year of the project for more in depth and targeted studies which will involve additional analysis and testing (e.g. age, diet, contaminant and toxin exposure and reproductive state). The number of individuals and species will be determined in collaboration with the steering group, but it is likely to involve 20/25 individuals and primarily focus on the following species: harbour seals, harbour porpoise, bottlenose dolphins and minke whales.

iv. Undertake post mortem examinations on marine wildlife (e.g., cetaceans, seals, turtles and sharks) stranded around the Scottish coast to determine major causes of death, including by-catch, physical trauma and the incidence of disease. A wide species and geographical spread of post mortems should be achieved, and this will be informed by decisions within the project steering group.

v. Increased efforts should be made to collect data (via the stranding network or post mortem) from harbour seals reported stranded around the Scottish coast to inform current work investigating harbour seal decline in Scotland. Seals in all stages of decomposition should be targeted.

vi. Provide scientific advice to the Scottish Government as necessary about major causes of death in stranded marine mammals, including any trends or unusual events. 
vii. Maintain the database for all Scottish strandings which brings together accurate and geo-reference data on both strandings and necropsy data. All data should be fed into the cetacean database for the "UK Cetacean Strandings Investigation Programme" (UKCSIP) which is held by the Institute of Zoology (IoZ).

viii. Maintain and expand the Scotland-wide volunteer network to assist with identification, triage and possible measurement and sampling of cases reported to the stranding scheme. This should allow for improved depth, accuracy and efficiency in the information recoverable from strandings.

ix. Provide training courses and refresh training courses, and post mortem demonstrations to teach volunteers how to accurately and safely collect skin and blubber tissue samples from cases otherwise unsuitable for recovery. In addition to samples, volunteers will be trained to collect morphometric and locational data and a series of digital photographs.

x. Support relevant research organisations (e.g. SMRU, SAMS, University of Aberdeen) and ongoing research streams in relation to marine mammals. This will involve, but not be limited to, undertaking post mortems, working with SMRU on field trials, and scrutinising the current scheme in terms of its ability to answer questions that are identified through collaborative research programmes (e.g. harbour seal decline and interactions between marine mammals and marine renewable energy devices).

xi. Investigate opportunities to form collaborations with new academic and scientific partners. This objective should involve biannual workshops/meetings with appropriate research institutes to investigate opportunities for collaborative working as well as identifying new research streams and funding opportunities.

xii. Increase awareness of the project through ongoing publicity. Contribute to the production of strandings training material and workshop events, and maintain a public facing website and social media presence.

xiii. Maintain the tissue archive for all samples collected under the current and previous projects, to ensure that there is a time series of samples for all individuals sampled or necropsied.

xiv. A review of archived samples should be undertaken as part of the project and in partnership with relevant organisations to determine future storage options. This should be undertaken with input from the wider UK and Scottish steering groups. 
xv. Ensure that the catalogue of data and samples is or can be made readily accessible on request. The appropriate detail on what data are available should be clearly stated and should be accessible either through the project's website or through meta data archives. Advertise the holdings in the scientific community to widen the access and the potential for collaboration.

xvi. Contribute to existing Scottish Government, and wider marine mammal projects as required.

xvii. To make information on strandings and post mortems results available to the Scottish Government on a quarterly basis and publicly available by annual reports. 


\section{Section 2: $\quad$ Strandings}

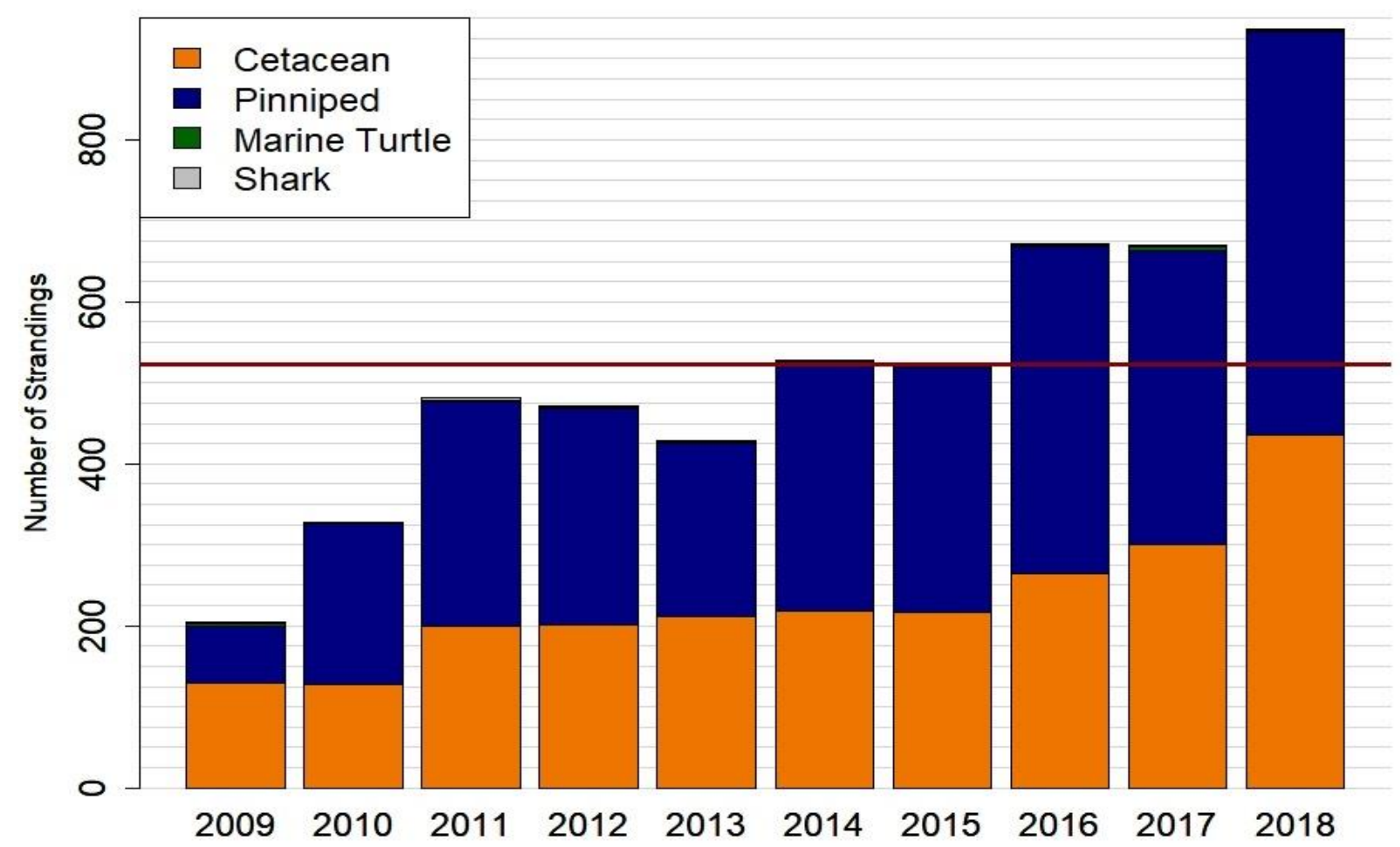

Figure 1: Total number of strandings reported 2009-2018. Red line shows the mean number of strandings over this 10year period (522)

\subsection{Strandings overview}

From the 1st January to 31st December 2018, 932 reports of 937 marine animals were reported to the Scottish Marine Animal Stranding Scheme (SMASS), comprising 499 seals, 435 cetaceans, 2 basking shark and single marine turtle (Table 1). Of these, 76 cases $(8.1 \%)$, comprising 49 cetaceans, 27 seals were necropsied to establish a cause of death. A further 171 (18.3\%) animals, comprising 122 cetaceans, 48 seals and single basking shark were sampled by trained volunteers. In those cases not necropsied, advanced autolysis or carcase accessibility were the most common reasons precluding further examination with 326 (34.8\%) cases being too decomposed to allow further examination. Figure 1 presents the total number of strandings reported to SMASS since 2009 and shows the increase in strandings reports, although 2018 shows a significantly higher year-on-year increase compared to previous years. Figure 2 shows the breakdown of strandings by subclass for 2018. Figure 3 shows the cumulative number of strandings by month for each individual year since 2018 and shows that particularly March, April, August and December were higher than previous years and hence influential on the high annual total. 


\begin{tabular}{|c|c|c|c|c|}
\hline Species & $\begin{array}{l}\text { Sent for } \\
\text { Necropsy }\end{array}$ & Sampled & $\begin{array}{c}\text { Not } \\
\text { Examined }\end{array}$ & Total \\
\hline Cetaceans & 49 & 122 & 264 & 435 \\
\hline Atlantic white-sided dolphin (Lagenorhynchus acutus) & 1 & & 2 & 3 \\
\hline Bottlenose dolphin (Tursiops truncates) & & 3 & & 3 \\
\hline Cuvier's beaked whale (Ziphius cavirostris) & 2 & 31 & 24 & 57 \\
\hline Harbour porpoise (Phocoena phocoena) & 23 & 47 & 124 & 194 \\
\hline Humpback whale (Megaptera novaengliae) & & 1 & & 1 \\
\hline Killer whale (Orcinus orca) & & 1 & & 1 \\
\hline Long-finned pilot whale (Globicephala melas) & 5 & 4 & 4 & 13 \\
\hline Minke whale (Balaenoptera acutorostrata) & 3 & 3 & 16 & 22 \\
\hline Northern Bottlenose whale (Hyperoodon ampullatus) & & 7 & 7 & 14 \\
\hline Risso's dolphin (Grampus griseus) & 1 & 1 & 5 & 7 \\
\hline Short-beaked common dolphin (Delphinus delphis) & 6 & 11 & 15 & 32 \\
\hline Sowerby's beaked whale (Mesoplodon bidens) & 2 & 2 & 2 & 6 \\
\hline Sperm whale (Physeter macrocephalus) & 2 & & 3 & 5 \\
\hline Striped dolphin (Stenella coeruleoalba) & 2 & & 3 & 5 \\
\hline White-beaked dolphin (Lagenorhynchus albirostris) & 2 & 5 & 15 & 22 \\
\hline Cetacean (indeterminate species) & & 3 & 28 & 31 \\
\hline Baleen whale (indeterminate species) & & & 3 & 3 \\
\hline Beaked whale (indeterminate species) & & 2 & 2 & 4 \\
\hline Dolphin (indeterminate species) & & & 12 & 12 \\
\hline Pinnipeds & 27 & 48 & 424 & 499 \\
\hline Grey seal (Halichoerus grypus) & 6 & 39 & 265 & 310 \\
\hline Harbour seal (Phoca vitulina) & 20 & 9 & 66 & 95 \\
\hline Harp seal (Phoca groenlandica) & 1 & & & 1 \\
\hline Seal (indeterminate species) & & & 93 & 93 \\
\hline Other & & 2 & 2 & 3 \\
\hline Leatherback turtle (Dermochelys coriacea) & & & 1 & 1 \\
\hline Basking shark (Cetorhinus maximus) & & 1 & 1 & 2 \\
\hline GRAND TOTAL & 76 & 171 & 690 & 937 \\
\hline
\end{tabular}




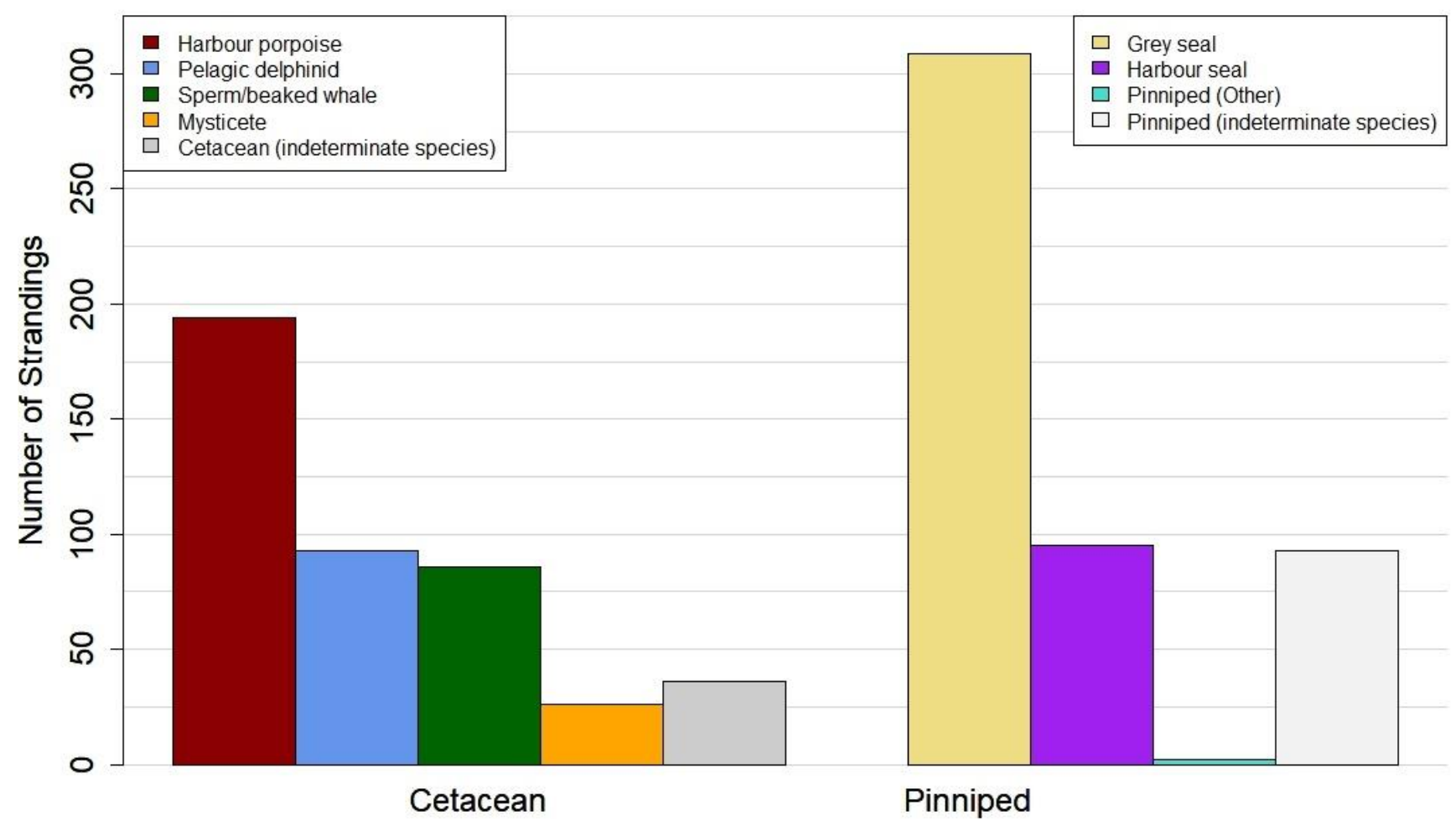

Figure 2: Total number of species reported in 2018, by subclass

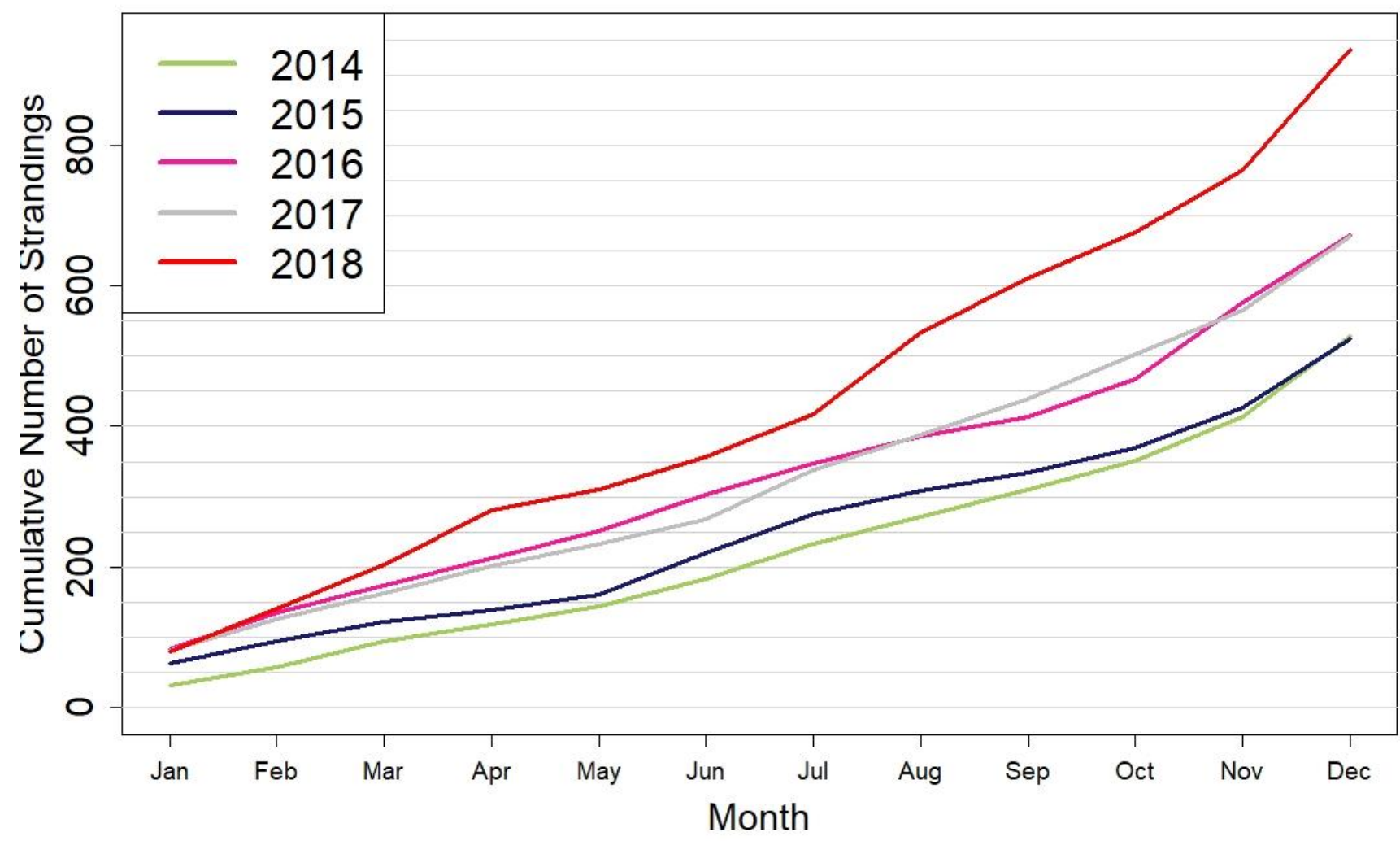

Figure 3: Cumulative number of cases all species by month for 2014 - 2018 


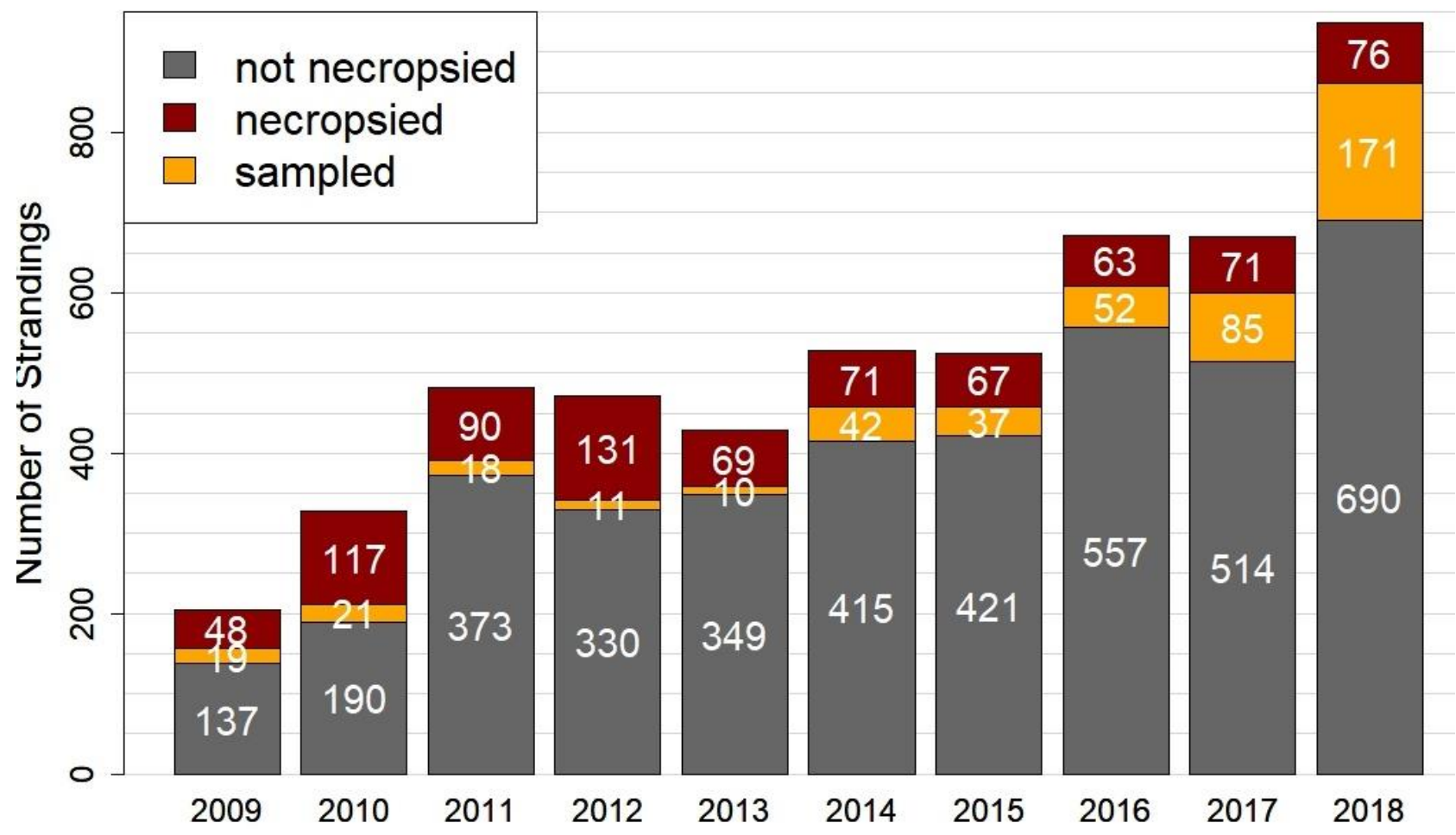

Figure 4: Cases necropsied and sampled 2009-2018

Figure 4 shows the number of cases necropsied, sampled, and not necropsied respectively during 2018 compared to the past ten years. There was again an increase in the number of cases sampled by trained volunteers, with $18.2 \%$ of the cases being sampled compared to only $12.7 \%$ last year. The percentage of cases necropsied (7.7\%) was however slightly lower than 2017 when $10.6 \%$ of the total number of strandings were necropsied. This implies that the increase in strandings was mainly driven by an increase in animals not suitable for necropsy. Cases may be unsuitable for collection for a number of factors, with autolysis being the most common reason. A more detailed overview of this as well as findings at necropsy can be found in Section 3 of this report.

\subsection{Spatial maps of strandings}

There were cases reported in all coastal regions, although notable clusters of strandings were seen around Fife and the south east, Orkney and the south west (Clyde area). In addition, a higher number of strandings were observed on the Western Isles following the unusual mortality event of beaked whales occurring along the Atlantic coastline (more information on this can be found in section 4). Recovery of carcases and obtaining data from animals stranded in the southwest of Scotland was largely constrained by logistical difficulties, or poor information about the stranding, whereas the cluster of non-recovered animals from the eastern coast from Fife to Aberdeen was usually due to animal condition rather than the capacity for recovery.

Continued and hugely valued assistance from our trained volunteers around the coastline, the Sea Mammal Research Unit (SMRU) in Fife, and Hillswick Wildlife Sanctuary and Scottish Natural Heritage (SNH) in Shetland has enabled many animals suitable for necropsy to be recovered, or stranding morphometrics to be recorded. 
The maps below show the spatial distribution of strandings necropsied (Figure 5) and not necropsied (Figure 6) during 2018. Figure 7 is a density map showing areas, in red, of high stranding reports for all species. A density plot is a surface calculated from individual stranding points using a kernel function to fit a smoothly tapered surface, and is a way of visualising areas of high stranding density. 


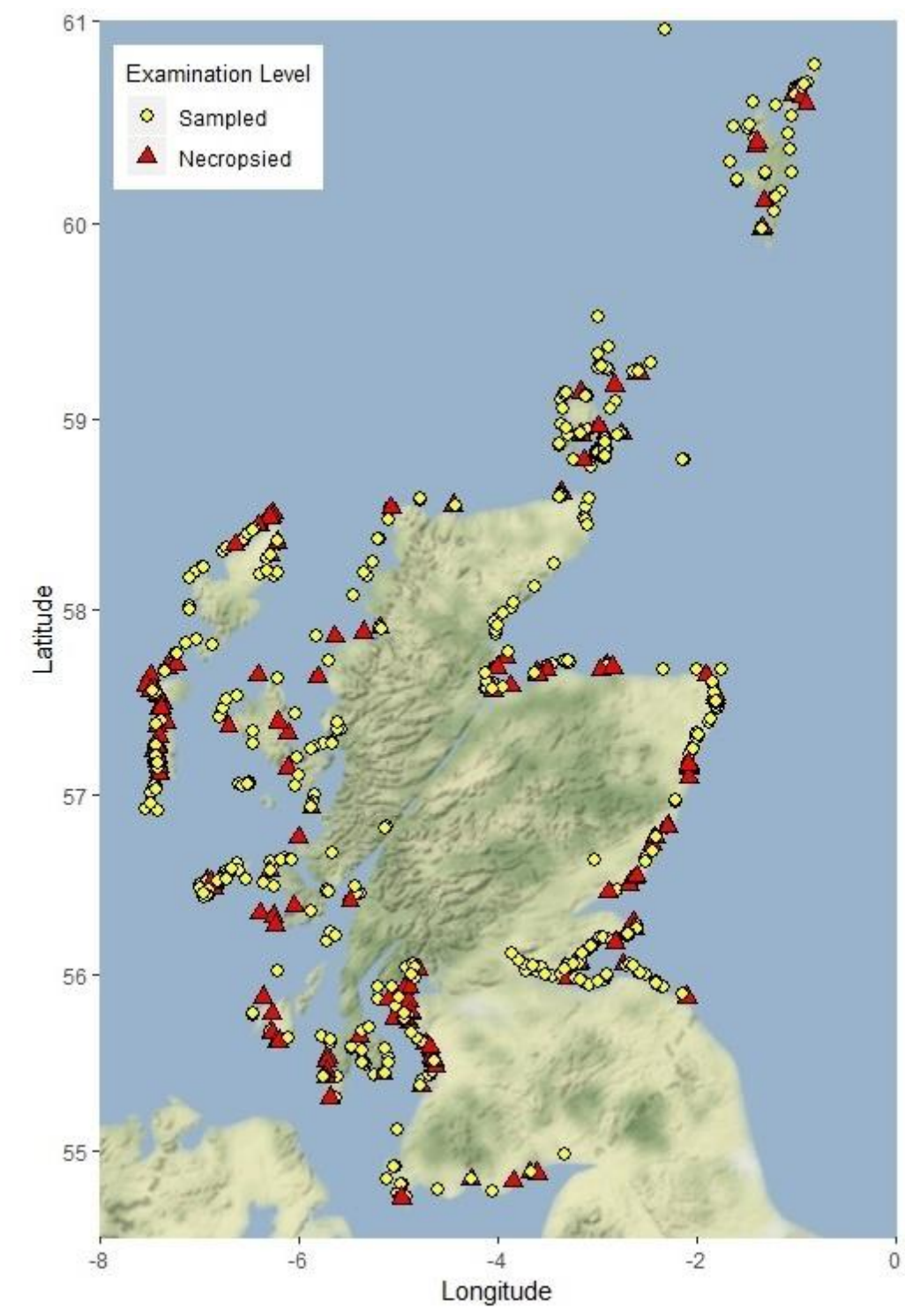

Figure 5: Strandings necropsied or sampled 2018

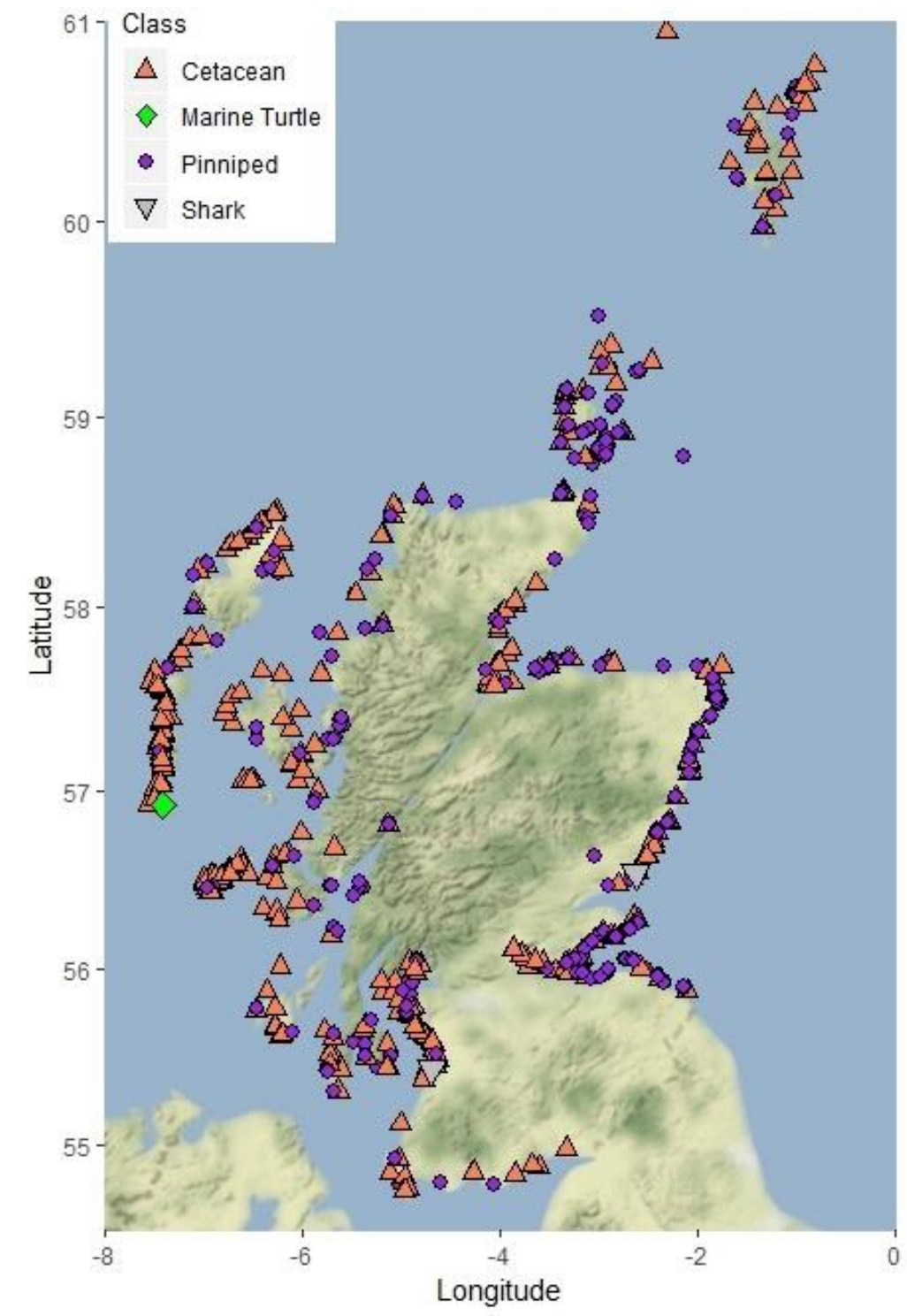

Figure 6: Strandings not necropsied 2018 


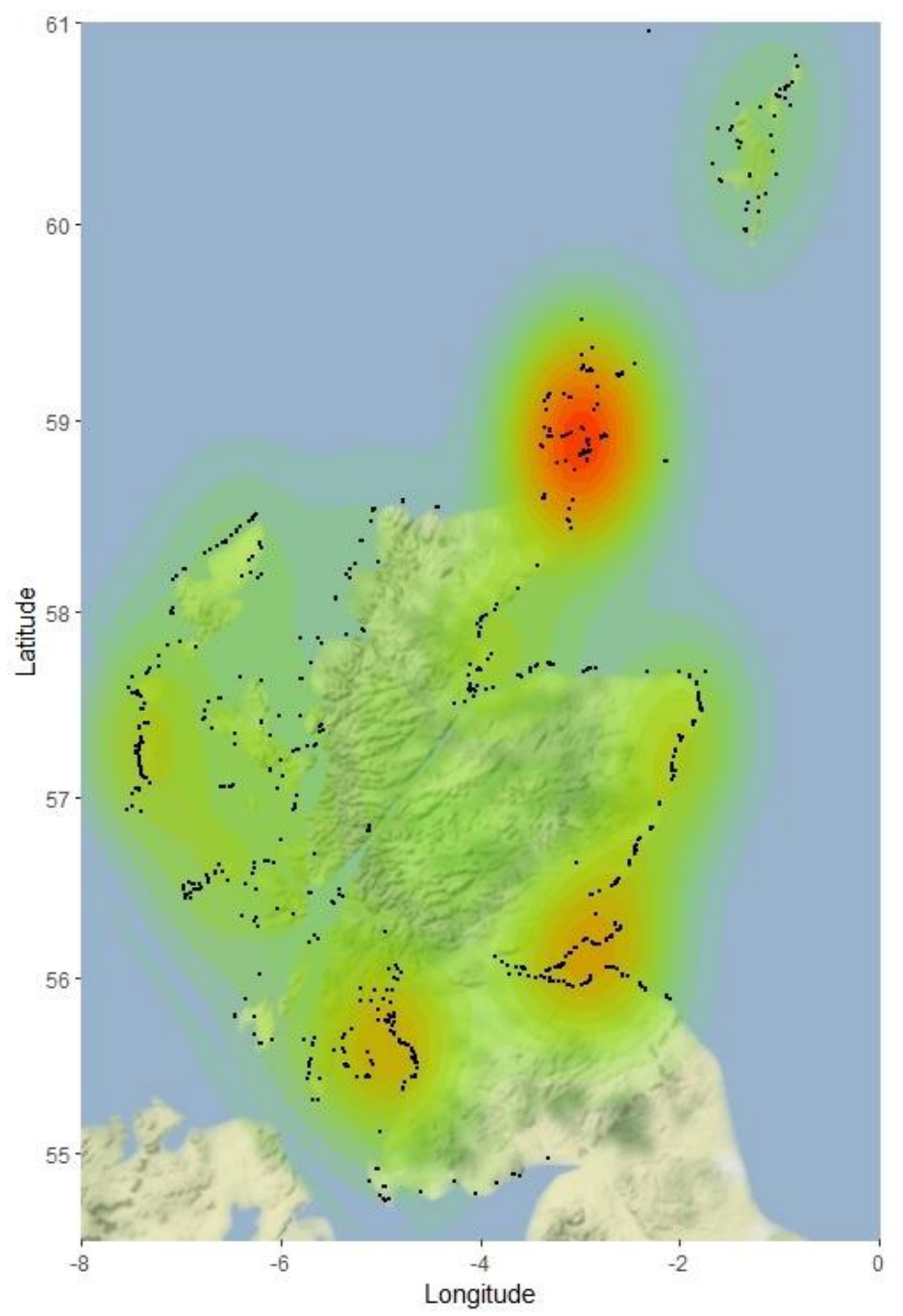

Figure 7: Kernel density plot of all strandings 2017. Colour spectrum from green (low) to red (high)

\subsection{Pinniped strandings}

Four hundred and ninety-nine seals were reported to SMASS in 2018 comprising of 310 grey seals (Halichoerus grypus, $\mathrm{Hg}$ ), 95 harbour seals (Phoca vitulina, Pv), a single harp seal (Pagophilus groenlandica) and 93 pinnipeds that were too autolysed or data deficient for accurate speciation (Figure 10, Table 2). Of those reported, the majority (94.5\%) were not recovered for necropsy, mainly due to the carcase being an advanced state of autolysis or poor information from the reporter about the case. It is seldom a pinniped carcase is discovered in a suitable state of preservation to make it justifiable to recover for necropsy. Nevertheless 48 cases were sampled by volunteers compared to 18 cases in 2017.

Twenty-seven animals (5.4\%) were recovered for necropsy. Physical trauma attributable to grey seal predation was the most common finding for both $\mathrm{Hg}(n=43)$ and $\mathrm{Pv}(n=12)$ seals. Eight animals died as a result of entanglement, four harbour seals died due to starvation following maternal separation, three juvenile seals died following starvation/hyperthermia, and six were found to have died as a result of pneumonia (either bacterial, parasitic, or of unknown aetiology). In three animals a cause of death was not established and four are still 
pending additional histology/bacteriology results. A summary of all findings can be found in section 3 of this report.

This report does not include the detail on cases reported as shot under seal management licences $(n=3)$. Information regarding these cases is available from Marine Scotland or online at:

http://www.scotland.gov.uk/topics/marine/licensing/seallicensing.

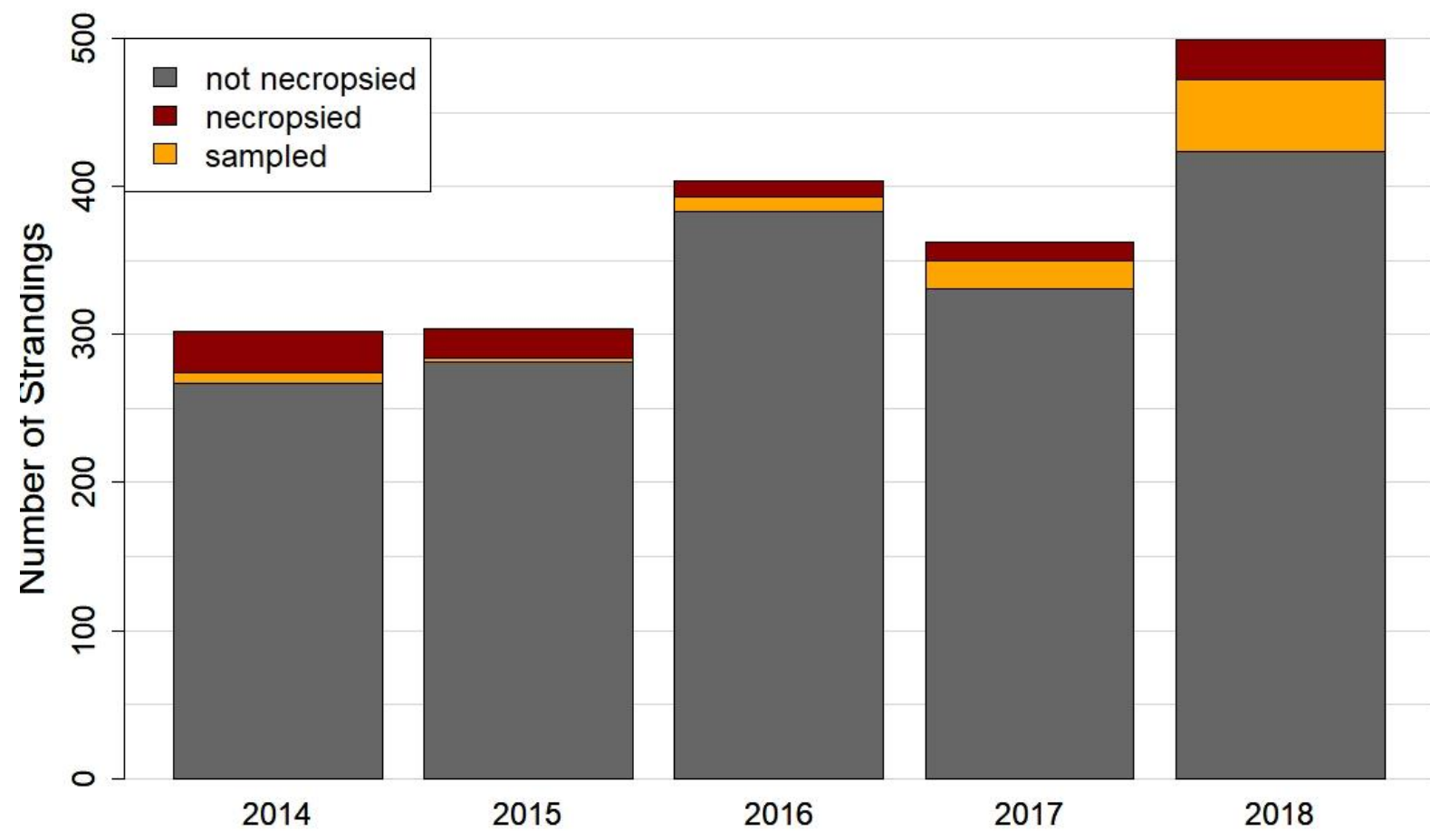

Figure 8: Pinniped strandings (all species) 2014- 2018, separated by level of examination

\subsection{1 'Corkscrew' or spiral trauma cases}

Fifty-seven seals were reported as having trauma consistent with spiral or corkscrew injuries. These cases were reported from nine different regions of Scotland. The majority of these were Hg seals ( $n=43)$ : Pv $(n=12)$ and those too decomposed or data deficient to be identified $(n=2)$. It is now considered highly likely that the majority of historic "spiral or corkscrew" cases were due to predation, most likely by adult grey seals. More detail can be found in Section 6 .

\subsection{Pinniped age structure}

Table 2 shows the age structure of pinnipeds reported to SMASS for the five year period from January 2014 to December 2018. Figure 9 graphs the structure for 2018 only.

Between 2014 and 2018, there were 1871 strandings of seals, of which the age could not reliably be established in $50.3 \%$ of the cases. Of those where the age could be determined, 
$14.8 \%$ were pups, $21.8 \%$ were juveniles and $13.1 \%$ were adult animals. By species, adults made up $16.5 \%$ of grey seals and $13.3 \%$ of harbour seal strandings.

In 2018 the age class could not be established for $42.8 \%$ of the 499 reported strandings. Of those where the age class could be ascertained, $18 \%$ were pups; $25.9 \%$ were juveniles and $13.3 \%$ adults. By species, adults made up $16.5 \%$ of grey seals and $11.6 \%$ of harbour seal strandings. Figure 9 shows the age structure of cases by quarter, and for both species there is an increase in strandings after the $\mathrm{Pv}$ and $\mathrm{Hg}$ breeding seasons in early summer and late autumn respectively. Figure 10 shows the spatial distribution of pinniped strandings by species.

Table 2: Age structure of pinniped strandings 2014- 2018

\begin{tabular}{|c|c|c|c|c|c|}
\hline & Pup & Juvenile & Adult & Unknown & $\begin{array}{l}\text { Grand } \\
\text { Total }\end{array}$ \\
\hline Grey seal & 200 & 309 & 182 & 408 & 1099 \\
\hline Harbour seal (Common seal) & 52 & 82 & 45 & 159 & 338 \\
\hline Harp seal & & 1 & & & 1 \\
\hline Hooded seal & & & & 1 & 1 \\
\hline Seal (indeterminate species) & 27 & 16 & 17 & 372 & 432 \\
\hline Grand Total & 276 & 408 & 244 & 940 & 1871 \\
\hline
\end{tabular}




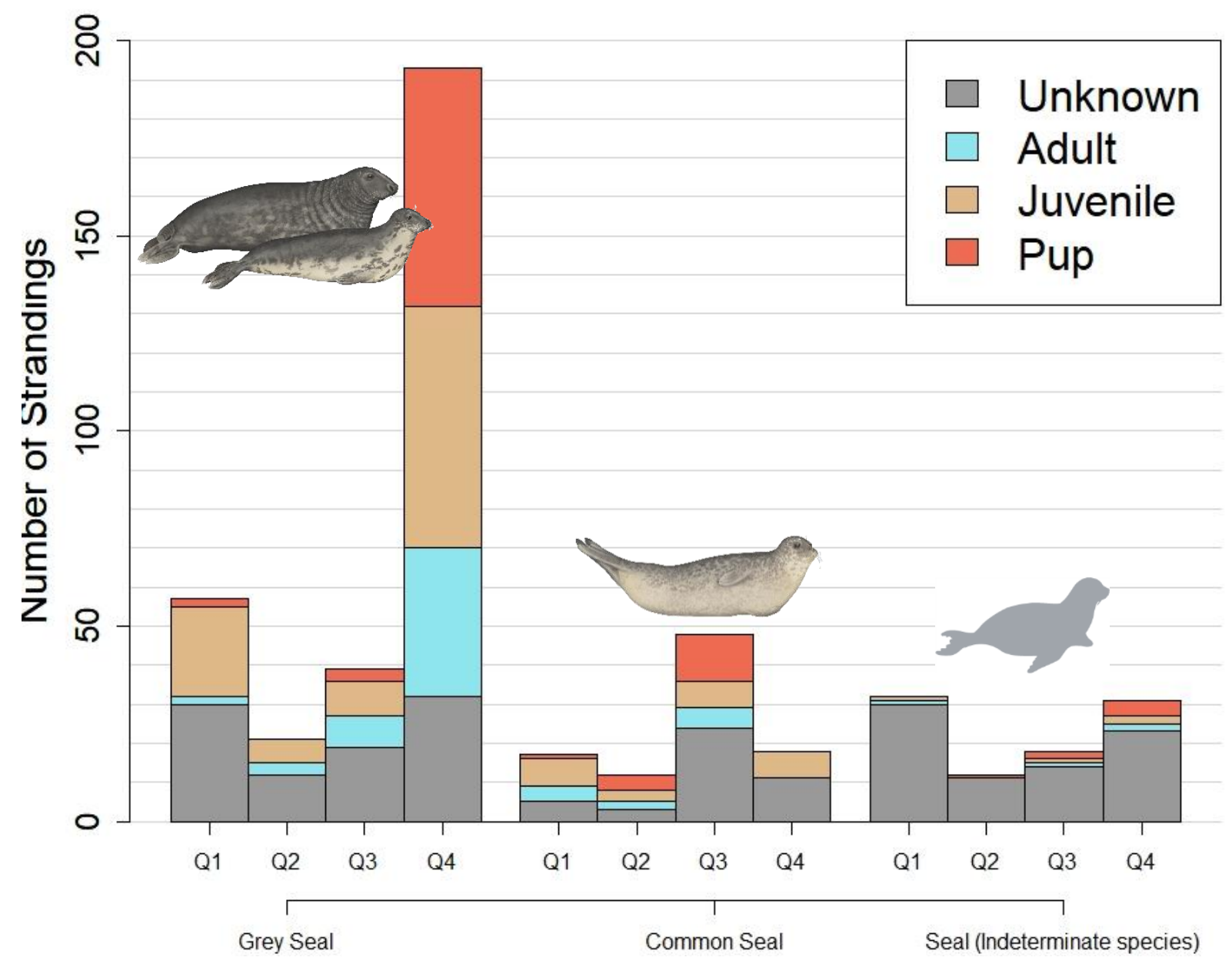

Figure 9:- Age structure of pinniped strandings 2018 , by age group and species 


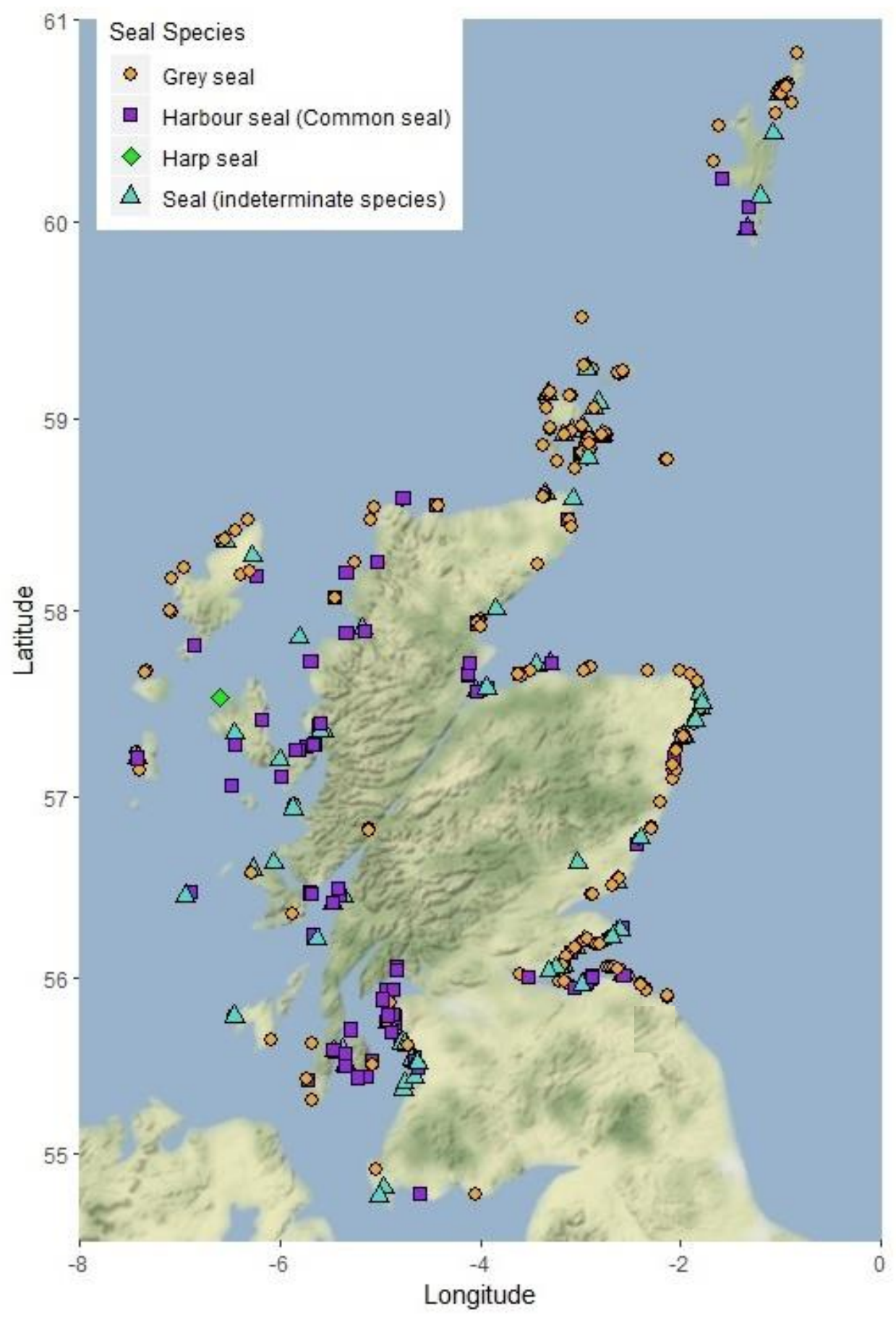

Figure 10: Pinniped strandings 2018

\subsection{Cetacean strandings}

Four hundred and thirty-five cetaceans, comprising of 15 different species were reported to SMASS in 2018. The most frequently reported species was the harbour porpoise (Phocoena phocoena) ( $n=194,44.5 \%)$ with an increase on the number reported last year. There was no particular geographical bias of these cases. Due to the beaked whale UME event, Cuvier's beaked whales $(n=57,31.1 \%)$ were the second most commonly reported species. Shortbeaked common dolphins (Delphinus delphis) was only the third most commonly reported species in 2018 ( $n=32,7.3 \%)$. Minke whales (Balaenoptera acutorostrata) and white beaked 
dolphins (Lagenorhynchus albirostris) were both reported in equal numbers ( $n=22,5 \%)$. Northern bottlenose whales were the fifth most commonly reported cetacean $(n=14,3.2 \%)$ see more detail in section 4 UME and accounted for more reports than long-finned pilot whales (Globicephala melas) 13 cases (2.9\%). Fifty (11.4\%) animals were reported that could not be identified to a species level because of either decomposition or lack of data. Of those, seven (1.6\%) were animals that were either common or striped dolphins but the photos were not of suitable quality to allow differentiation. Of the remaining eight species all were single figure strandings: Risso's dolphin (Grampus griseus) ( $n=7,1.6 \%$ ), Sowerby's beaked whale (Mesoplodn bidens) ( $n=6,1.3 \%)$, sperm whale (Physeter macrocephalus) and striped dolphins (Stenella coeruleolba) (both $n=5,1.1 \%$ ) which is the same number as last year. The remaining species were in descending order: bottlenose dolphin (Tursiops truncatus) and Atlantic whitesided dolphin (Lagenorhynchus acutus), both ( $n=3,0.6 \%)$. Killer whale (Orcinus orca) and Humpback whale (Megaptera novaeangliae) strandings were each a single case $(0.2 \%)$.

Of the 435 animals, 49 (11.2\%) cases were necropsied, figure 12. This was a slight decrease in numbers compared to 2017. This implies that the observed increase in total number of strandings in 2018 was mainly driven by an increase in animals not suitable for necropsy. Of those animals that were not necropsied 123 (28.2\%) were sampled by volunteers this is an increase on 2017. Figure 12 shows the spatial distribution (excluding harbour porpoise) of cetaceans for 2018. Figure 13 shows the spatial distribution of harbour porpoise cases for 2018.

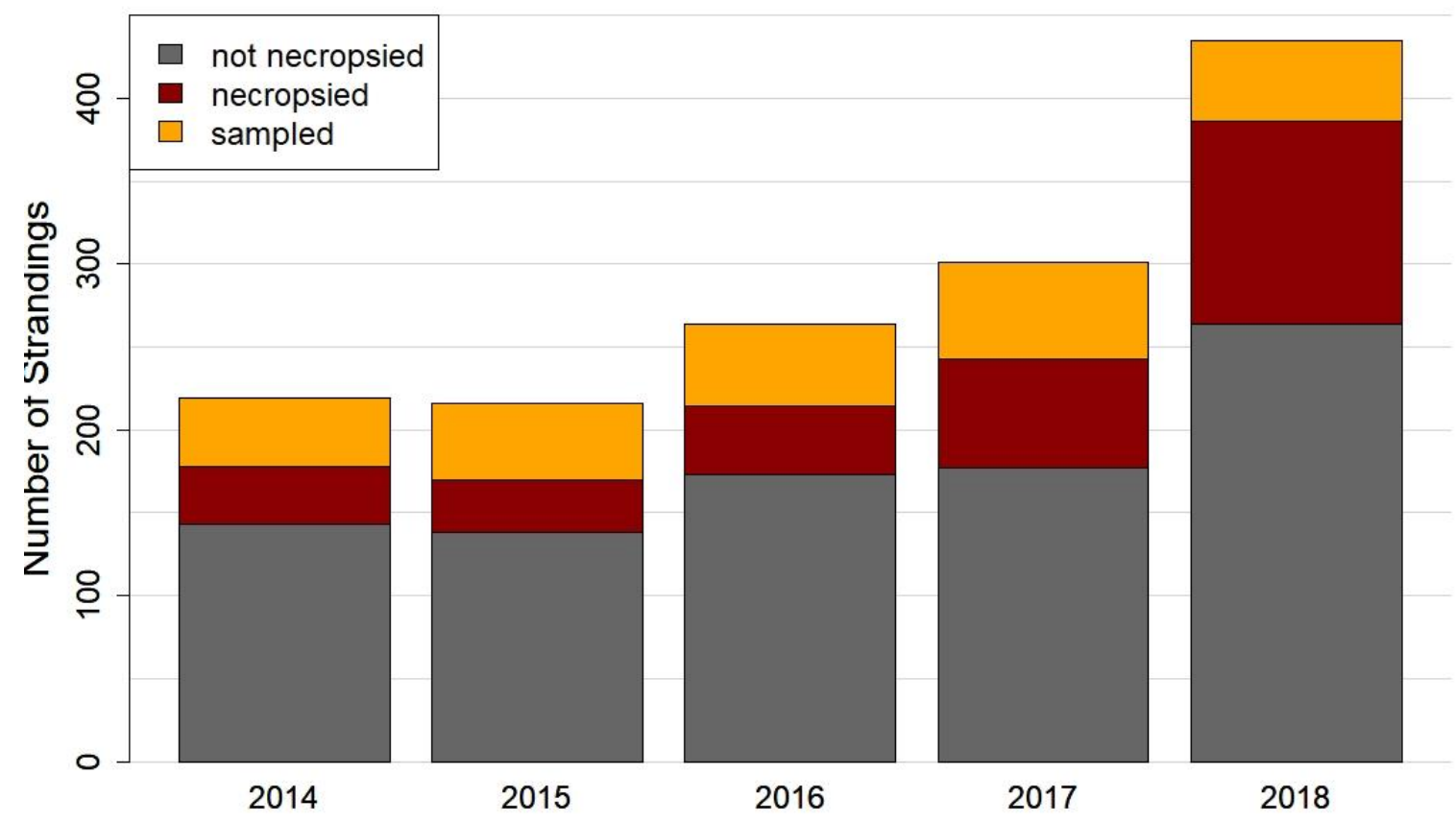

Figure 11: Cetacean strandings 2014-2018, all species

Twenty-three harbour porpoise were subjected to necropsy, comprising $30.3 \%$ of the total number of cases necropsied by SMASS in 2018. This is a lower proportion to 2017 when $42.3 \%$ of the cases necropsied were harbour porpoise. The most common causes of death in harbour porpoise were bottlenose dolphin attack $(n=18)$ and physical trauma attributable to a grey 
seal attack $(n=11)$. As in previous years, the most common cause of death for other cetaceans was live stranding. This is defined as morbidity and eventual mortality as a result of the sequence of physical processes invoked by becoming stranded. This diagnosis is attributed to cases where there is good clinical or pathological evidence of live stranding and no other cause can be identified which would otherwise explain the stranding, for example trauma, poor body condition or concurrent infectious disease. A detailed overview of the findings/cause of death of all cetaceans necropsied, sampled and not necropsied in 2018 can be found in Tables 3 and 4 in Section 3 of this report.

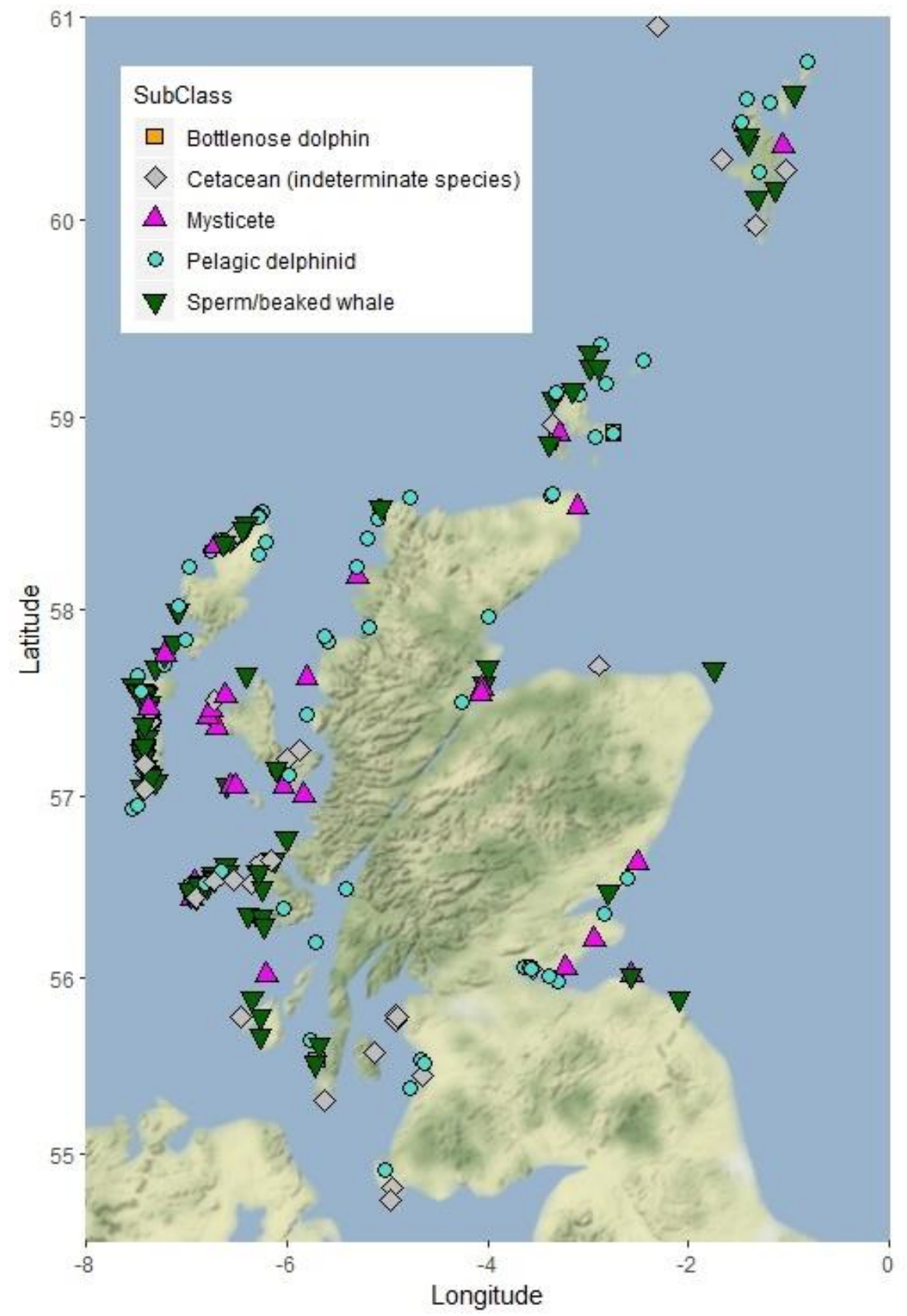

Figure 12: All cetacean strandings excluding harbour porpoise 2018

\subsection{Harbour porpoise strandings 2018}

There were 194 harbour porpoise strandings in 2018. This comprises of $44.5 \%$ of the total cetacean strandings for the year. Figure 13 shows the spatial distribution of harbour porpoise 
cases from 2018. As in previous years, the age make up of harbour porpoise strandings differs depending on time of year with more juveniles and sub-adults stranding between January and June, most likely as a consequence of loss of condition through the winter months. Neonates are obviously only found during and immediately subsequent to the calving season between June and September. Adults strand regularly throughout the year with the highest incidence in June and July. The majority are females and this may be attributable to extra stress during the calving season. Fewer animals are reported in the last three months of the year.

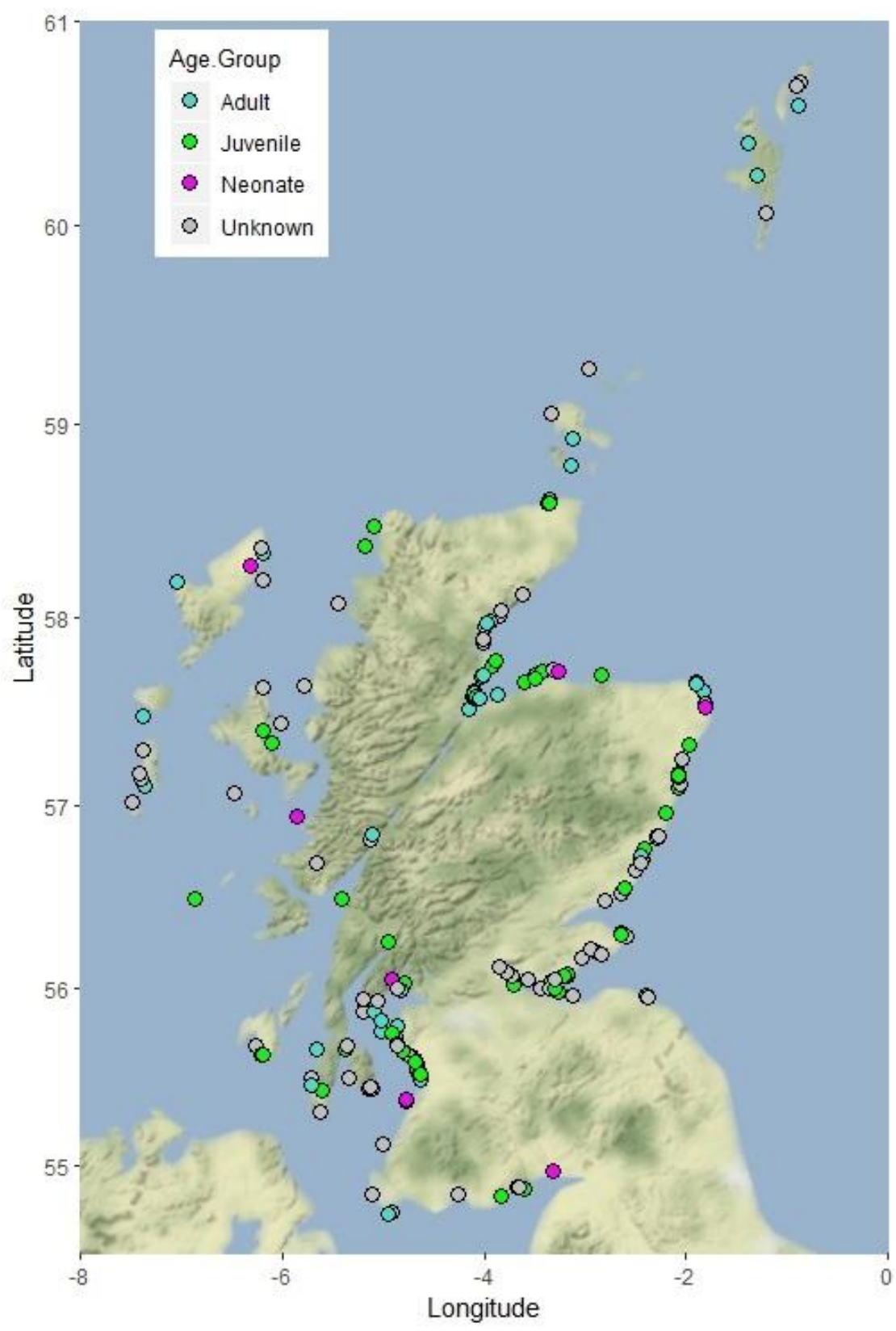

Figure 13: Spatial distribution of Harbour porpoise strandings, by age class, 2018 


\section{Section 3: Cause of death/findings summary tables}

Table 3: Cetaceans necropsied or examined 2018

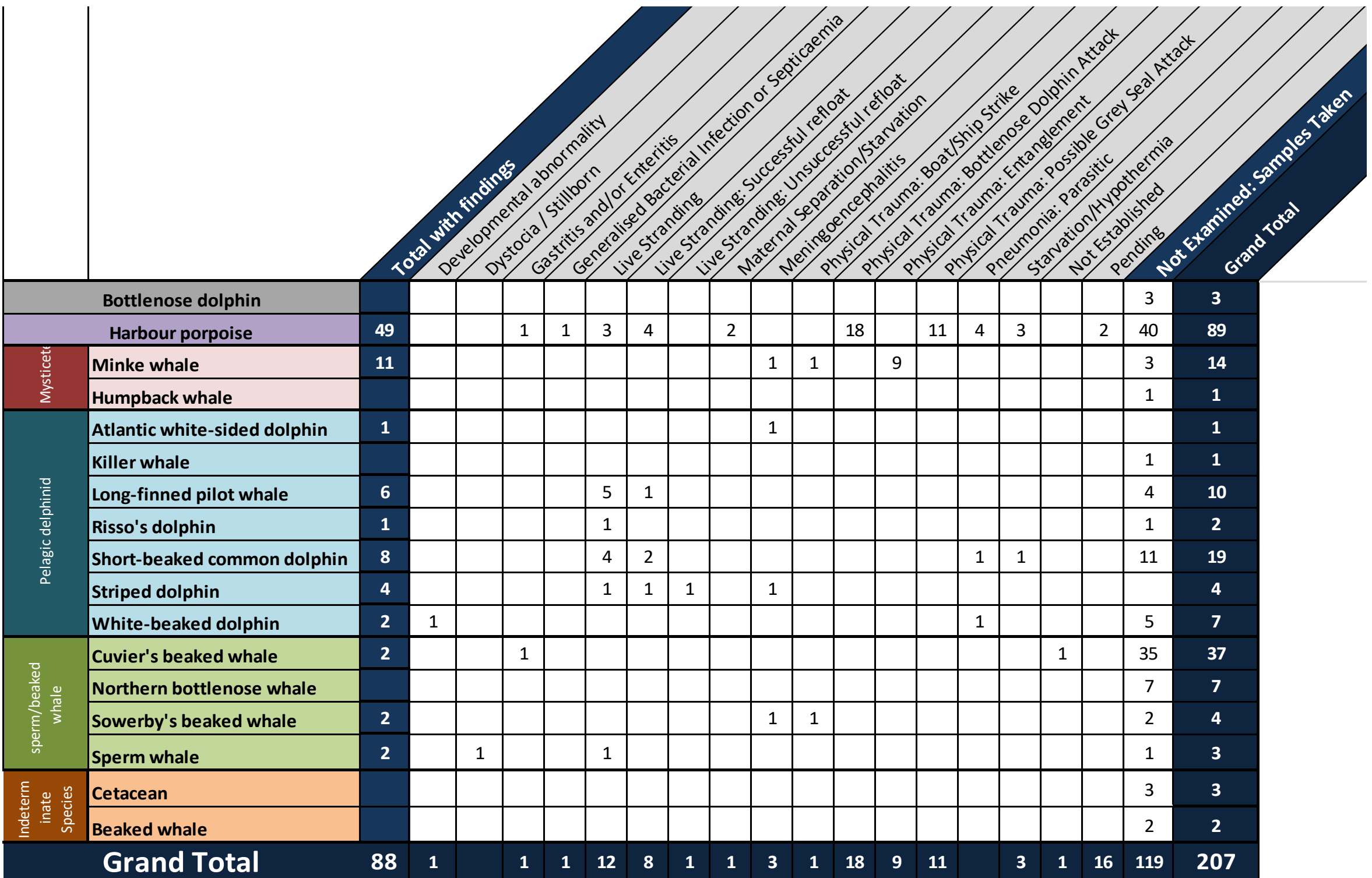




\begin{tabular}{|c|c|c|c|c|c|c|c|c|c|c|c|c|c|}
\hline \multicolumn{14}{|c|}{ Bottlenose dolphin } \\
\hline & Harbour porpoise & 47 & 1 & 32 & 1 & & 4 & 1 & & 14 & 2 & 3 & 105 \\
\hline \multirow{2}{*}{ 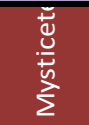 } & Minke whale & 6 & 2 & & & & & & & & & & 8 \\
\hline & Humpback whale & & & & & & & & & & & & \\
\hline \multirow{7}{*}{ 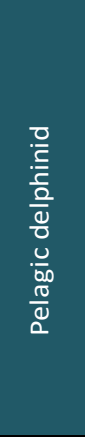 } & Atlantic white-sided dolphin & 1 & & & & & & & & & & 1 & 2 \\
\hline & Killer whale & & & & & & & & & & & & $\mathbf{0}$ \\
\hline & Long-finned pilot whale & 3 & & & & & & & & & & & 3 \\
\hline & Risso's dolphin & 3 & & 2 & & & & & & & & & 5 \\
\hline & Short-beaked common dolphin & 7 & & 3 & & & & & & 1 & & 2 & 13 \\
\hline & Striped dolphin & 1 & & & & & & & & & & & 1 \\
\hline & White-beaked dolphin & 9 & & 1 & & & & & & 2 & & 3 & 15 \\
\hline \multirow{4}{*}{ 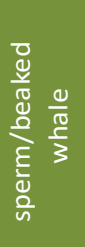 } & Cuvier's beaked whale & 15 & 1 & 4 & & & & & & & & & 20 \\
\hline & Northern bottlenose whale & 1 & & 6 & & & & & & & & & 7 \\
\hline & Sowerby's beaked whale & 1 & & & & & & & & 1 & & & 2 \\
\hline & Sperm whale & 1 & 1 & & & & & & & & & & 2 \\
\hline \multirow{4}{*}{ 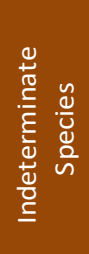 } & Baleen whale & 1 & & 1 & & & & & & 1 & & & 3 \\
\hline & Beaked whale & 1 & & 1 & & & & & & & & & 2 \\
\hline & Cetacean & 8 & 6 & 4 & & 1 & 6 & & 1 & 2 & & & 28 \\
\hline & Dolphin & 11 & & 1 & & & & & & & & & 12 \\
\hline & Grand Total & 116 & 11 & 55 & 1 & 1 & 10 & 1 & 1 & 21 & 2 & 9 & 228 \\
\hline
\end{tabular}




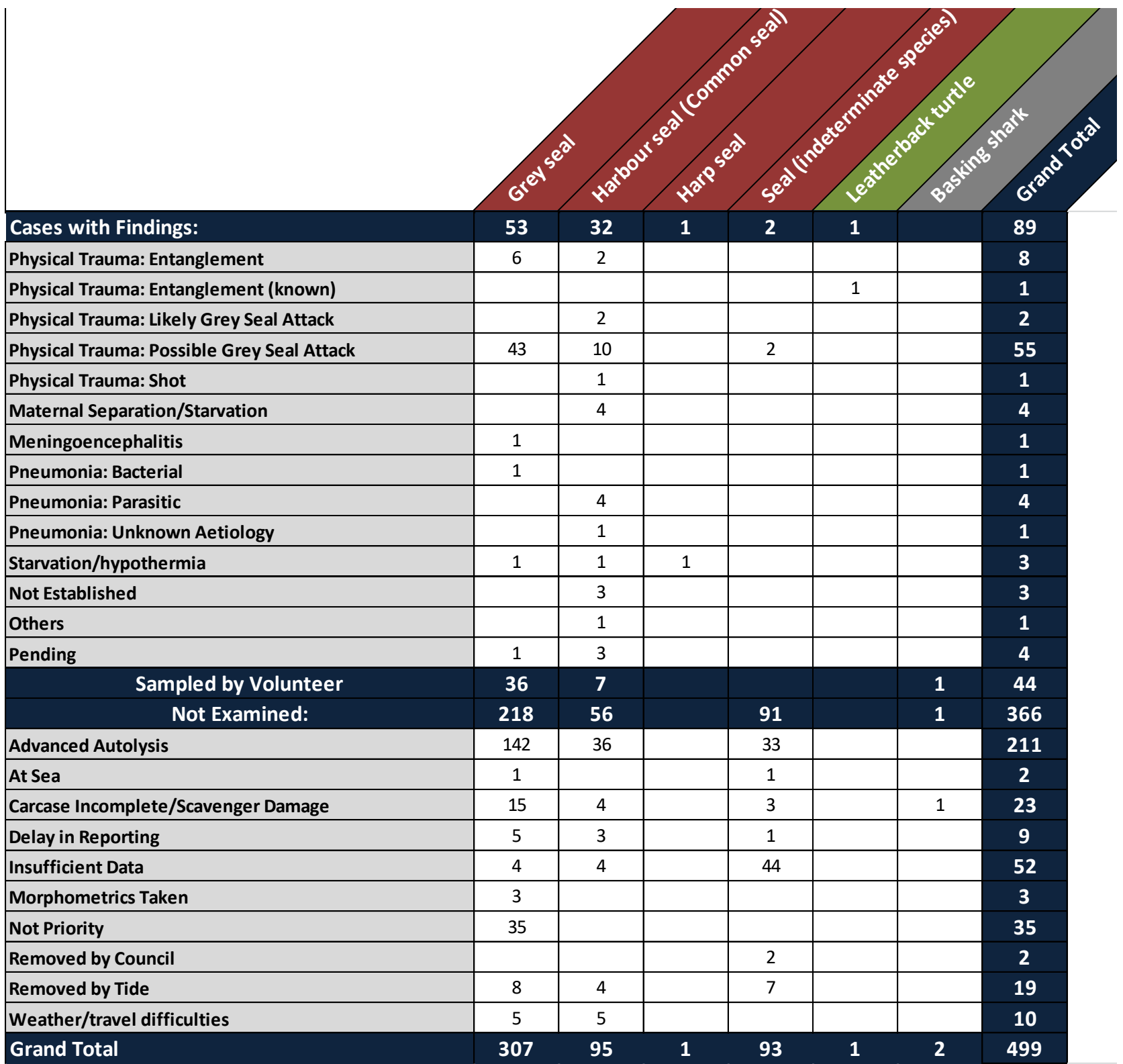

\subsection{Cause of death; direct anthropogenic versus other causes of death.}

Cause of death (COD) findings was usually determined following a full necropsy examination undertaken by Andrew Brownlow; a veterinary pathologist with experience of marine mammal necropsies. In the case of grey seal predation and bottlenose dolphin attacks, some of these cases had lesion patterns sufficiently pathognomonic to also enable reliable diagnosis from examination of photographs. Total number of diagnosed cases was 234: 88 cetaceans, 91 pinnipeds, and one leatherback turtle.

Figure 14 shows cases divided in three main categorie, $s$ based on if their likely cause was due to direct human impact. In 2018, the direct anthropogenic causes comprised entanglement, boat/ship strike, and seals thought to have been shot outwith a licence. Non direct 
anthropogenic causes of death, graphed as 'other' comprise everything else: all the metabolic and infectious disease cases and trauma cases not related to human impact. There were three cases for which the cause of death could not be established despite having been necropsied.

As can be seen, mortality due directly to anthropogenic activity comprise 23 cases, or about $16 \%$ of the cases which are finalised. This is a slight increase compared to 2017 when only $5 \%$ was diagnosed to have a direct anthropogenic cause of death. It should be additionally noted that this doesn't account for indirect anthropogenic impact or mortality due to chronic or cumulative effects, for example due to contaminant exposure, prey depletion or disturbance. Six cases are still pending a final diagnosis.

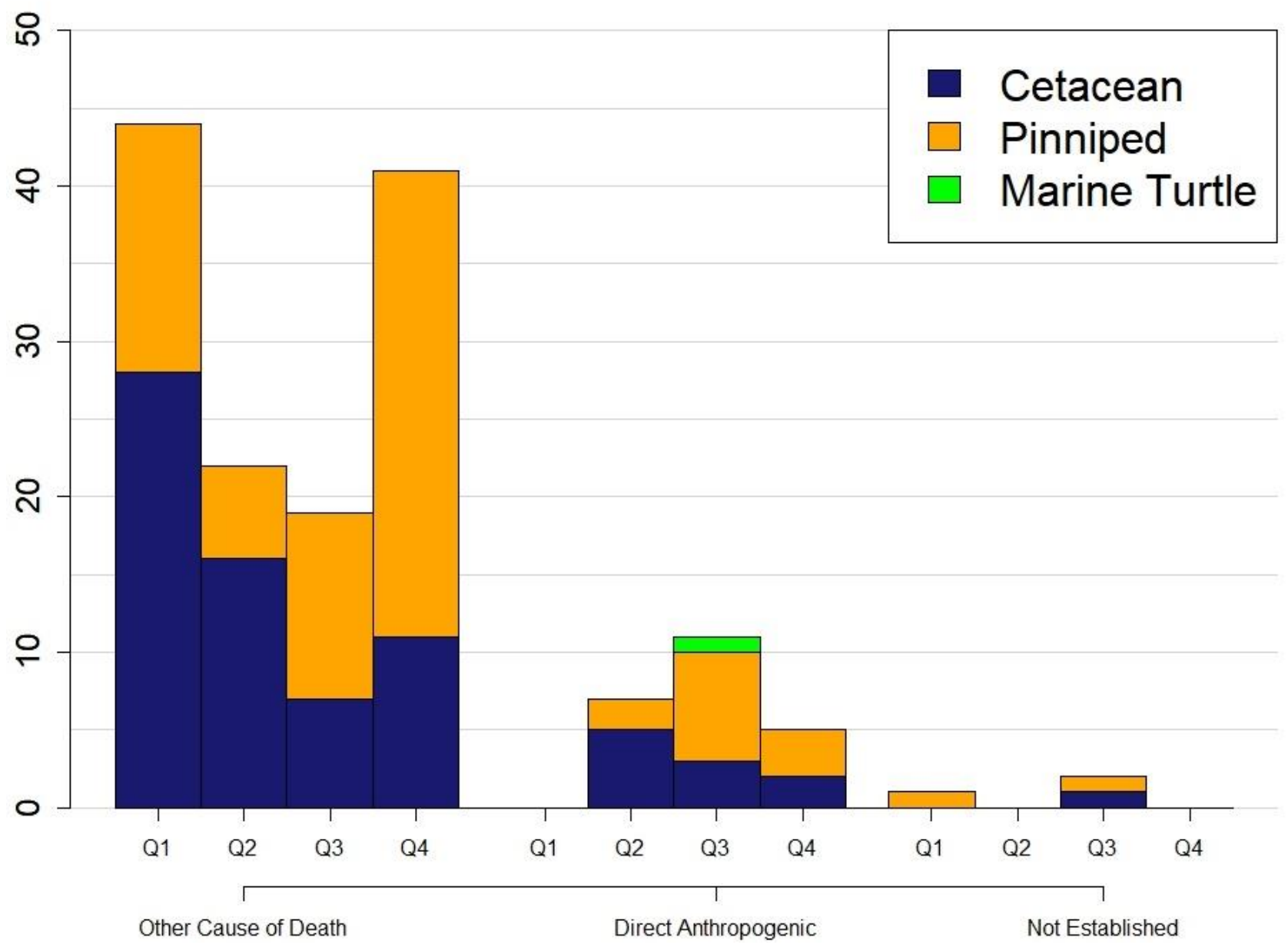

Figure 14: Cause of death findings per species class. Direct anthropogenic versus other causes of death. 


\section{Section 4: $\quad$ Mass stranding events (MSE's) and Unusual mortality events (UME's).}

\subsubsection{Mass stranding events (MSE's) multiple strandings and unusual mortality events}

Note: A mass stranding event (MSE) is defined as two or more animals that are not a cow/calf pair. There were four MSE's during 2018. An unusual mortality event (UME) is usually defined as a stranding that is unexpected; involves a significant die-off of any marine mammal population; and demands immediate response.

(https://www.fisheries.noaa.gov/national/marine-mammal-protection/marine-mammalunusual-mortality-events)

\subsection{M193.1- M193.2/18 harbour porpoise (Phocoena phocoena)}

Two harbour porpoise were observed to live strand on the 28th of March at Fortrose near Chanonry point. One animal (M193.1/18) died on the beach with the second animal (M193.2/18) apparently successfully refloated by members of the public. The animal that died was a juvenile female harbour porpoise. The individual exhibited multiple recent, but not peri-mortem skin lacerations with evidence for early stage wound healing/remodelling and possible infection possibly due to interactions with bottlenose dolphins. There was evidence for live stranding and the animal was thin and had not recently fed. The liver showed evidence for mild fatty change. Bacteriology did not reveal any significant isolates. Histopathology revealed a severe, sub-acute to chronic, focal, mixed inflammatory cell dermatitis.

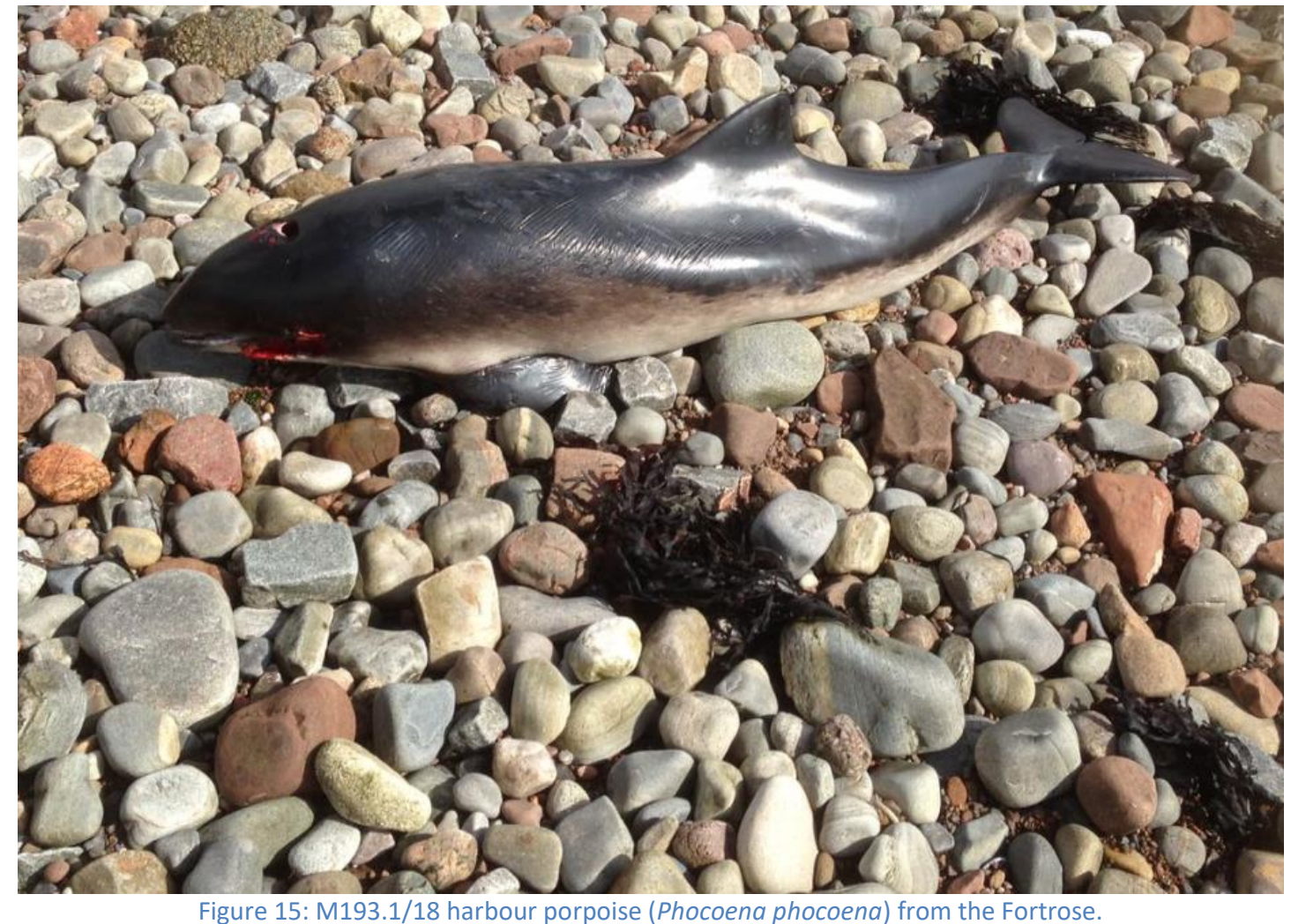




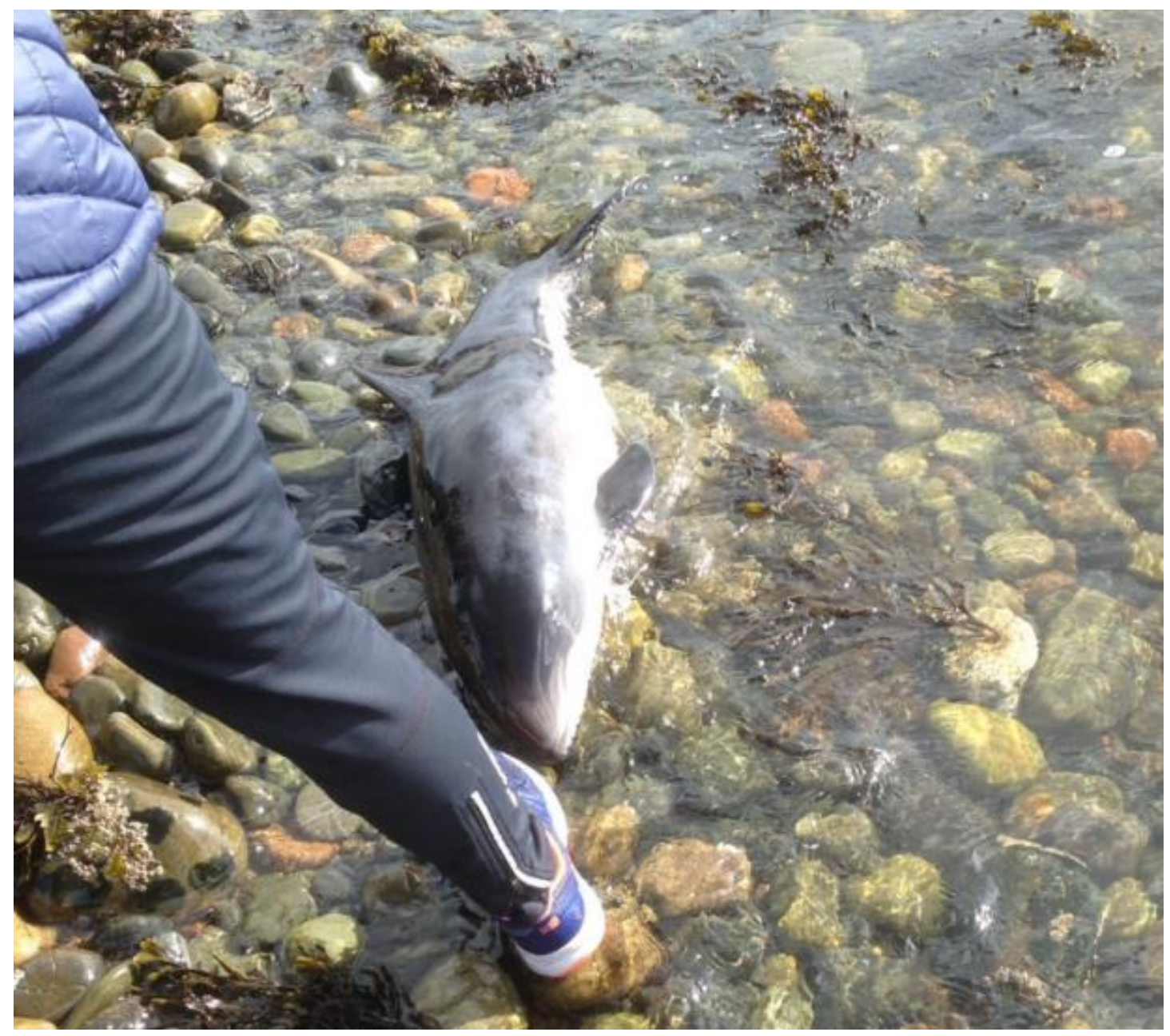

Figure 16: M193.2.2/18 harbour porpoise (Phocoena phocoena) from Fortrose prior to refloat 
Two common dolphins live stranded at Cairn Ryan Beach near Stranraer on the $18^{\text {th }}$ of April. They appeared to be a cow and calf pair. The calf died at the scene whilst the adult was refloated by a British Diver's Marine Life Rescue (BDMLR) medic and a member of the public. Unfortunately by the time the rescue had finished the dead animal had been taken by the tide and was not recovered for necropsy.

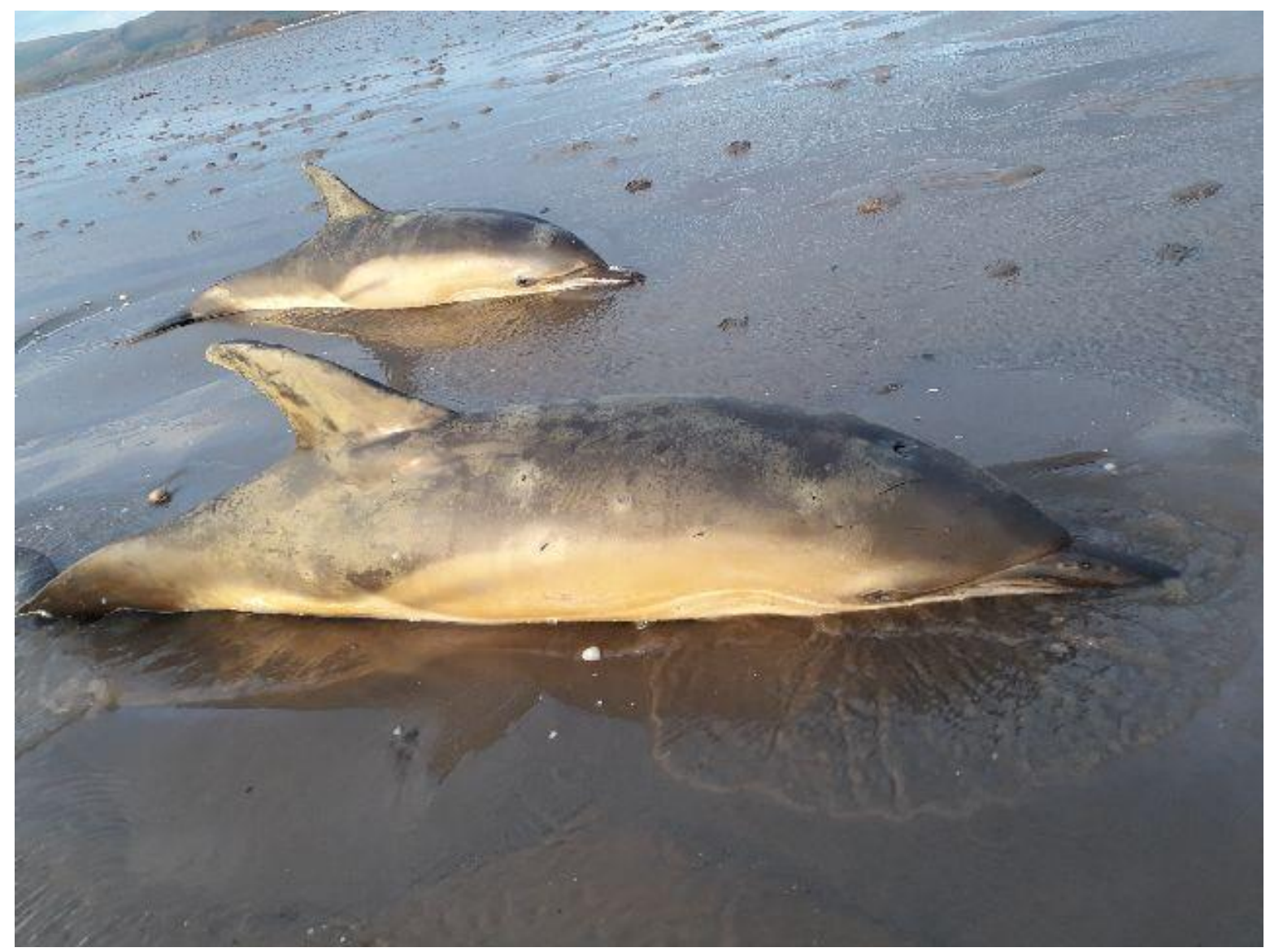

Figure 17: M245.1 \&.2/18 common dolphins (Delphinus delphis) from Cairn Ryan Beach near Stranraer 
Two juvenile common dolphins live stranded on the $20^{\text {th }}$ of April on South Uist close to the causeway to Benbecula. The smaller animal, a female, (M245.1/18) died on the beach and was sampled by the SMASS volunteer network; the second, larger animal a male (M245.2/18) was initially refloated and appeared to swim off strongly however it was found dead the following day. This animal was recovered and couriered to Inverness. At necropsy, the animal was in poor nutritional condition with no evidence of recent catabolism. There was no evidence of recent feeding and stomach ulcers a moderate nematode burden in the cardiac section of the stomach. There was a moderate to high nematode burden in the lungs possibly Halocercus $s p$. The central nervous system was unremarkable with clear pinkish coloured CSF in normal volume and no ventricular dilation. This is a debilitated animal which may have been compromised enough to have been the cause of the live stranding. Bacteriology revealed a pure but scant growth of Edwardsiella hoshinae from lung, liver and brain the significance of this is uncertain and will be further investigated through histology. The proximal cause of death is live stranding.

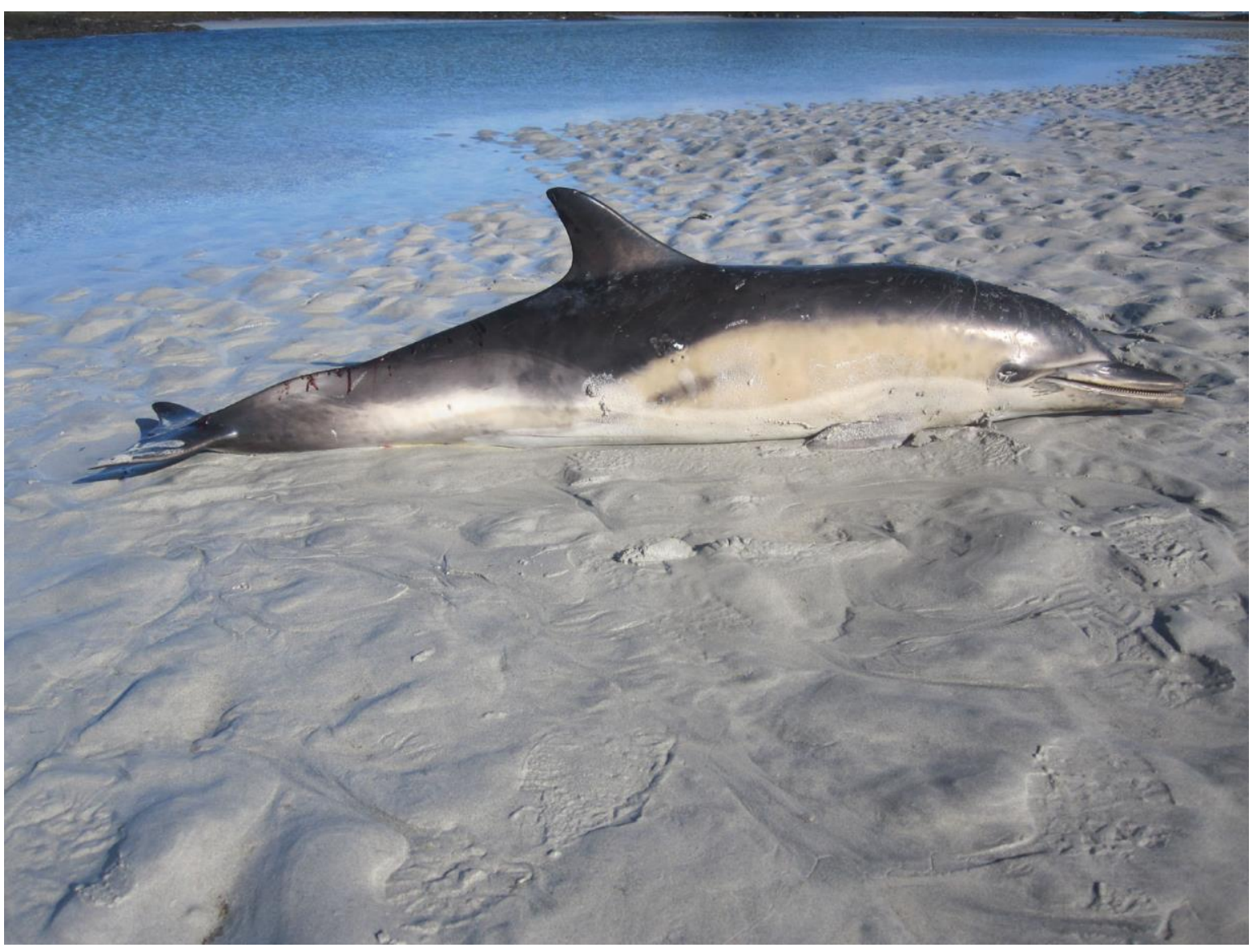

Figure 18: M251.1/18 common dolphin (Delphinus delphis) from South Uist. 


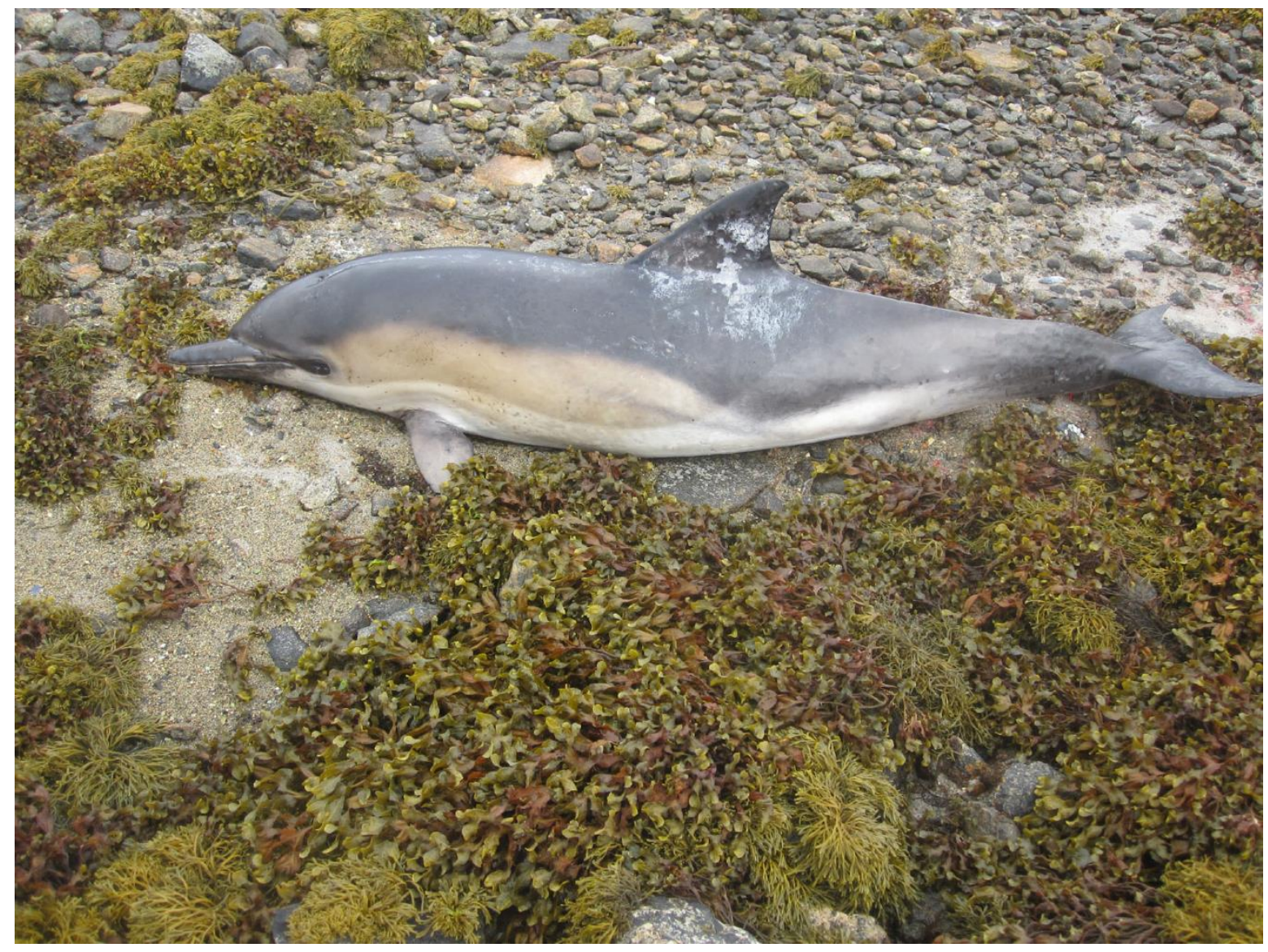

Figure 19: M251.2/18 common dolphin (Delphinus delphis) from South Uist.

\subsection{M769.1- M769.5/18 long-finned pilot whale (Globicephala melas)}

Five long-finned pilot whales were reported close to shore near Culross, Fife on the Firth of Forth on the $4^{\text {th }}$ of December. Several of the animals became stuck on the mud but refloated themselves later as the tide came in. On the 6th of December one female animal was found dead stranded and two others males live stranded further along the coast at Toryburn Fife. Because these two animals were highly probably restrandings, their prognosis for survival was poor and the decision was taken to euthanase them. Both animals were shot through the heart with a .308 rifle. A fourth animal was found dead later the same day at North Queensferry. All four animals were transported to the SRUC's laboratory in Edinburgh for necropsy. The fifth animal was not seen again.

On post mortem the animals were in good nutritional condition. There was pathology present consistent with live stranding, such as excoriations, lung asymmetry, fluid in the lungs. Both male animals had evidence of recent feeding with squid beaks present. The female animal did not have any food remains in its stomach. The fourth animal, the female found dead stranded at North Queensferry exhibited a large swelling on the right tailstock, around $70 \mathrm{~cm}$ in diameter running dorsoventrally caudal to the dorsal fin. Incision showed this swelling to be a large abscess containing purulent yellow necrotic material. It is likely this was chronic and originally traumatic in origin Similar abscesses were present in the subcutis over the left kidney and attached to the colon, possible old Monorygmia parasitic cysts. Bacteriology 
produced a pure culture of Edwardsiella tarda from most sites cultured, a pure growth of E.coli from the abscess and this same organism was recovered in mixed culture from the liver, meninges and colon abscess/cyst. The significance of the Edwardsiella is likely a post mortem invader however E.coli may well be significant as it is an uncommon isolate from cetaceans. This has been sent for whole genome sequencing (WGS) at the Animal and Plant Health Agency (APHA) and further histology is underway. In addition, the lungs were congested and haemorrhagic and the alanto-occipital joint was almost entirely fused. The brain appeared congested and the meninges thickened, with inflamed choroid plexus and necrotic material/fibrin present. CSF appeared normal and the lateral ventricles were not dilated. There was some evidence of recent feeding with scant squid beaks present in the cardiac section of the stomach. There was a high fluke burden in the pyloric section of the stomach.

This animal appeared to be suffering from a bacterial infection originating from the flank abscess. It is possible that this case might have been the matriarch of this pod, and regardless was clearly ill with a generalised bacterial infection. Given the very social nature of this species, this may provide a reason why several animals were involved in this stranding.
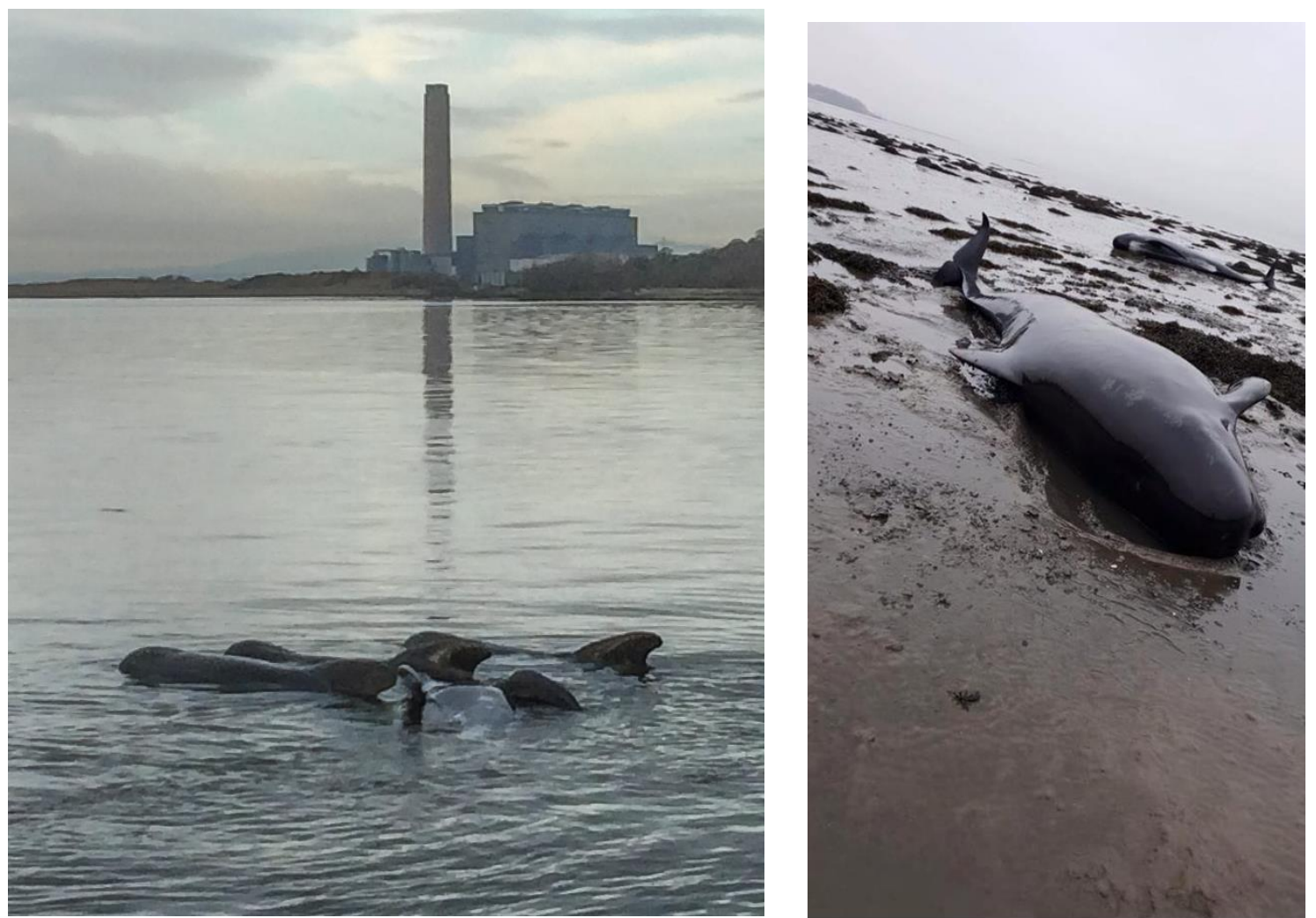

Figure 20: M769.1- M769.5/18 long-finned pilot whale (Globicephala melas) near Culross, Fife on the Firth of Forth on the 4th of December. 


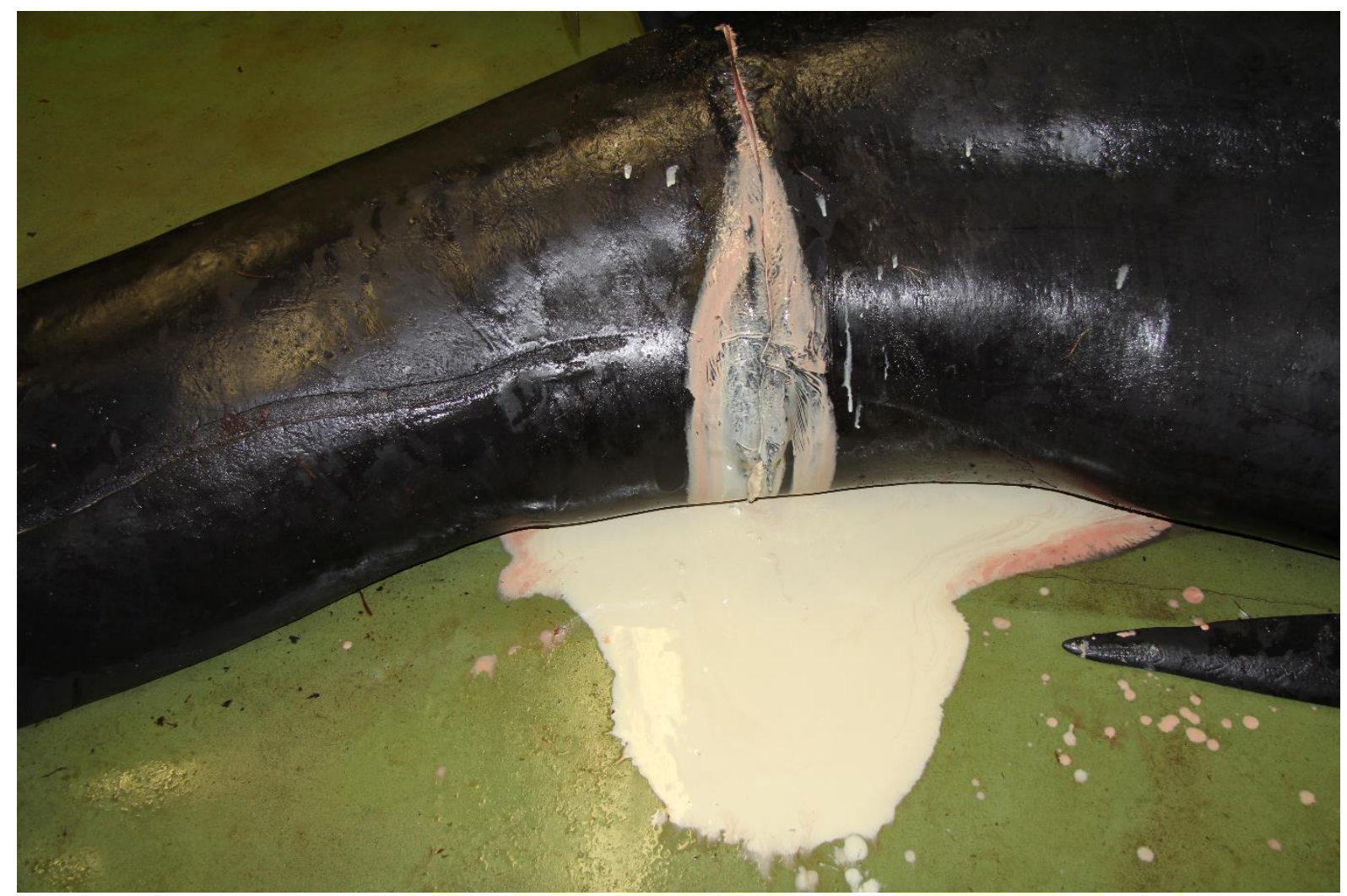

Figure 21: M769.4/18 long-finned pilot whale (Globicephala melas) showing extent of purulent abscess on tailstock.

\subsection{Cuvier's beaked whale (Ziphius cavirorostris) and Northern bottlenose whale (Hyperoodon ampullatus) UME (s)}

Between July and October 2018, 118 beaked whales were reported dead stranded in advanced stages of decomposition in countries bordering the NE Atlantic. The majority of cases $(n=83)$ were Ziphius cavirostris strandings along the west and north coasts of Ireland $(n=24)$ and the west of Scotland $(n=49)$ in August and early September, with a smaller cluster of Hyperoodon ampullatus $(n=8)$ reported in northern Scotland in October (other species or regions=19). In Iceland, there was a reported increase in the observed number of live or dead strandings $(n=15)$ of beaked whales reported over this period.

The UK figures represent over a thousandfold increase on the mean annual number reported over the preceding four year period (relative to an mean of $n=5,2014-2017$ ). At an individual country level this represented an unprecedented strandings incidence for these species, and together comprised the largest unusual mortality event of beaked whales recorded globally.

This is the third beaked whale UME recorded in the region over the last ten-year period, with similar but smaller events, again primarily involving Cuvier's beaked whales, in 2008 (Dolman et al. 2010) and 2014/15 (Brownlow et al. 2015). 
Ziphius cavirostris are a deepwater species known to be highly susceptible to noise, in particular mid-frequency active sonar. Identification of potential aetiologies solely through necropsy examination was limited however, as carcases were in an advanced state of decomposition and logistics restricted detailed necropsy examination(see Plates 3 and 4). Detailed necropsies were only possibly on two cases, although tissue sampling for contaminant, virology and genetic analysis was taken from a further 52 cases in Scotland. Samples were also archived from several Iceland and Irish cases.

A multidisciplinary integrative approach taken to investigate this event. The following work is in progress to identify plausible source regions and aetiologies for mortality:

1. Health and pathological data derived from cases recovered for necropsy;

2. Species and sex identification using short mitochondrial DNA fragment analysis of sampled cases;

3. Drift simulations for potential carcase origins, incorporating modelled ocean surface currents with effect of prevailing wind;

4. Acoustic analysis of broadband static and towed acoustic arrays operational in the NE Atlantic contemporaneously with this UME.

Collaborations with SMRU and the Smithsonian Institute in the USA are in place to undertake genetic analysis on those sampled cases, including sex and species confirmation and, eventually, finer resolution population structure. In collaboration with oceanographers at the Scottish Association for Marine Science, drift modelling has identified a plausible origin for the carcases along the shelf edge to the west of Ireland. Given the known susceptibility of Cuvier's beaked whales to the effects of anthropogenic underwater noise (in particular midrange sonar), these investigations will include collation of any data on naval activity and other sources of anthropogenic noise in the region. The investigation of this UME continues in collaboration with colleagues from IWDG and with support from the UK and Irish governments. Full results of the investigation will be disseminated in a future report. 


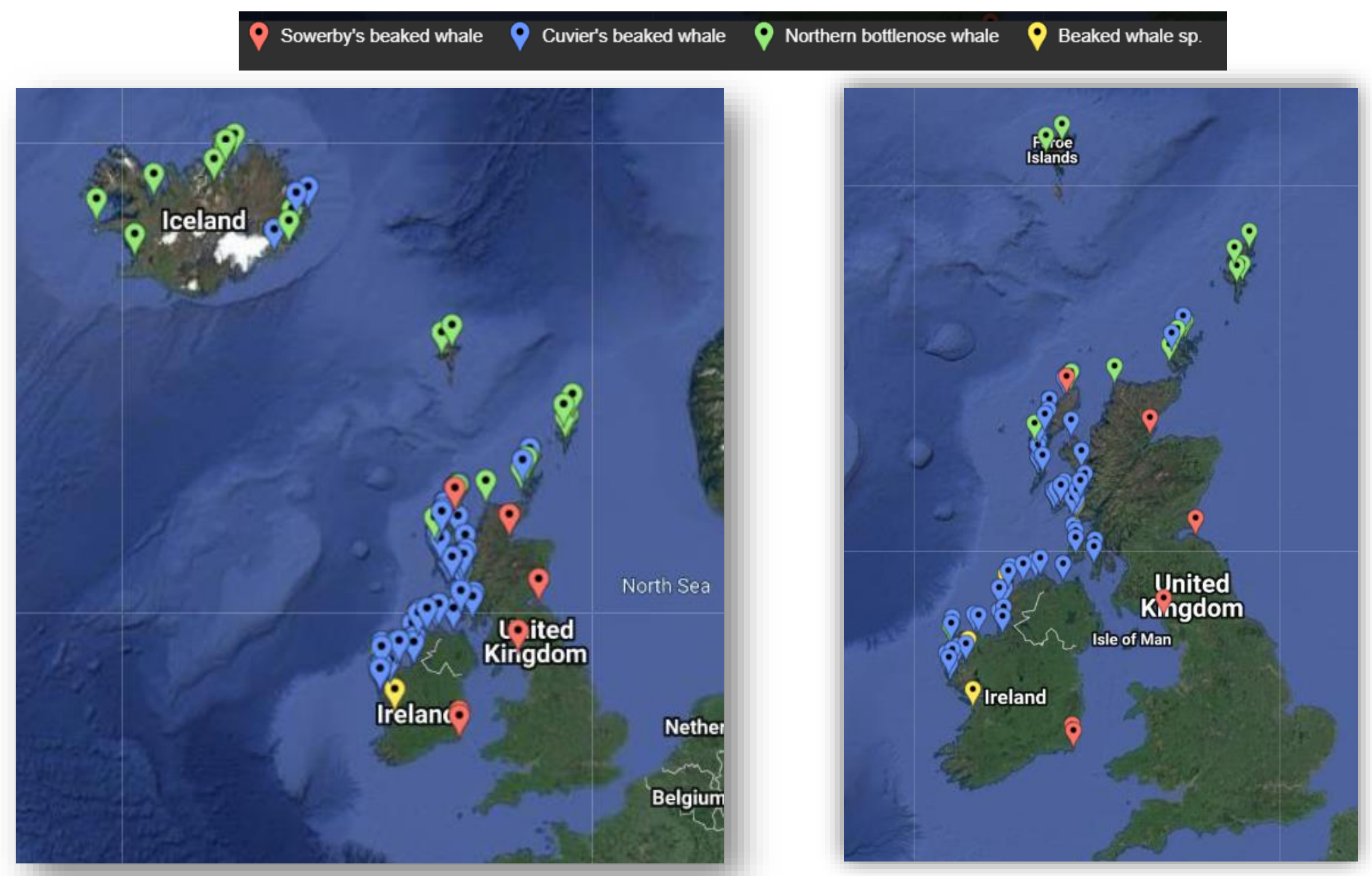

Figure 22: Distribution of beaked whale strandings 2018 


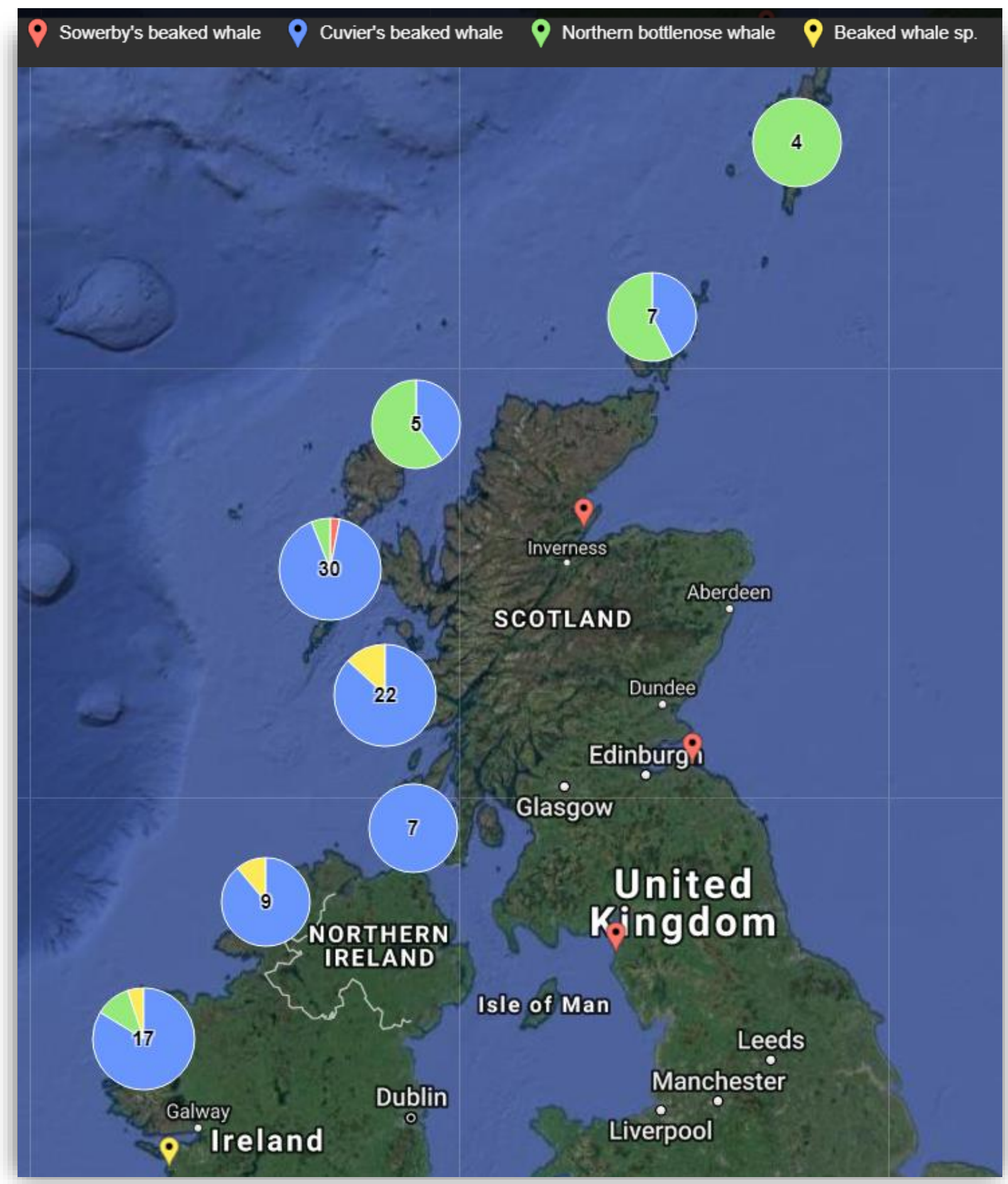

Figure 23: Distribution of beaked whale strandings 2018, grouped by region 


\section{Section 5: $\quad$ Entanglement cases}

The term entanglement usually only applies to large whales (particularly mysticetes), leatherback turtles and occasionally basking sharks. More recently, the term entanglement has also been applied to pinnipeds that have become entangled in fishing gear or other marine debris.

Animals are sometimes seen with gear attached, usually flukes and fins but occasionally through baleen plates in the mouth. Over $70 \%$ of dead stranded cases are discovered with no material remaining on the animals and diagnosis is made by lesion pattern. Acute cases similar to bycatch, sub-acute cases result in exhaustion and impaired feeding and evidence of water aspiration or drowning. Chronic cases are often very thin and debilitated and show chronic wounds caused by abrasion and pressure from entangled equipment.

There was a single case of entanglement involving a leatherback turtle, which was released alive (see section 11).

\subsection{Cetacean entanglement cases.}

Nine minke whales were reported as entanglement cases, one of which was subjected to a complete necropsy. Three from Tiree, and one from Shetland, Canna, Fife, East Lothian, and Highland.

\subsubsection{M592/18 - minke whale (Balaenoptera acutorostrata)}

This juvenile female minke whale was found at Dalcross, Highland on the 25th of September. It was in a moderate/advanced state of decomposition and entangled with a meshed fishing net through the mouth. It was sampled on the beach without assistance of plant machinery, hence only the left side of the animal could be examined and this as well as the level of decomposition resulted in minimal assessment of visceral organs. The net was fixed in the baleen likely hampering the ability to feed effectively, and had caused severe haemorrhage around the top mandible. There was bruising around and behind the left eye; most likely caused by the drag of the net. The left lung was mildly congested and appeared to contain fluid, yet floated in formalin. The animal was in a moderate - thin condition and had not recently fed. These observations fit with debilitation following a chronic entanglement. The net was removed from the animal and appeared to be a section of damaged trawler gear from a nephrops fisheries. Judging by the cut lines, it was likely discarded or washed overboard following the repair. 


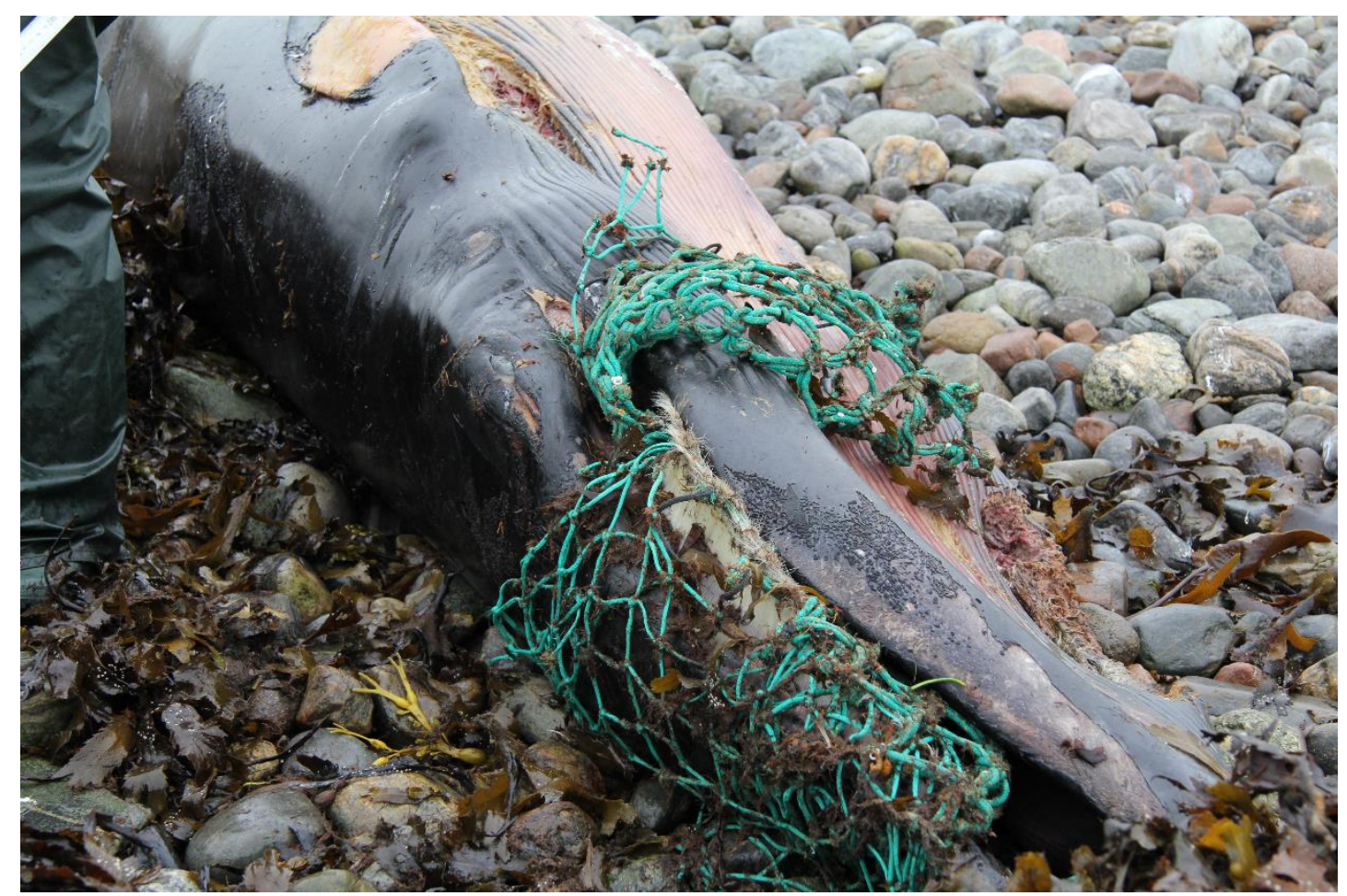

Figure 24: M592/18 minke whale (Balaenoptera acutorostrata) from Ardeseir, Highland.

\subsection{Pinniped entanglement cases.}

Eight seals; six grey and two harbour seals were reported as entangled. Two animals one grey and one harbour were subjected to necropsy.

\subsubsection{M364/18 - Grey seal (Halichoerus grypus)}

This juvenile grey seal was found alive at Skaw beach, Unst, Shetland on the $5^{\text {th }}$ of July with an encircling mass of net around its neck. The animal was taken into rehabilitation and the entanglement removed but died soon after. It was in poor nutritional condition with an full thickness lesions extending around approximately $70 \%$ of the circumference of the animal's neck In addition there was a moderate to high gastric nematode burden and the lungs were congested and showed some refluxed and aspirated bile/mucus, possibly also a degree of pneumonia due to larval migration. 


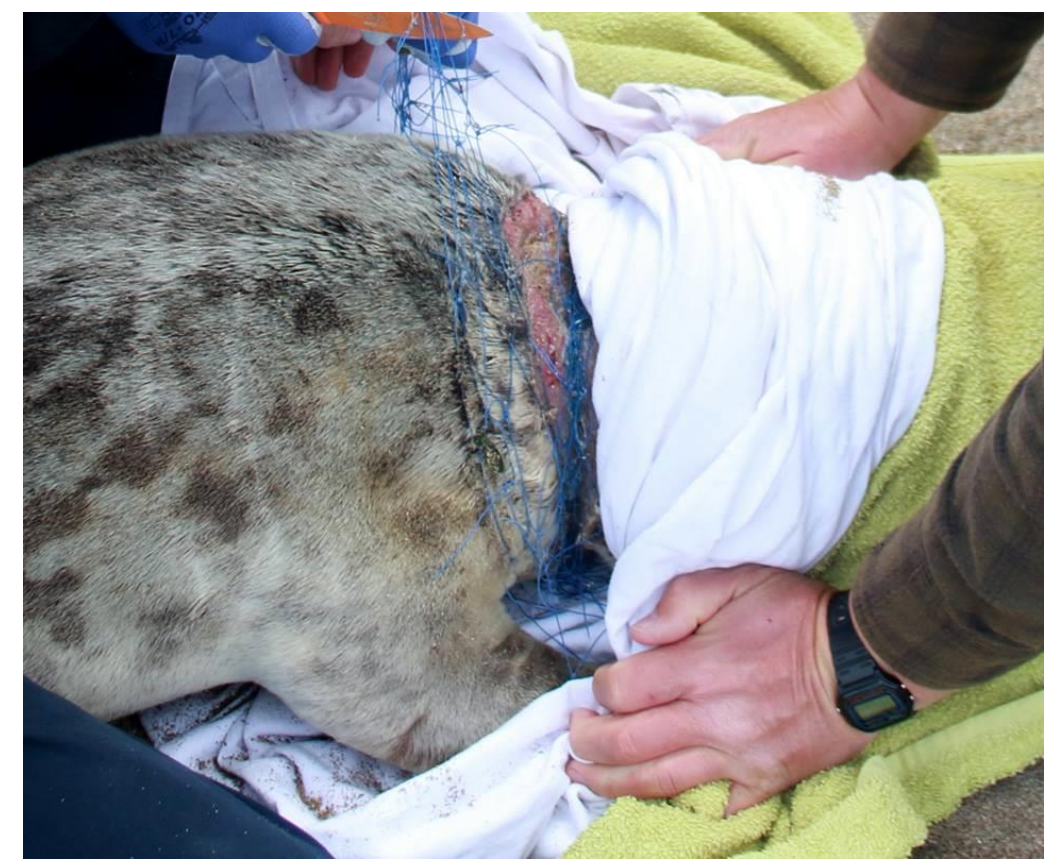

Figure 25: M364/18 grey seal (Halichoerus grypus) from Skaw beach, Unst, Shetland with net entanglement around neck.

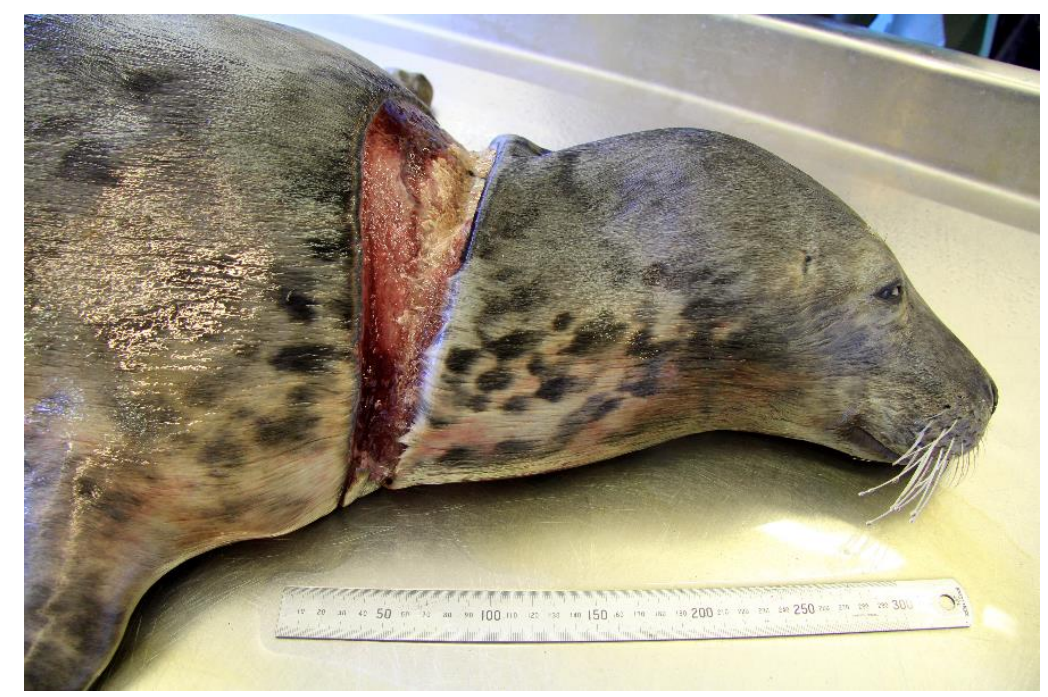

Figure 26: M364/18 grey seal (Halichoerus grypus) from Skaw beach, Unst, Shetland showing lesion once net has been removed.

\section{Section 6: $\quad$ Grey seal predation (cetaceans).}

This recently described phenomenon has so far only been seen on harbour porpoise from regions with sympatric grey seal populations. It is characterised by extensive trauma to blubber and underlying musculature, tissue loss and puncture marks around the head and around wound margins. Often large sections of tissue (both blubber and muscle) are removed, assumed predated, particularly the back muscle either side of the spine. Puncture marks through blubber often around the head and throat area. Blubber and skin commonly 
stripped resulting in missing tissue and flaps of blubber. Internal organs and skeleton are normally intact in very fresh cases. In some situations, the porpoise initially escapes the seal only to die of bacterial sepsis arising from bite wounds. There were 13 animals suspected as seal predation cases, of these 11 were classified as possible or probably primary trauma cases. Primary trauma cases are given an adjectival score based on pathological assessment of lesion patterns and exclusion of other causes of trauma:

- Unlikely: Lesion pattern is inconsistent with cases of seal predation or other causes of death are more likely.

- Possible : Lesion pattern is consistent with cases of seal predation but other causes of death cannot be excluded

- Probable: Lesion pattern is consistent with cases of seal predation and significantly more likely than any other cause of death

- Definite: Cases observed to be victims of conspecific seal predation

Two further cases were diagnosed with lesions that indicated past grey seal attack and infection with pathogens consistent with seal bites.

\subsection{Primary trauma cases suspected to be seal predation on harbour} porpoise

1. M14/18, 07/01/2018 near Irvine, North Ayrshire. Photographs provided show a large amount of tissue missing from the thoracic region of the carcase, Possible seal predation case.

2. $M 29 / 18,11 / 01 / 2018$ Dornoch, Highland. Photographs provided show a large amount of tissue missing from the thoracic region of a very autolysed carcase Possible seal predation case.

3. M78/18, 30/01/2018 Largs, North Ayrshire Photographs provided show a stripped carcase (Figure 24), Probable seal predation case.

4. M120/18, 17/02/2018 Glackbabuie, Bute, Argyll and Bute. Photographs show a stripped carcase (Figure 25), Probable seal predation case.

5. M132/18, 26/02/2018 Kinghorn, Fife. Photographs provided show a stripped carcase, Probable seal predation case.

6. M145/18, 06/03/2018 Black sands, Aberdour, Fife Photographs provided show a stripped carcase, Probable seal predation case.

7. M152/18, 06/03/2018 Forvie Nature reserve, Aberdeenshire. Photographs provided show a stripped carcase. Possible seal predation case. 
8. M185/18, 23/03/2018, Millport, Cumbrae, North Ayrshire. Photographs provided show a stripped carcase, Probable seal predation case.

9. M195/18, 30/03/2018, South Queensferry, Edinburgh. Photographs provided show a stripped carcase, Probable seal predation case.

10. M234/18, 14/04/2018 Scurdie Ness, Angus. The photo provided show a stripped carcase, Probable seal predation case.

11. M270/18, 01/05/2018 Irvine, North Ayrshire. Photographs provided show a stripped carcase, Probable seal predation case.

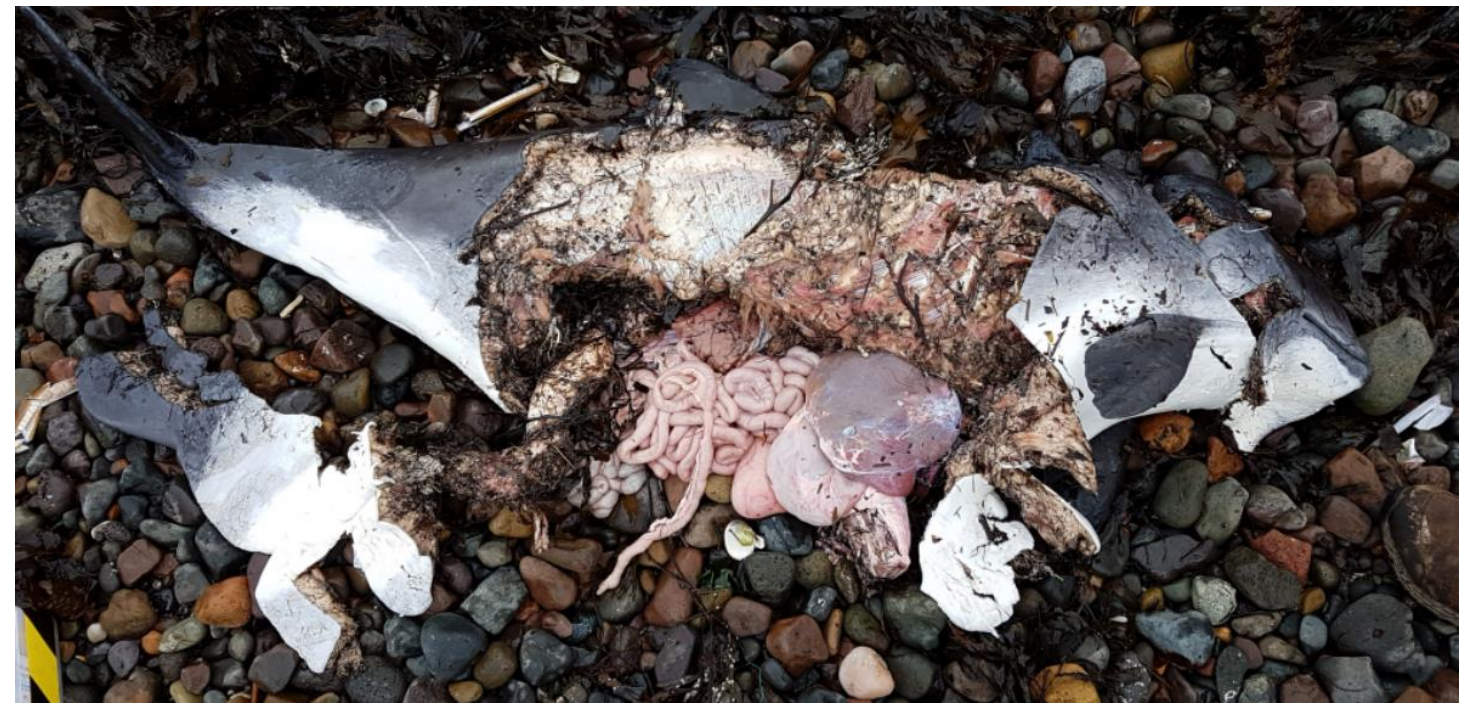

Figure 27: M78/18 harbour porpoise (Phocoena phocoena) Largs, North Ayrshire showing lesions typically associated with grey seal predation.

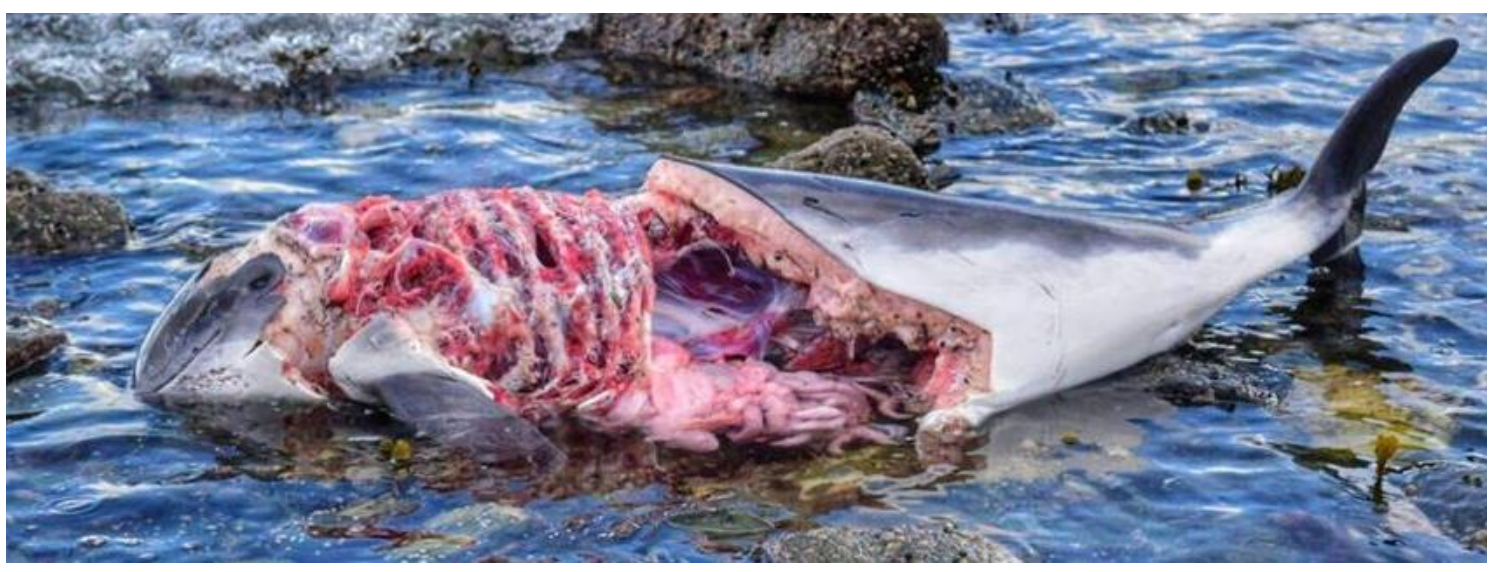

Figure 28: M78/18 harbour porpoise (Phocoena phocoena) Glackbabuie, Bute,showing lesions typical of grey seal predation with likely post-mortem avianscavenging. 


\subsection{Secondary infection possibly due to seal bite lesions on harbour porpoise}

1. $M 175 / 18,23 / 03 / 18$, Thorntonloch, East Lothian. Photographs would suggest that this was a probable grey seal predation case. This adult female harbour porpoise was found dead stranded and frozen prior to necropsy. It was in poor nutritional condition and pregnant with a mid-semester foetus. Of most significance was a severe diffuse lymphadenopathy and diffuse pulmonary lymphocytic abscessation, likely originating from a chronic infection following injury to the right pectoral fin (Figures $26 \& 27$ ). Cultures from the bite wound produced a mixture of organisms including Neisseria animaloris. This same organism was isolated in pure from the lung and lung lesion. This organism has been associated with seal bites. This suggests that the original injury was a seal bite and this seeded Neisseria animaloris into the fin, sub-sequentially disseminating through the lymphatics and causing a sepsis. Histology was hampered by the freeze thaw damage. However, the presence of the bacterial colonies in the lung and pulmonary lymph node are highly suggestive of pre-mortem infection rather than post-mortem invasion. This is a case of sepsis due to Neisseria animaloris. This case and an 7 others with similar lesions attributed to the same pathogen from England and the Netherlands are the subject of a recently submitted paper.

2.

3. M254/18, 21/04/18, Crammond Island, Edinburgh. This juvenile female harbour porpoise was found live stranded. There was an unsuccessful refloat attempt and the animal was euthanased using barbiturate. The animal was in poor nutritional condition with poor blubber deposits and back muscle mass. There was no evidence of recent successful feeding with only a few otoliths, fish bones and a single small crustacean present in the oesophagus and cardiac stomach. There was a large purulent lesion suggestive of a bite wound present on the right underside of the tailstock. There were five purulent necrotic skin lesions on the right side of the animal that extended almost too full blubber depth. The liver was friable and congested. The lungs were purple congested and full of stable foam. The brain was congested and "toxic in appearance. The lesions on the tailstock and flank are suggestive of a grey seal attack. Bacteriology produced a mixed culture of an Aeromonas sp., Enterococcus sp. and Streptococcus phocae from various sites including the bite wound lesions suggesting a sepsis originating from these. The presence of Streptococcus phocae is highly suggestive of a grey seal bite. Histology revealed a moderate, chronic-active, multifocal, verminous pneumonia with a granulomatous response. Minimal, peracute, multifocal, necrotising hepatitis. Severe, per-acute, multifocal, epidermal trauma. These findings are suggestive of very recent trauma and would not be inconsistent with grey seal attack. There was a verminous pneumonia but I would classify this as within normal limits given the species and the age. The systemic recovery of the various bacteria in the absence of any extensive lesions is an anathema. The necrosis in the liver suggests it may have been in the very early stages but not of the severity yet to cause death. The cause of death is live stranding due to trauma due to a grey seal attack. 


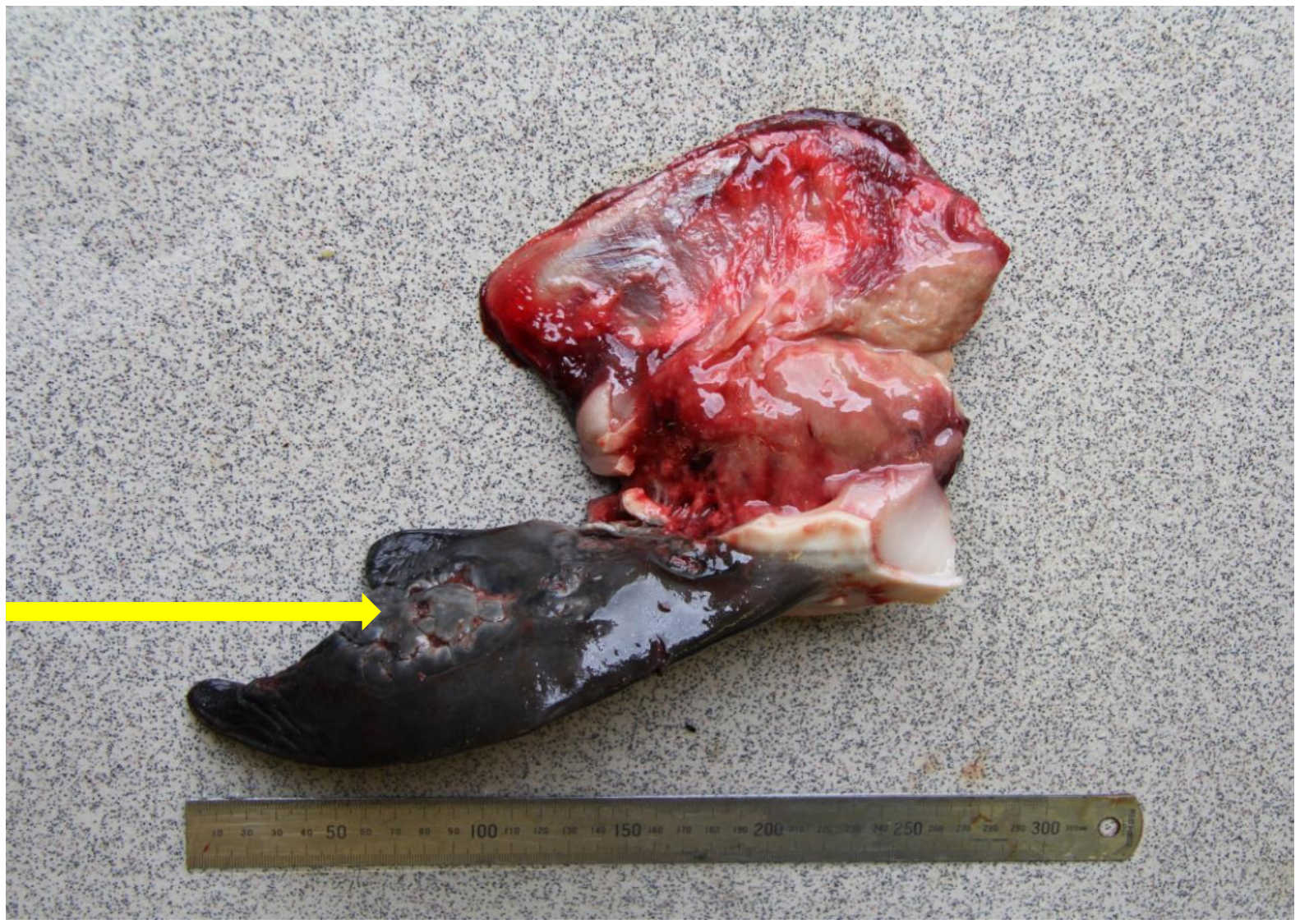

Figure 29: M78/18 harbour porpoise (Phocoena phocoena) showing infected bite wound to right pectoral fin (arrow).

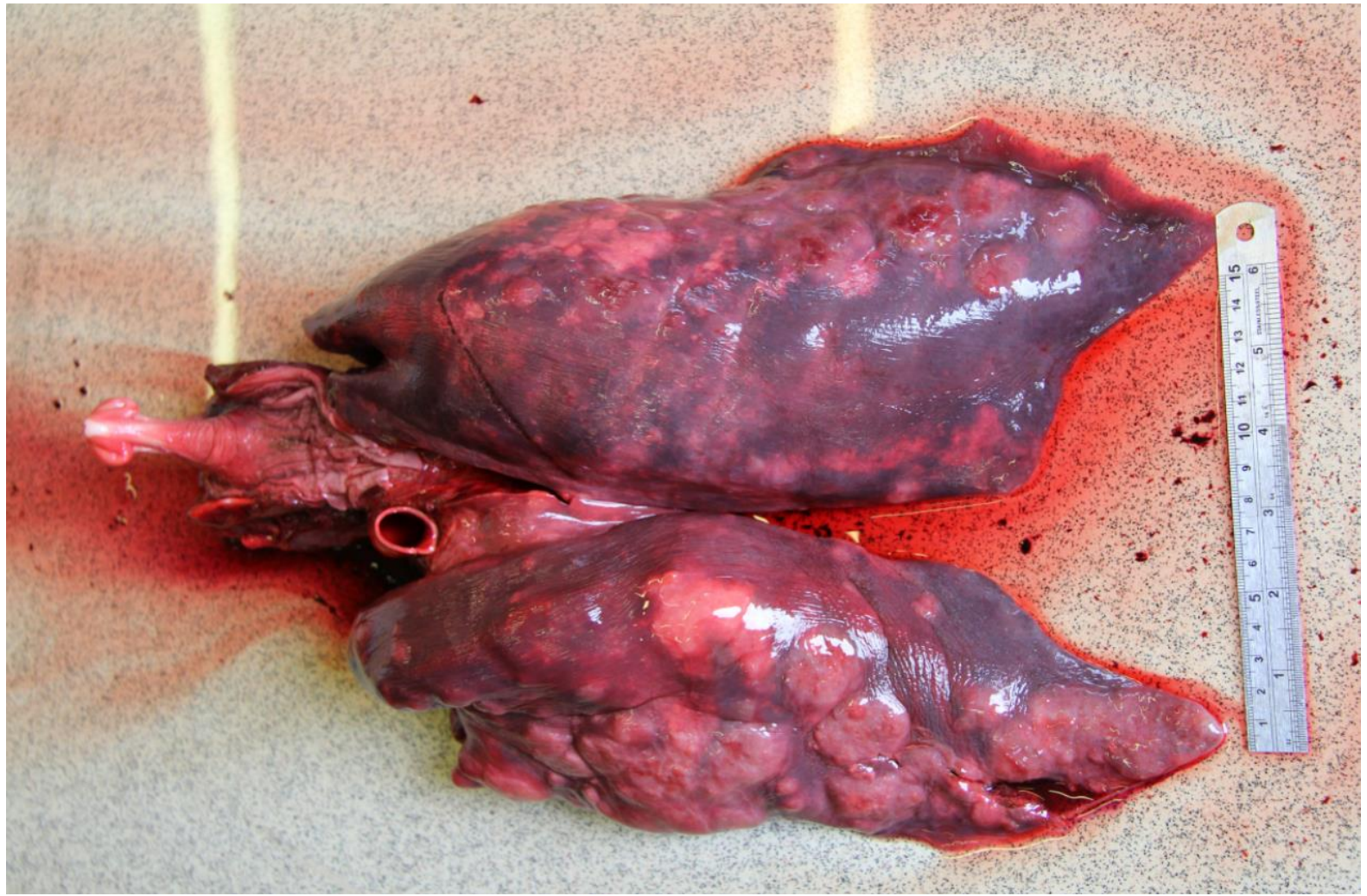

Figure 30: M78/18 harbour porpoise (Phocoena phocoena) showing lung abscessation. 


\section{Section 7: $\quad$ Neurobrucellosis cases}

This term is applied to any cases where gross pathology of the brain would suggest this condition and/or where Brucella sp. was isolated from the central nervous system (CNS) of an animal. The diagnosis is backed up through histopathology. The condition is often associated with live stranding; these animals often exhibit erratic and unusual swimming behaviours. The disease seems to affect predominantly the families Delphinidae and Ziphiidae. There were three confirmed cases reported during this period.

\subsection{M129/18 - Atlantic white-sided dolphin (Lagenorhynchus acutus)}

This adult female Atlantic white-sided dolphin was found dead stranded on Hoy, Orkney on the $25^{\text {th }}$ of February. It was in moderate nutritional condition with no evidence for recent successful feeding. Gross examination of the liver did not indicate any acute blubber catabolism. The animal was pregnant, unusually in the right uterine horn, with a mid-term foetus which appeared to have been viable up to maternal death. Other visceral organs were unremarkable, the lungs indicating possible agonal water aspiration and terminal live stranding, although there was no indication of any prolonged time spent alive on the beach. The stable foam and cranial thoracic bruising would be indicators for bycatch, but given the other pathologies it is considered unlikely. Of particular interest was the brain, which exhibited pathology classically, associated with neurobrucellosis-, increased volume of CSF, dilated ventricles and hyperaemic choroid plexus. Bacteriology revealed pure growths of Brucella ceti from the CSF taken from the ventricles and the atlanto occipital joint, the same organism was found in all sites of the spinal cord cultured. Histopathological examination showed a severe, sub-acute to chronic, locally extensive to generalised, lymphocytic meningitis. Cause of death is neurobrucellosis.

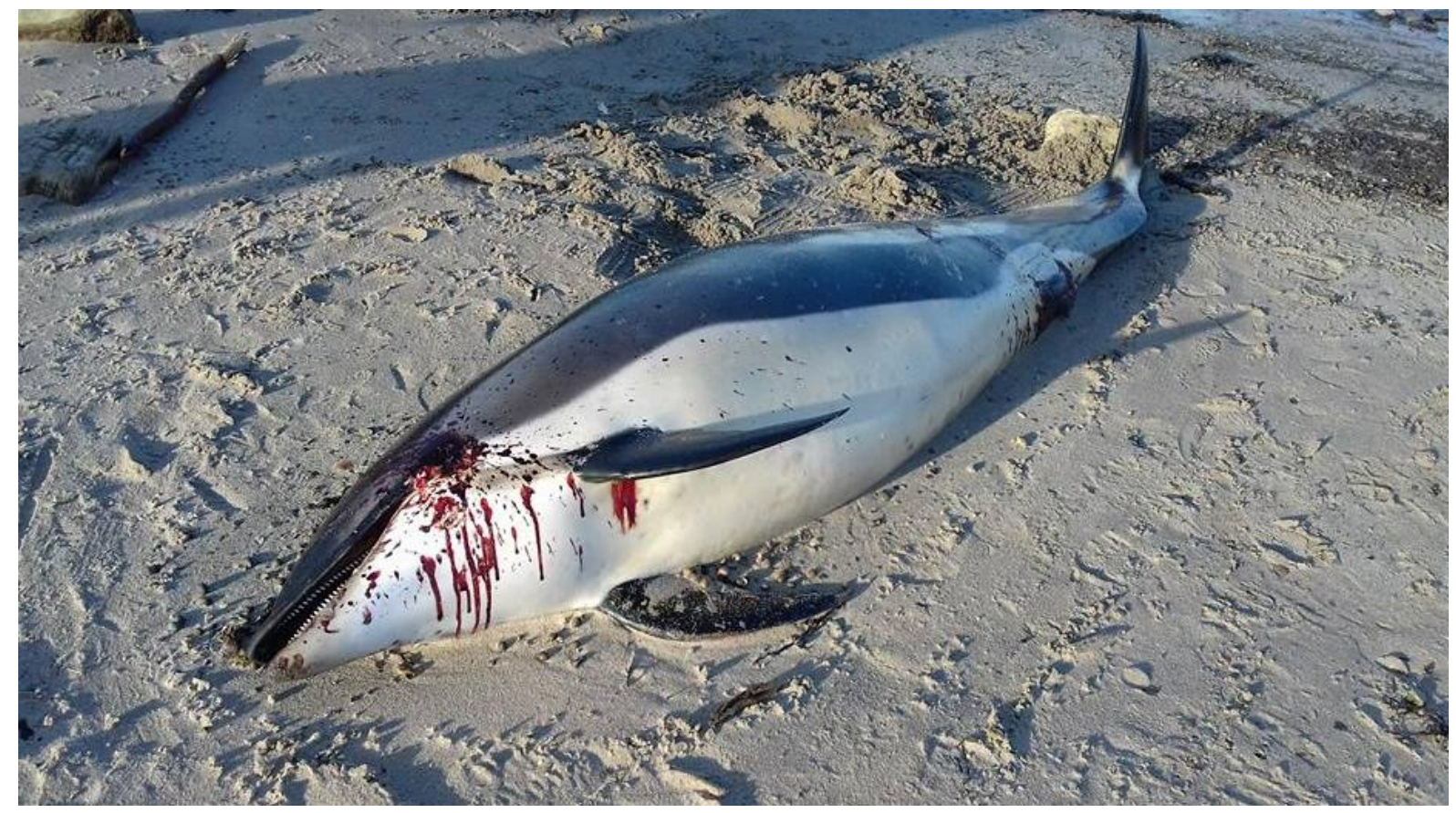

Figure 31: M129/18 Atlantic white-sided dolphin (Lagenorhynchus acutus) Hoy, Orkney. 


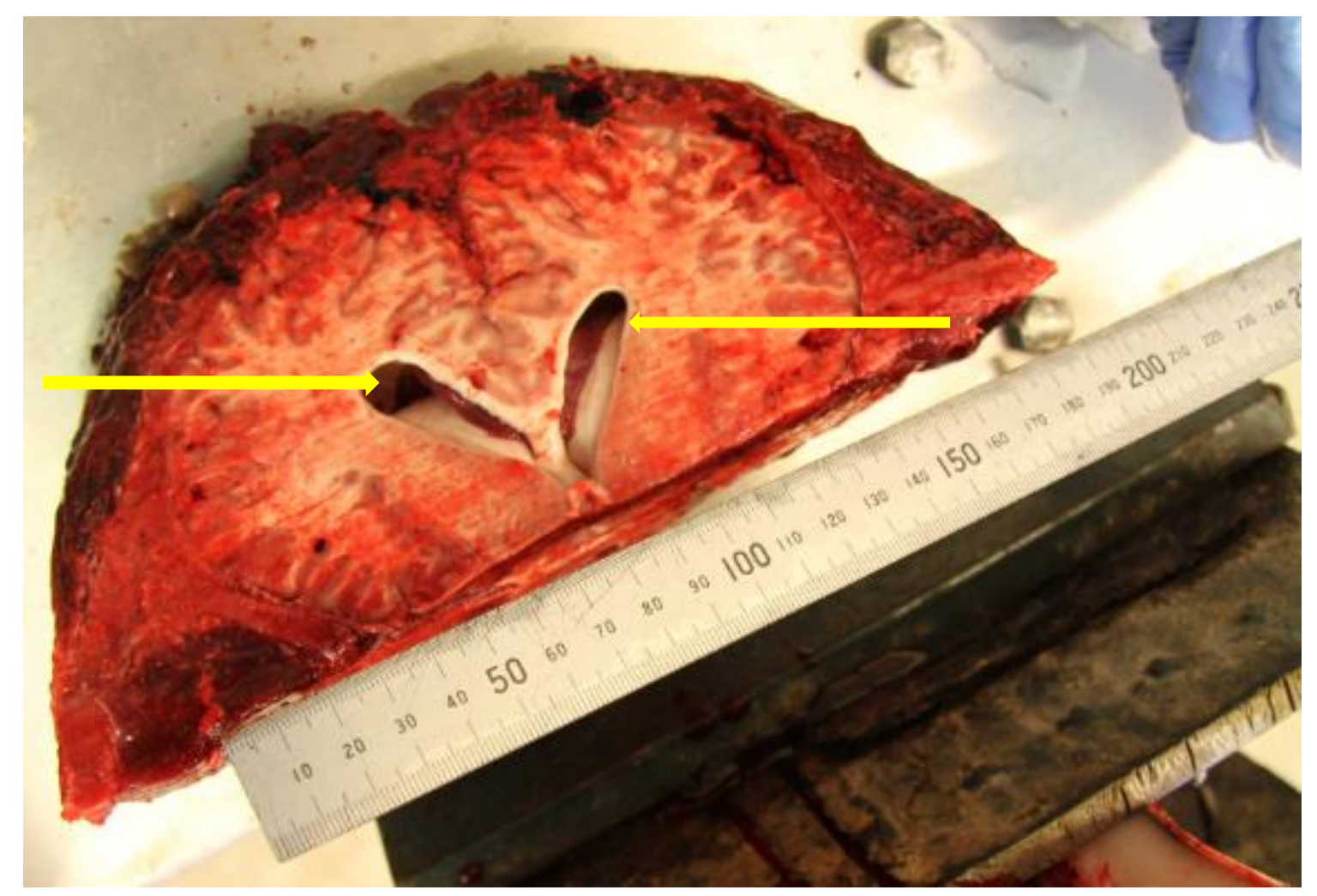

Figure 32: M129/18 Atlantic white-sided dolphin (Lagenorhynchus acutus) showing severe dilation of lateral ventricles (arrows) of the brain.

\subsection{M391/18 - Sowerby’s beaked whale (Mesoplodon bidens)}

This juvenile male Sowerby's beaked whale was necropsied on a rocky beach at Brue, on the Isle of Lewis on the $27^{\text {th }}$ of July. The animal was in moderate nutritional condition with reasonable blubber deposits and back muscle mass. There was little notable visceral pathology apart from asymmetric lungs consistent with live stranding and water aspiration. There was no evidence of recent feeding with bile staining of the cardiac stomach and throughout the intestines. There was some evidence of congestion in the muscles of the right side, perhaps suggesting the animal stranded on the right side. Of most significance however was the neural pathology. The brain was congested with much dilated lateral cerebral ventricles containing an excess amount of turbid fluid and the meninges were thickened and hyperaemic. Histology showed a mild to moderate, sub-acute, multifocal, angiocentric, predominantly lymphoid meningoencephalitis. Moderate to severe, acute, multifocal, hepatocellular necrosis. Severe, sub-acute, locally extensive, mixed inflammatory cell gastritis/enteritis. The brain lesions are consistent with neurobrucellosis but mild compared to those seen in other species such as striped, Atlantic white-sided or white beaked dolphins. This along with the isolation of Brucella ceti from the CSF is very consistent with a Brucella meningoencephalitis (neurobrucellosis) leading to live stranding. 


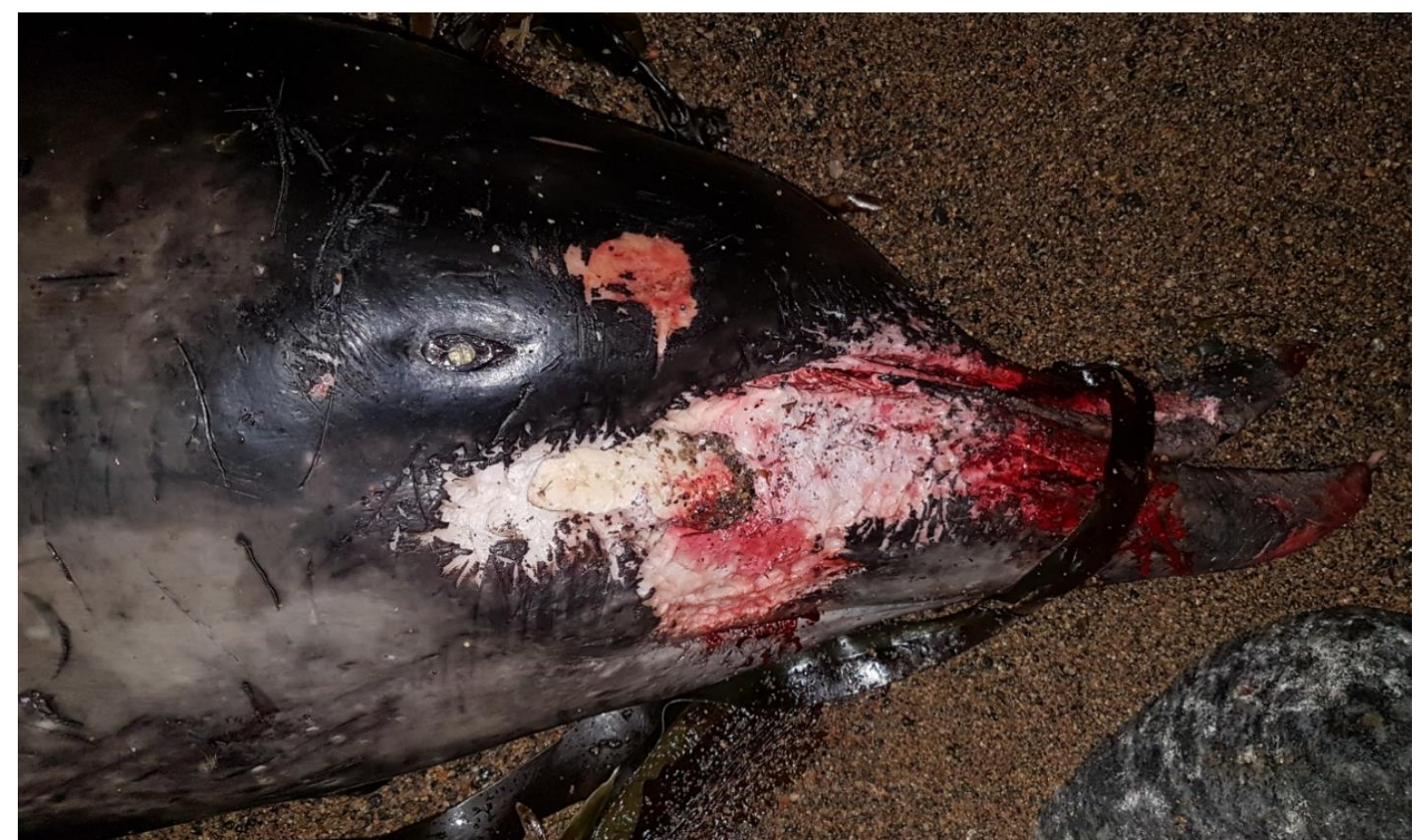

Figure 33: M391/18 Sowerby's beaked whale (Mesoplodon bidens) Brue, Lewis.

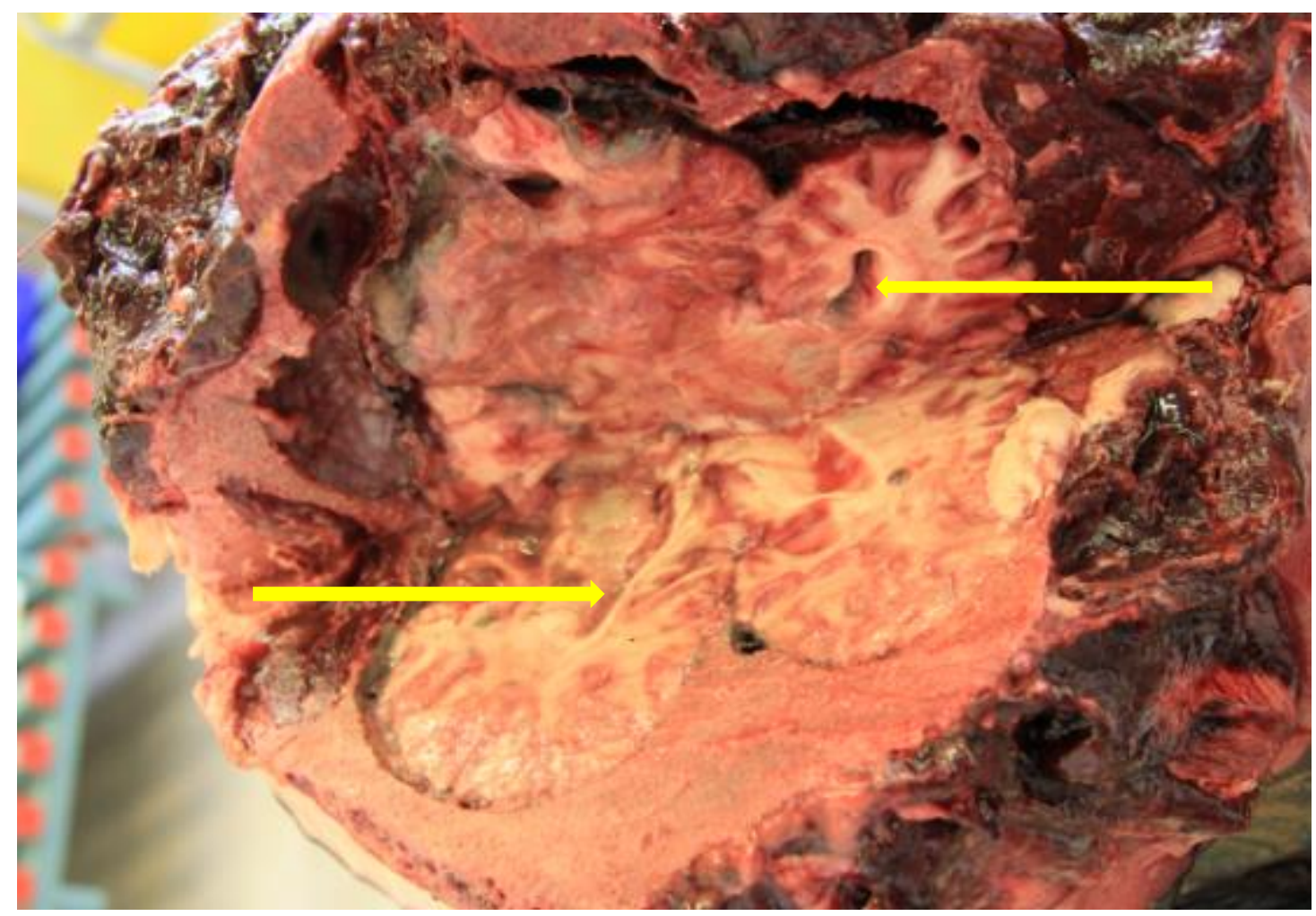

Figure 34: M391/18 Sowerby's beaked whale (Mesoplodon bidens) brain showing enlarged lateral ventricles (yellow arrows).

\subsection{M553/18- striped dolphin (Stenella coeruleoalba)}

This juvenile female striped dolphin was found dead stranded at Benderloch, Argyll and Bute on the $10^{\text {th }}$ of September. It was in moderate to poor nutritional condition but freshly dead 
and showed evidence of live stranding and possible agonal water aspiration. The animal had not recently fed, had poor blubber deposits and moderate muscle mass. The liver was congested and the lungs hyper inflated with a low nematode burden and fluid in the airways. There was a large volume of serosanguinous fluid present in the pleura. The most significant lesions were present in the CNS with severely dilated lateral ventricles, excess CSF, cortical hyperaemia and thickened meninges. Brucella ceti was isolates from the CSF and brain. Histology revealed a severe, sub-acute, generalised, lymphocytic meningitis. Moderate to severe, sub-acute, generalised peri-neuritis of the optic and trigeminal nerves. Very mild, subacute to chronic, multifocal, verminous pneumonia with abscess formation. These lesions are consistent with neurobrucellosis.

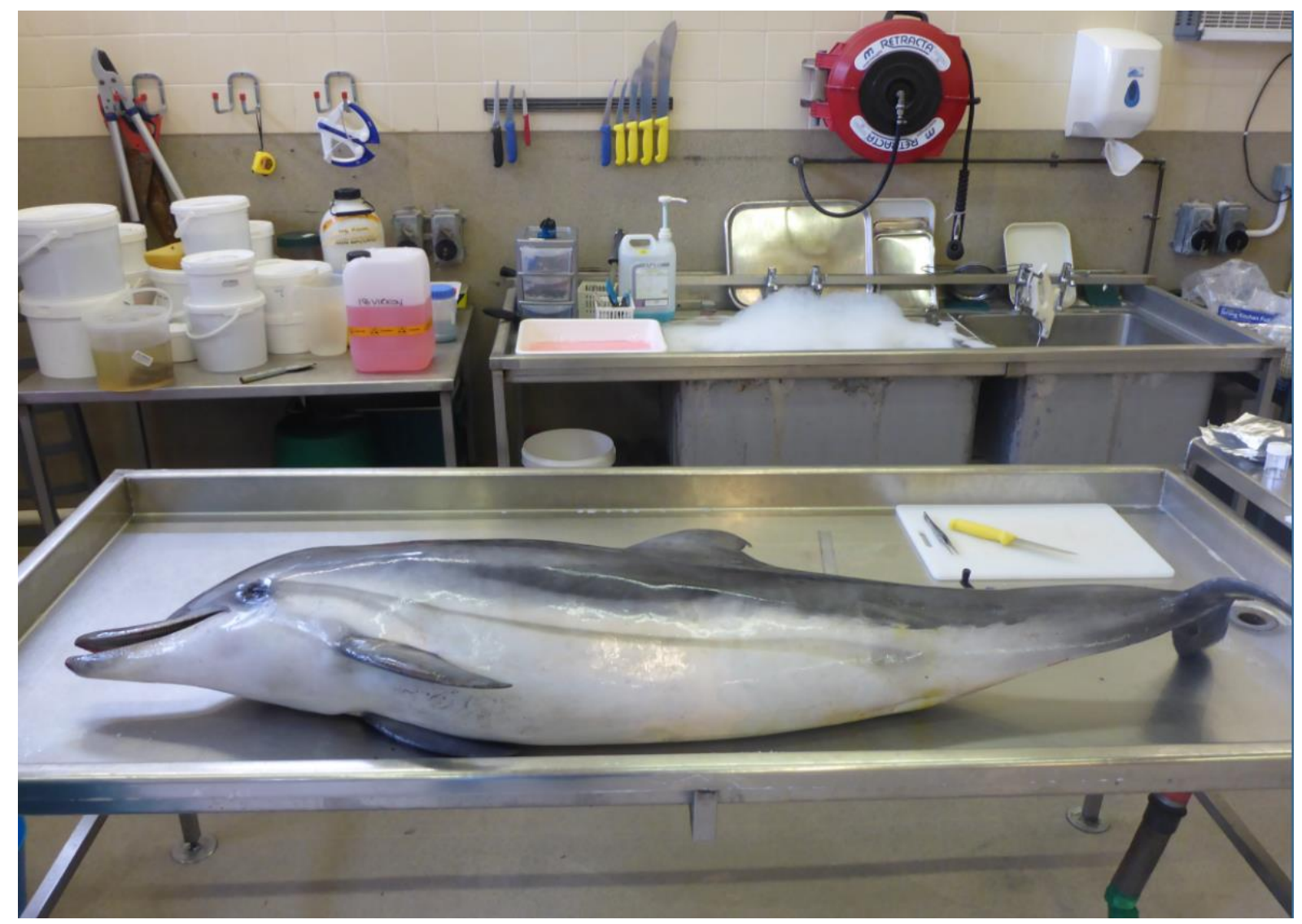

Figure 35: M553/18 striped dolphin (Stenella coeruleoalba) from Benderloch, Argyll and Bute. 


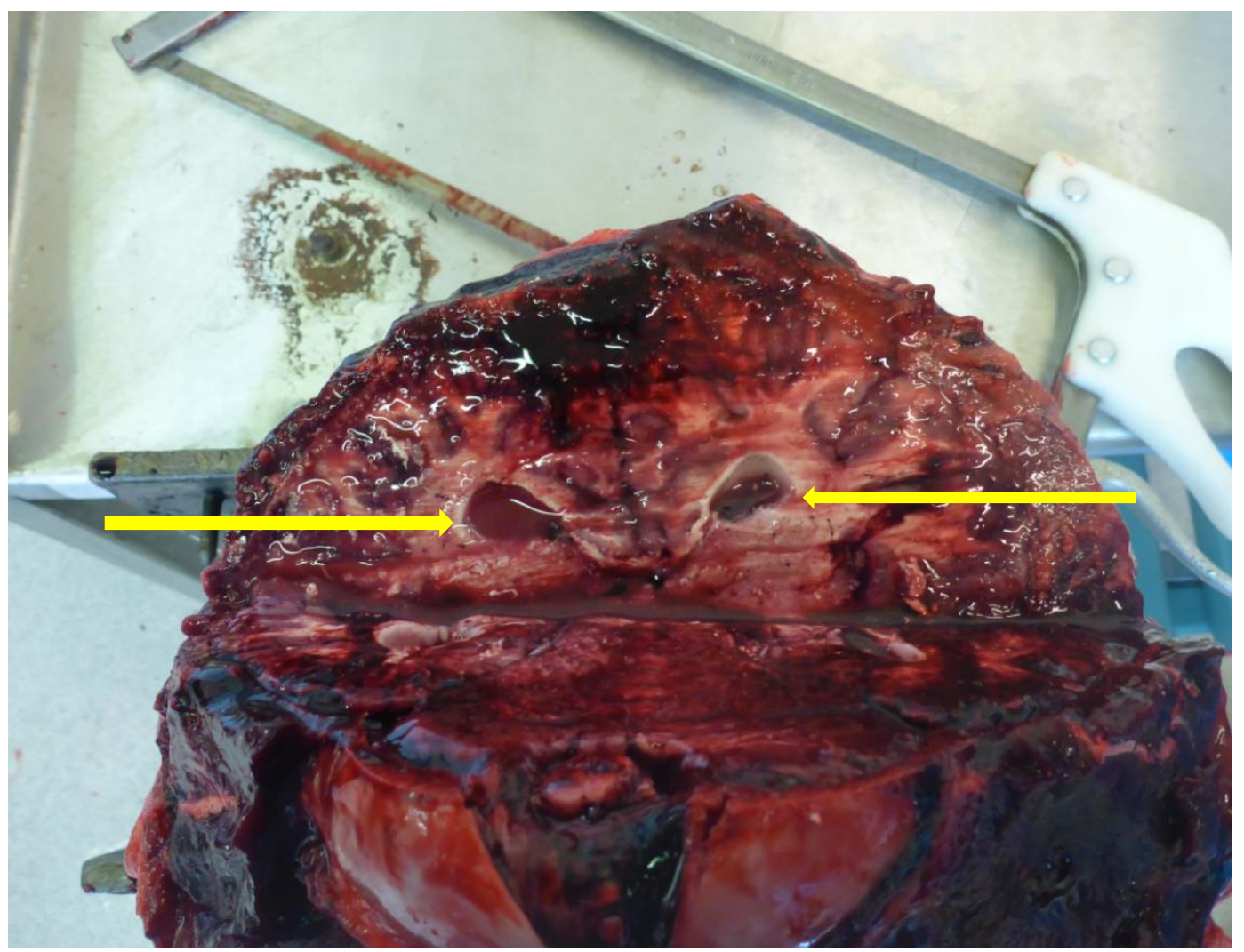

Figure 36: M553/18 striped dolphin (Stenella coeruleoalba) showing dilated lateral ventricles and turbid CSF arrows.

\section{Section 8: $\quad$ Other notable single strandings}

\subsection{M59/18- Long-finned pilot whale (Globicephala melas)}

This aged male long-finned pilot whale was observed to live strand, seizure and expire within 90 minutes of initial stranding on a wide soft sand beach, Calgary, Isle of Mull on the $19^{\text {th }}$ of January. No other LFPW were observed in the area before or since this incident. It was covered and necropsied on site 72 hours after death. PM examination revealed an adult, likely aged animal in moderate body condition with agonal evidence of live stranding but little other significant gross visceral pathology. There was clear evidence for water aspiration and ingestion, with the stomach containing a notable volume of sand but scant food. Lungs were asymmetric and fluid filled consistent with live stranding on right side. There was no significant bruising or indication of recent previous stranding event and no evidence for trauma, eg entanglement or bycatch. The adrenal cortico-medullary ratio appeared $>3: 1$ suggestive of chronic stressors. The brain revealed a generalised severe dilatation of cerebral vasculature and several focal areas of sub-meningeal bruising, in particular around the brainstem. It is not clear if this is just agonal. The ears were not extracted due to the death to post mortem interval. Ventricles were not dilated and CSF was pink, slightly turbid but in normal volume. Bacteriology only revealed post mortem contaminants. Histopathology revealed severe, chronic-active, locally extensive, granulomatous broncho-pneumonia. Mild, per-acute, multifocal, necrosis of skeletal muscle fibres. The pneumonia appeared to be in one lung sample only and the extent of this would dictate to the clinical significance and may be related to live stranding. There are various age-related lesions present but the damage to 
the skeletal muscle was acute so most likely related to the stranding process. These findings are suggestive of an aged individual but it is not possible to determine if there were any cognitive deficits that lead to this animal's demise. The cause of death would appear to be live stranding possibly age related.

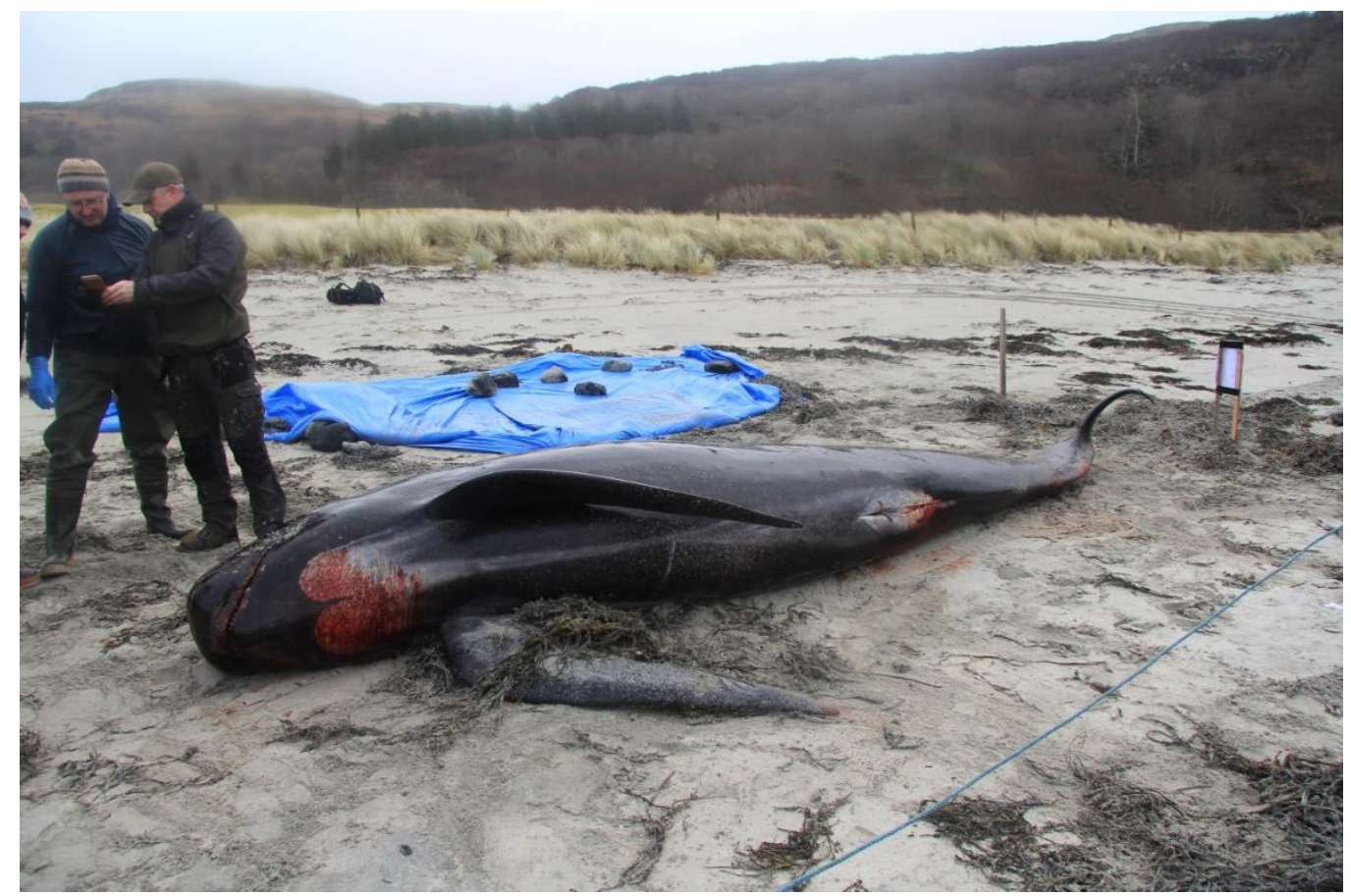

Figure 37: M59/18 long-finned pilot whale (Globicephala melas) on Calgary beach, Mull.

\subsection{M181/18 - Sperm whale (Physeter macrocephalus)}

This adult male sperm whale was found dead stranded on a very tidal region of the Tay estuary on the $21^{\text {st }}$ of March. It was reported to have died on the Wed evening and was initially examined on Fri morning, however due to issues moving the animal most of the visceral sampling occurred on the Sat, by which time the carcase was showing indications of significant autolysis. There was clear evidence of live stranding, including severe ventral bruising, antemortem excoriations and approximately 300 litres of seawater in the cardiac stomach. There were rake marks on the head likely to be from conspecific fighting, and several healed marks on the fluke which indicated past healed trauma. The animal was in good condition, with around $14 \mathrm{~cm}$ of blubber thickness and evidence for recent feeding based on a sample of fish jaw bones and squid beaks detected in the stomach. Due to the logistics of sampling, the stomach contents were only samples, not examined entire. In addition there were three coproliths in the rectum, around 4 feet from the anus, the largest of $17 \mathrm{~kg}$ in mass and rounded in appearance. Two smaller irregular shaped coproliths of around 1-2kg each were proximal to the larger mass. These objects were not causing an obstruction and were surrounded by liquid faeces, but there did appear to be dilation of the rectum around these objects. The visceral tissues were significantly autolysed, and thus detailed examination was not reliable, but did not show overt indications of disease or parasite burden. The head was removed and a sample of brain tissue and CSF collected through the foramen magnum. This tissue was autolysed but again was sufficient for sampling. Bacteriology produced a mixed bag of isolates including a aHaemolytic Streptococcus sp. with a profile that matches an isolate from 
the liver of a fin whale from Devon. The significance of this isolate is at present uncertain. Histology confirmed autolysis in those organs that were identifiable. The cause of death is live stranding, and it is plausible that, given the location, time of year and stomach contents, that this is a generally healthy animal which entered the north sea from the North and entered the firth on the east coast of Scotland in an attempt to head further west.

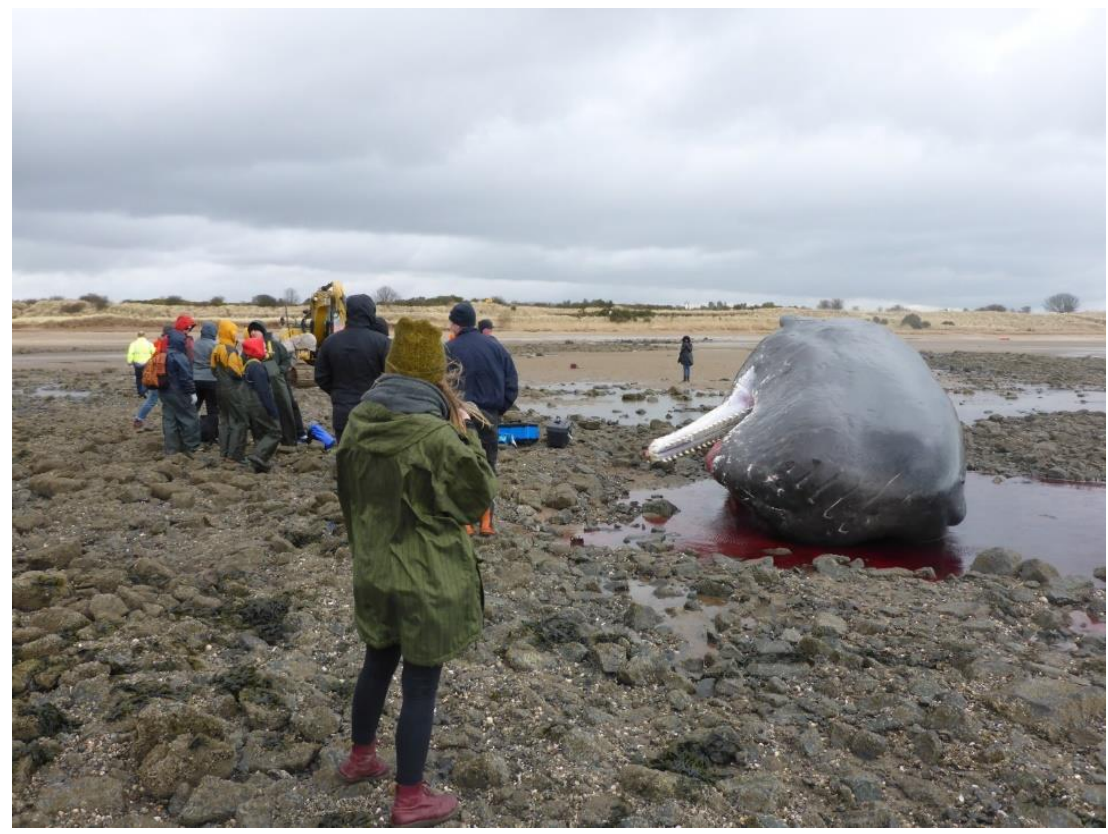

Figure 38: M181/18 sperm whale (Physeter macrocephalus) from the Tay estuary.

\subsection{M285/18 - harbour porpoise (Phocoena phocoena)}

This juvenile male harbour porpoise was found dead stranded at Fort George on the $14^{\text {th }}$ of May, 24 hours after a group of bottlenose dolphins were seen attacking a small harbour porpoise. The animal was in good nutritional condition. It showed severe trauma typical of a bottlenose dolphin attack, exhibiting extensive and diffuse thoracic and hepatic trauma. This included complete bilateral fractures of the ribcage, spinal fracture around $\mathrm{T} 4-\mathrm{T} 5$, and extensive hepatic rupture and exsanguination into the abdominal cavity. The animal was otherwise in good body condition and had evidence of recent successful feeding based on enteric rather than gastric contents. Cause of death was confirmed as attack by bottlenose dolphins. 


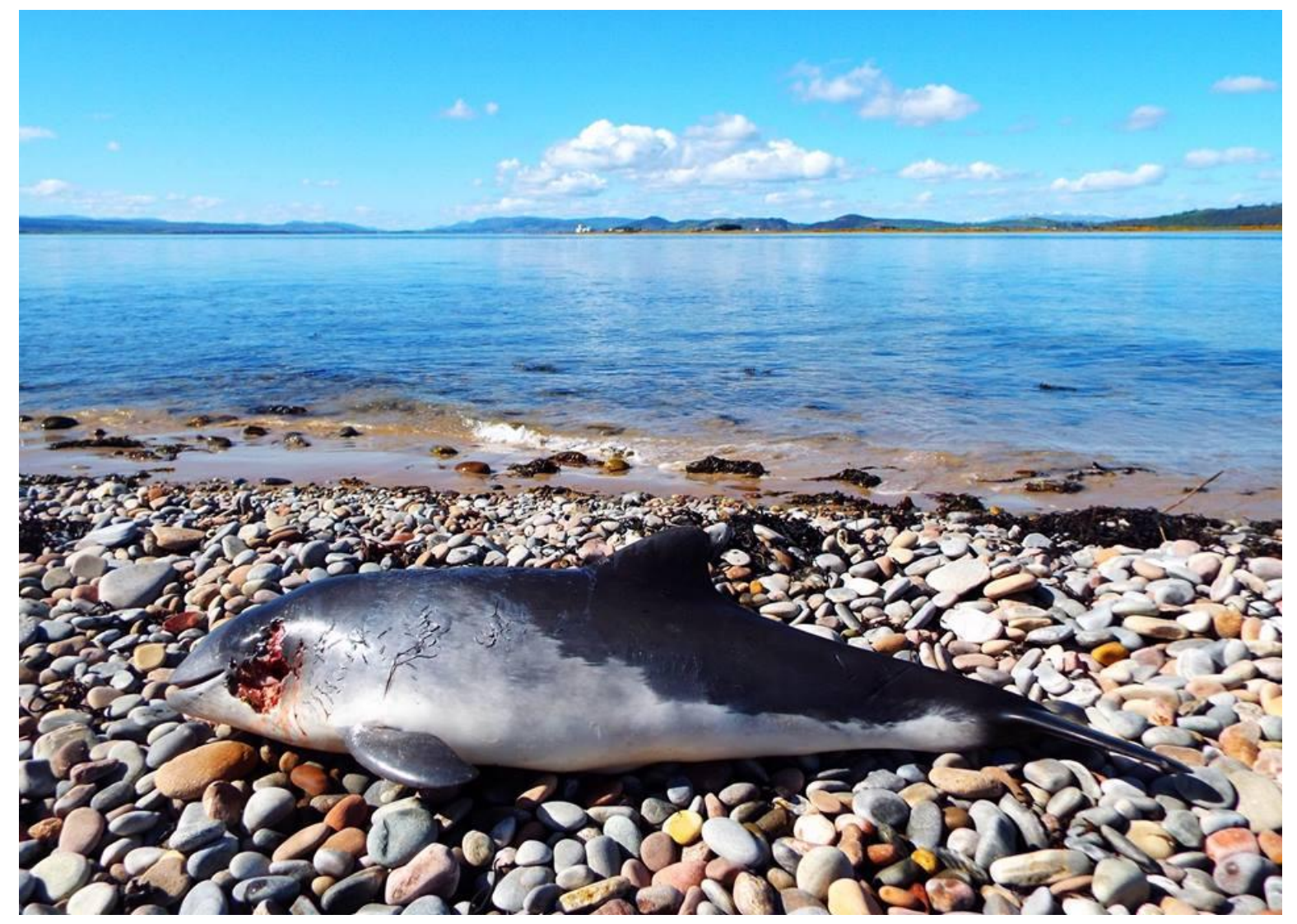

Figure 39: M285/18 harbour porpoise (Phocoena phocoena) from Fort George. Photo credit John Hourston.

\subsection{M402/18- Sowerby's beaked whale (Mesoplodon bidens)}

This juvenile male Sowerby's beaked whale live stranded at Belhaven beach on the $29^{\text {th }}$ of July. There were attempts to re float the animal however these were not successful and the animal died prior to euthanasia. It was stored chilled at the National Museum of Scotland prior necropsy at Inverness. The animal was moderately autolysed and in moderate to good nutritional condition. Lipid was exuding from the cut blubber. There was clear evidence of live stranding with lung asymmetry, and ventral bruising. There was no evidence of recent feeding with only some very fine nematodes present in the cardiac stomach. The most striking finding was the bilateral rib fractures with 8 ribs fractured on both sides with associated haemorrhages. There was no obvious subcuticular bruising and the skin and blubber was intact. The brain showed dilated cerebral vasculature but no fractures or sub dural haemorrhage. Bacteriology did not reveal any significant isolates. Histological examination of the tissues from this case showed them all to be moderate to severely autolytic, often with post-mortem gas holes present the degree of autolysis obviously significantly affected assessment of these tissues including the identification of some of them. Histology revealed a mild, acute, multifocal, suppurative cytstitis, a moderate, per-acute, multifocal, necrotising myopathy and a severe, sub-acute to chronic, focal, suppurative lymphadenitis. Examination of rib-end decalcified showed no tissue or cellular reaction present. This would indicate the rib fractures might have been a post-mortem event, possibly from a strap used to transport. We were unable to determine the reason for the live stranding of this animal however there was no clear evidence for an infectious or traumatic cause in this case. 


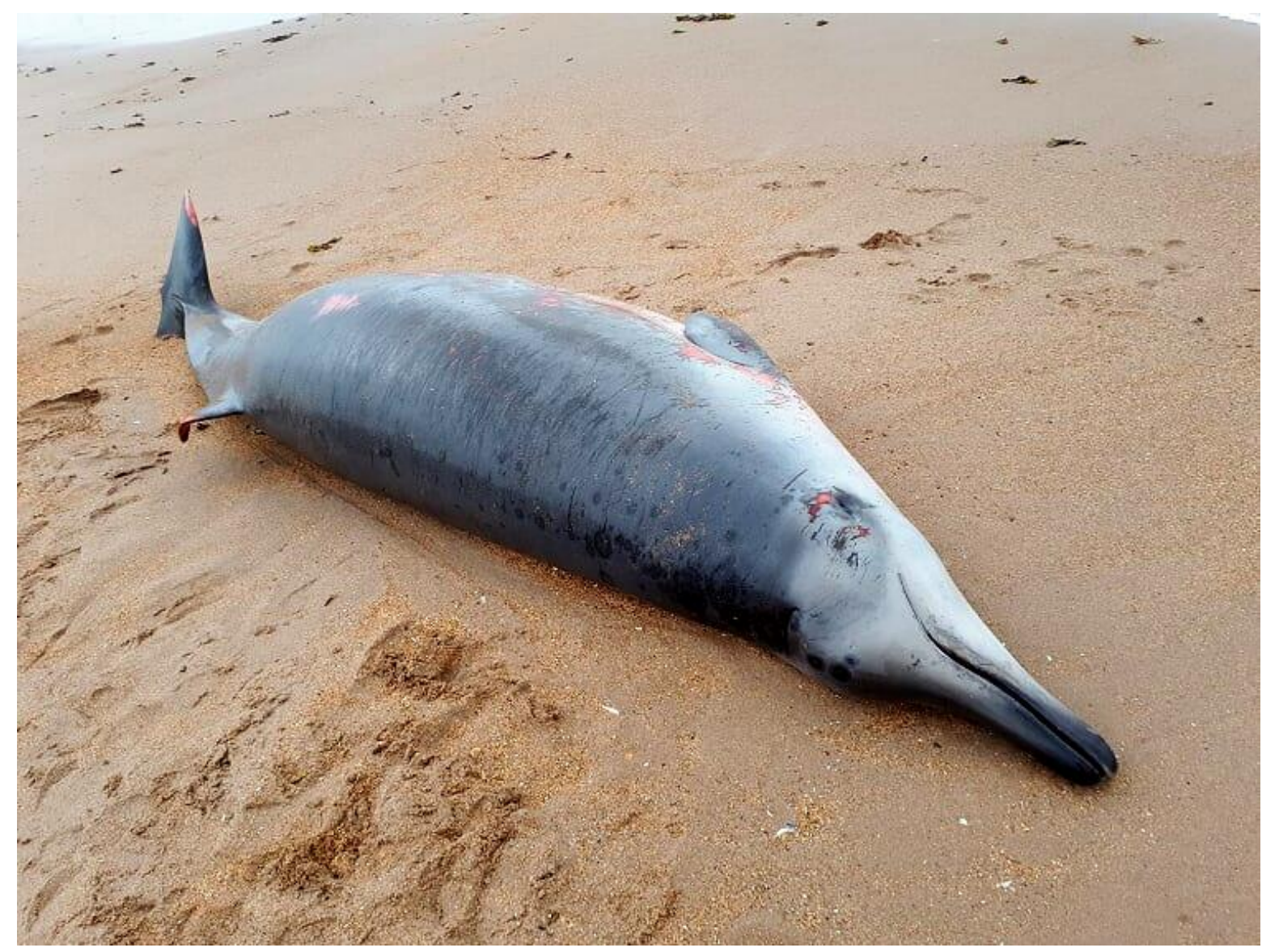

Figure 40: Sowerby's beaked whale (Mesoplodon bidens) from Belhaven beach.

\subsection{M481/18 - Risso's dolphin (Grampus griseus)}

This very young juvenile male Risso's dolphin was found dead stranded at Aultbea, Highland on the $23^{\text {rd }}$ of August. It had numerous rake marks over both sides of the body and tale flukes. Some had spacing consistent those of bottlenose dolphins, there was associated focal haemorrhage in the blubber. The animal was in poor nutritional condition with thin dehydrated blubber deposits and poor back muscle mass deposits. There was evidence of live stranding with pronounced lung asymmetry and stable foam in the airways. There was a moderate nematode burden in the bronchi and smaller airways. The liver was pale, swollen, fatty and congested, suggesting catabolism. The brain was slightly congested but otherwise unremarkable. There was no evidence of recent feeding. All other systems appeared normal. There were no broken bones noted. Bacteriology did not reveal any significant isolates. This would suggest separated maternally dependant animal in poor condition due to starvation. The animal had had some violent interactions with either conspecifics or bottlenose dolphins though this encounter was not immediately fatal. Histology showed a severe, sub-acute, generalised hepatic fatty change. Mild, acute, multifocal, mixed inflammatory cell, superficial dermatitis. The changes in the liver are suggestive of inanition and the proximal cause of death is live stranding following separation of a maternally dependant animal. 


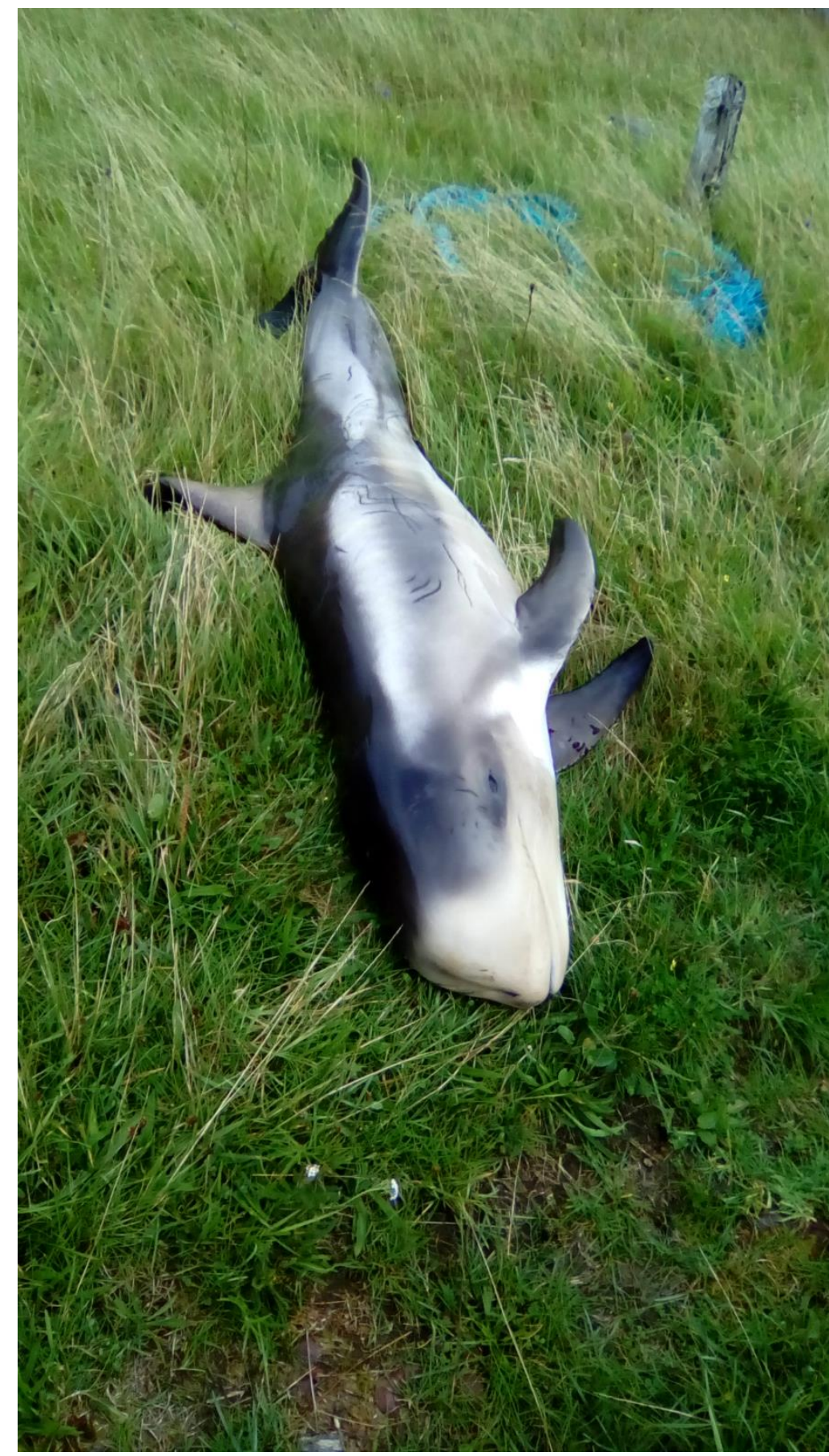

Figure 41: Risso's dolphin (Grampus griseus) nenonte from Aultbea, Highland.

\subsection{M488/18 - white beaked dolphin (Lagenorhynchus albirostris)}

This neonatal male white beaked dolphin was found dead stranded at Evie, Orkney on the $25^{\text {th }}$ of August. The animal was in moderate nutritional condition. The animal was jaundiced with a generalised, diffuse, peri acinar "nutmeg "appearance to a friable congested liver. The lungs showed some asymmetry with the left lung hyper inflated. There was a high nematode burden throughout the bronchial tree, most pronounced in the terminal bronchi and in the right lung. The heart also exhibited a profound hypertrophy of the right ventricle, most likely due to the patent duct/foramen ovale connecting the mitral valve to the tricuspid valve region. The duct was $3-4 \mathrm{~mm}$ in diameter and contained a clot indicative of patency. The 
hepatic pathology is possibly due to the congestive vascular hypertension, however screening to rule out viral involvement will be undertaken. Bacteriology did not reveal any significant isolates. The cardiac hypertrophy especially the right side is likely due to the patent shunt; however this may have been exacerbated by the verminous pneumonia and hypostatic effect on the pulmonary perfusion. Histology showed a severe, sub-acute, generalised, granulosuppurative verminous broncho-pneumonia, severe, sub-acute, generalised, granulomatous lymphadenitis, severe, sub-acute, generalised, hepatic fatty change and severely, acute, centrilobular, necrotising hepatitis. These indicate a possible infectious process in addition to the developmental vascular abnormalities

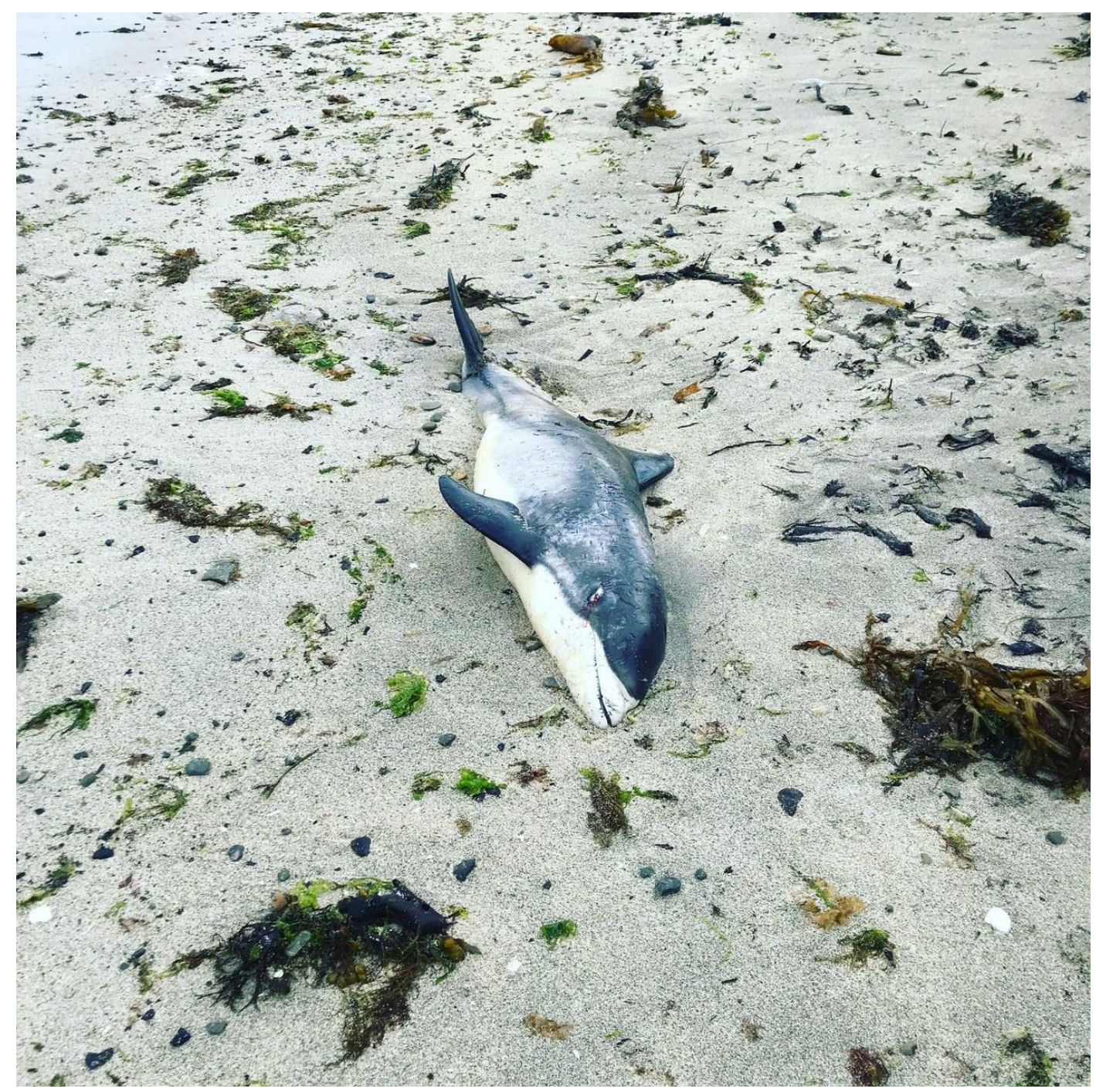

Figure 42: M488/18 white beaked dolphin (Lagenorhynchus albirostris) from Evie beach, Aiterness, Orkney.

\subsection{M586/18 - minke whale (Balaenoptera acutorostrata)}

This sub-adult female Minke whale was observed to swim erratically and attempted to live strand against a rainwater outflow pipe in Arderseir bay, Highland on the $18^{\text {th }}$ of September. A rescue attempt was mounted by BDMLR but the animal couldn't be kept upright and died at the scene. It was recovered and necropsied at DSC Inverness within 18 hours of death. The animal was in moderate nutritional condition with only moderate back muscle mass and blubber deposits. The lungs were inflamed and congested with stable foam in and fluid in the 
bronchi and smaller airways, fluid oozed out of the cut surface of the parenchyma. This suggests terminal drowning. The stomachs were also full of fluid (assumed seawater) and a moderate nematode burden (assumed Anasakis $s p$.) but no ingesta. The liver was congested with a moderate liver fluke burden (assumed B.goliath). The large intestine also had a moderate Acanthocephalan worm burden (assumed B.balaenae). There was moderate enlargement of parietal and mesenteric lymph nodes. Of most significance was severe neuropathy, characterised by significant hydrocephalus from profoundly dilated cerebral ventricles, diffuse meningeal adhesions, most severe around the brainstem and a purulent foci in the frontal cortex. The CSF was turbid and likely in excess of 2 litres, resulting in a loss of cortical tissue. This is compatible with impaired CSF drainage due to increased cellularity and protein deposits and is consistent with a meningoencephalitis due to neurobrucellosis. However, bacterial culture of the CSF and CNS tissues did not recover any Brucella sp. Histology revealed a severe, sub-acute to chronic, generalised, lymphocytic, meningoencephalitis. There wa moderate, acute, generalised hepatic fatty change. The encephalitis would have been highly significant and explained the clinical signs observed prior to live stranding. The lesion profile was not typical of neurobrucellosis and another intra-cellular pathogen was probably responsible such as a virus. Examination of frozen brain tissue for herpesvirus and cetacean morbillivirus will be undertaken. There seems to have been a significant ongoing humoral response underway in this animal as denoted by the number of plasma cells present in the brain and lymph node. The level of parasitism was within normal limits for an animal of this age.

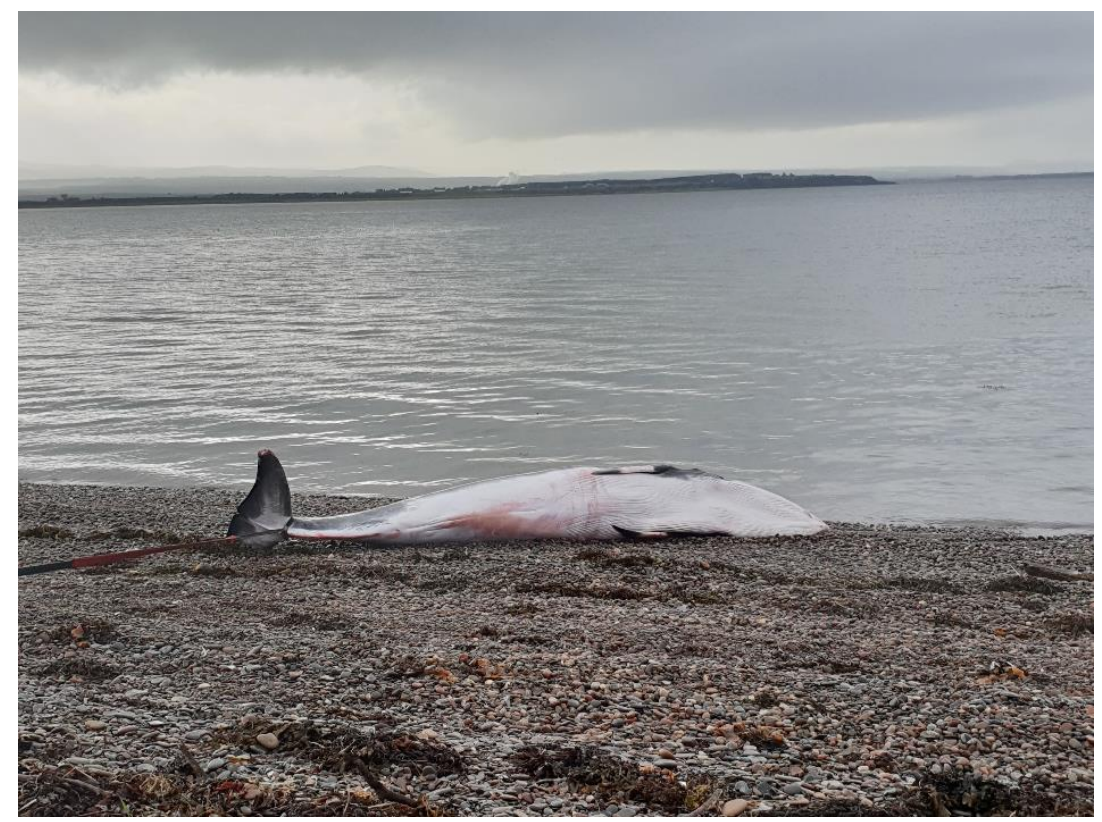

Figure 43: M586/18 minke whale (Balaenoptera acutorostrata) from Ardeseir, Highland.

\subsection{M644 /18- sperm whale (Physeter macrocephalus)}

This neonatal male Sperm whale was found on East Kilbride beach, South Uist under seaweed on the $27^{\text {th }}$ of October. Identification of the carcase was not possible until five days after it was found, however low temperatures and cover provided by the seaweed meant the carcase was still relatively well preserved. At $337 \mathrm{~cm}$ long, this individual was very close to but just under the birth length recorded for sperm whales, and the umbilicus was still present. The musculature was pale and the periphery of the bones was cartilaginous. There was significant 
haemorrhage around the skull and scapula's indicating the animal was alive at least at the start of the birth process. The visceral organs were generally congested and although interpretation may have been mildly hindered by autolysis, there was no evidence of gross pathology in any of the organs. There was no gross evidence of parasitism, the stomach was empty and there was a significant amount of meconium present in the intestines. Notably, the lungs were heavily congested and did not float, indicating that this animal had never taken a breath and most likely was either aborted, stillborn, or died during the birth process. Bacteriology produced a growth of Enterococcus faecalis from all sites. This organism may be a post mortem invader. Hopefully histopathology will shed more light on the significance of this isolate and assess any evidence of infection, which could have been a cause of the abortion. This was a neonatal calf, found in reasonable fresh condition, suggests its mum must have been close to the coast of the Western Isles. This is a highly unusual find given that female sperm whales usually remain and give birth in temperate and tropical waters mainly below $50^{\circ}$ latitude and there has only been one confirmed stranding of a female sperm whale on the British Isles in the entire 28 year running of the CSIP.

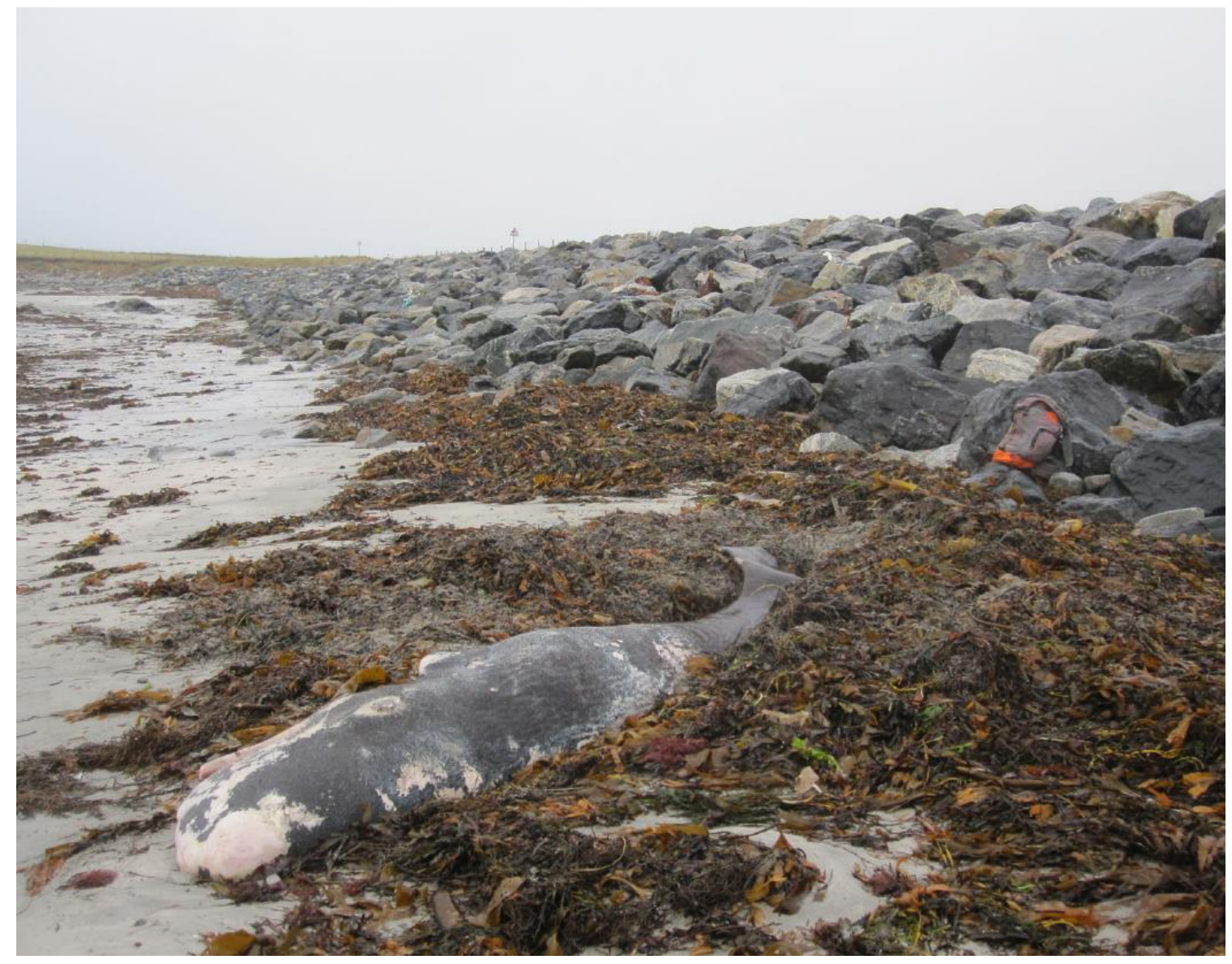

Figure 44: M447/17 neonate sperm whale (Physeter macrocephalus) East Killbride beach, South Uist.

\subsection{M773/18 - short-beaked common dolphin (Delphinus delphis)}

This juvenile male common dolphin was found dead stranded at Troon, South Ayrshire on the $5^{\text {th }}$ of December. It was in poor nutritional condition with poor blubber deposits and only moderate to poor back muscle mass. The was some evidence of recent feeding with some scant small otoliths present in the fundic stomach. The cardiac stomach had a $7 \mathrm{~cm}$ ulcer in the mucosa with a moderate to high Anasakis sp. burden. The lungs were symmetrical, hyper 
inflated and had a high burden of slender nematodes in the bronchi which completely occluded some of the smaller airways. I suspect these to be a Halocercus $s p$. The liver was showed some congestion. All other systems were unremarkable. Bacteriology produced Brucella ceti from nearly every organ cultured including the CSF possibly indicating a terminal sepsis. The isolation of this organism from the CSF raises the possibility of neurobrucellosis however; the lateral cerebral ventricles did not appear abnormally dilated nor was there an excessive amount of CSF. Histology is awaited to confirm the diagnosis. At present, this would appear to be a case of verminous pneumonia.

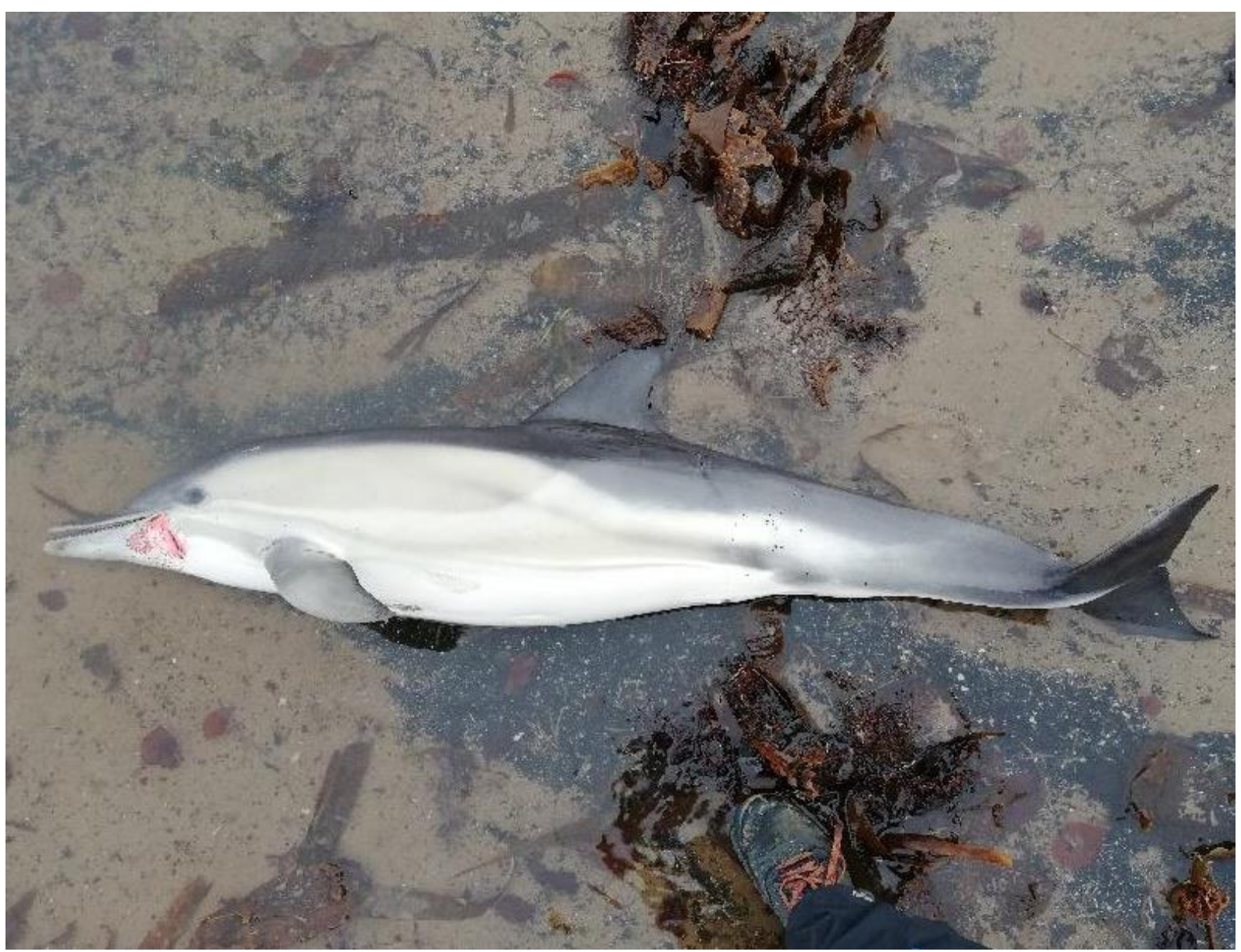

Figure 45: M773/18 short-beaked common dolphin (Delphinus delphis) Troon, South Ayrshire.

\subsection{M919/18 - Cuvier's beaked whale (Ziphius cavirostris)}

This aged male Cuvier's beaked whale was observed to live strand on Calgary beach on the $31 / 12 / 18$ and died soon after. There were multiple healed rake marks over the body and a goose barnacle attached to the left tooth but no indication of entanglement or trauma other than associated with the live stranding. The animal had not recently fed and appeared to have been ill for some time. There was indication of water aspiration, and the stomach was largely devoid of any contents, including mucus, suggestive of water ingestion and subsequent vomiting during live stranding. Of most note was a chronic verminous arteritis and multiorgan disseminated infection, including an active peritonitis. The arteritis is most likely due to infection with a Crassicauda sp. with pathogenesis proposed to involve a host response to 
larval migration from the intestine to the kidney through the mesenteric arteries, abdominal aorta, and renal arteries. This likely led to reduced vascular compliance, possibly chronic renal disease and predisposition to a disseminated multi organ disease from multiple septic foci. Bacteriology did not reveal any significant isolates.

Severe chronic arteritis in Cuvier's beaked whales is associated with renal parasitism Crassicauda spp. (Díaz et al 2016).

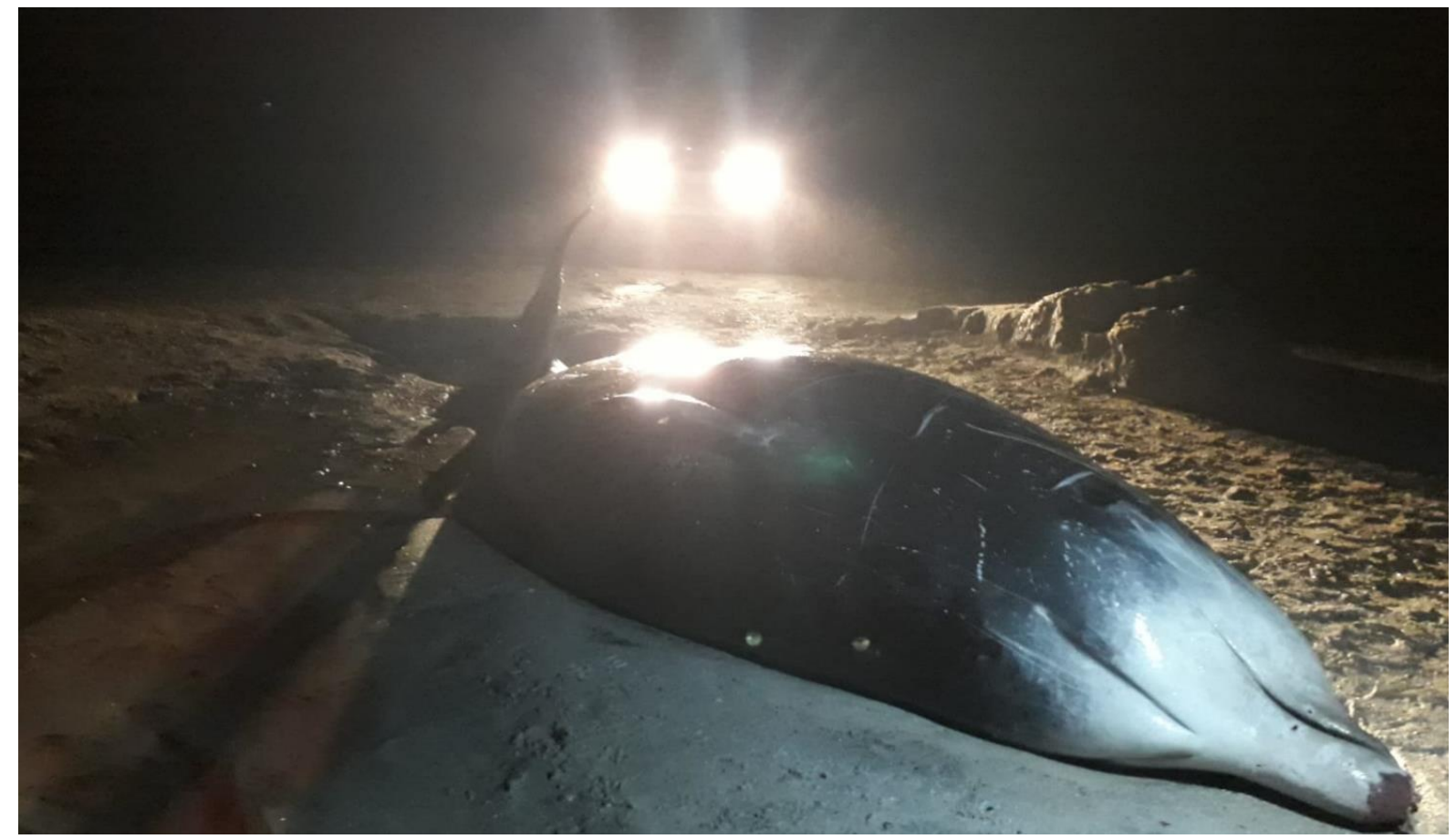

Figure 46: M919/18 Cuvier's beaked whale (Ziphius cavirostris) Calgary beach, Mull 


\section{Section 9: $\quad$ Spiral "corkscrew" trauma seal cases}

Sixty-seven seals were reported as having trauma consistent with spiral or corkscrew injuries. This is almost exactly the same number as 2017. These cases were reported from ten different regions. Most reports from Orkney with 23 followed by Highland and Fife both with 11 . There were also reports from other areas including Aberdeenshire (4), Argyll and Bute (7), East Lothian (4) North Ayrshire (2), and one each for Moray, Shetland and the Western Isles. The majority of these were grey seals (Halichoerus grypus) $(n=46 ; 70.7 \%)$. Harbour seals (Phoca vitulina) $(n=13 ; 18.4 \%)$ and those too decomposed or data deficient to be identified $(n=6$; $9.2 \%)$. Although it is considered highly plausible that a large majority of "spiral or corkscrew" cases are actually due to grey seal predation, research is still ongoing by SMRU in collaboration with SMASS.

Table 6 shows the details for all pinniped cases considered to be potential spiral trauma cases. The final two columns display an adjectival description of a) how likely it is that the case matches the archetypal spiral 'corkscrew' lesion and b) given the recent new evidence, how likely is it that the lesions could be due to grey seal predation. As in section 6 the following criteria were used

- Unlikely: Lesion pattern is inconsistent with cases of seal predation or other causes of death are more likely.

- Possible : Lesion pattern is consistent with cases of seal predation but other causes of death cannot be excluded

- Probable: Lesion pattern is consistent with cases of seal predation and significantly more likely than any other cause of death

- Definite: Cases observed to be victims of conspecific seal predation

Figure 44 below shows the spatial distribution of cases across Scotland.

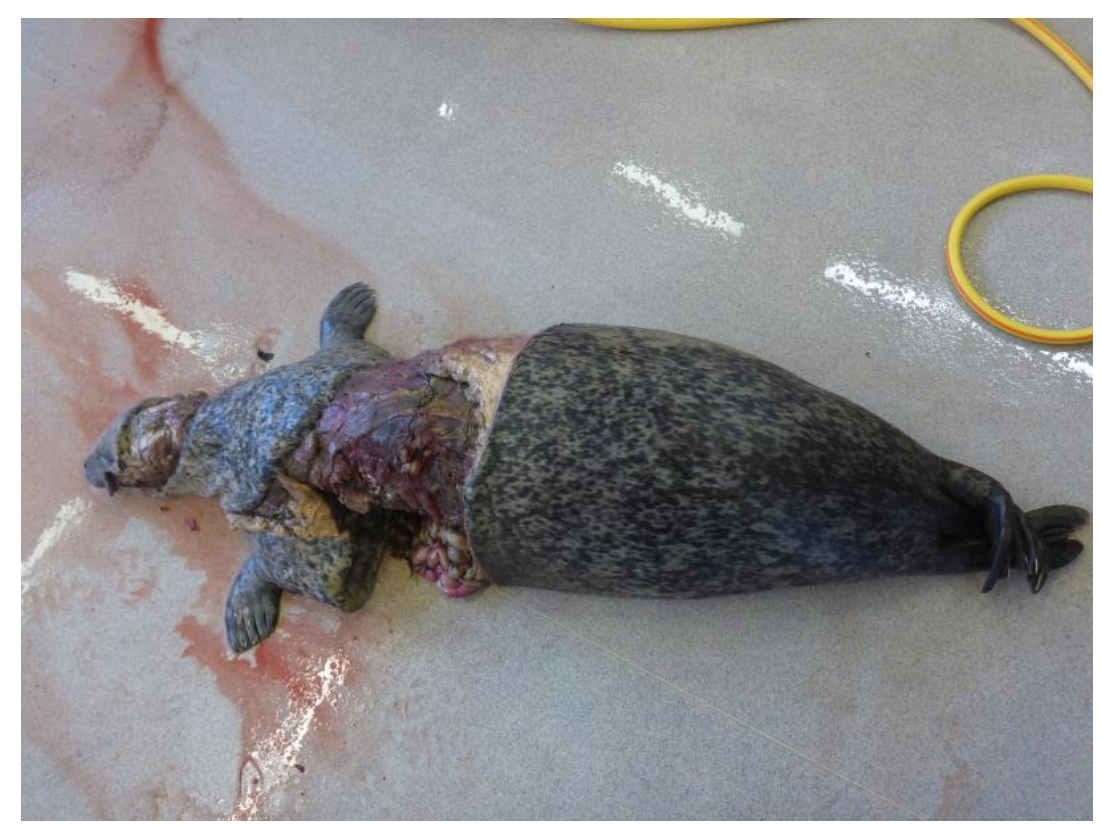

Figure 47: M324/18 harbour seal (Phoca vitulina) from Jemimaville, Highland showing typical corkscrew/spiral grey seal predation lesions 


\begin{tabular}{|c|c|c|c|c|c|c|c|}
\hline $\begin{array}{c}\text { SMASS } \\
\text { ID }\end{array}$ & Species & $\begin{array}{l}\text { Date } \\
\text { found }\end{array}$ & Region & Sex & $\begin{array}{l}\text { Age } \\
\text { Group }\end{array}$ & $\begin{array}{l}\text { Likelihood of } \\
\text { (grey) seal } \\
\text { predation }\end{array}$ & $\begin{array}{l}\text { Would } \\
\text { lesions fit } \\
\text { with the } \\
\text { archetypal } \\
\text { 'corkscrew' } \\
\text { pattern? }\end{array}$ \\
\hline $\mathrm{M} 18 / 18$ & Grey seal & $07 / 01 / 2018$ & Orkney & $U$ & Unknown & Possible & Unlikely \\
\hline M15/18 & Grey seal & $08 / 01 / 2018$ & East Lothian & $\mathrm{M}$ & Juvenile & Likely & Likely \\
\hline $\mathrm{M} 24 / 18$ & Grey seal & $10 / 01 / 2018$ & Aberdeenshire & $u$ & Juvenile & Likely & Likely \\
\hline M49/18 & Grey seal & $11 / 01 / 2018$ & Orkney & $u$ & Juvenile & Possible & Unlikely \\
\hline M52/18 & Seal (indeterminate species & $13 / 01 / 2018$ & Orkney & $U$ & Unknown & Unlikely & Unlikely \\
\hline M50/18 & Grey seal & $14 / 01 / 2018$ & Orkney & $U$ & Juvenile & no data & no data \\
\hline M48/18 & Grey seal & $17 / 01 / 2018$ & Orkney & $U$ & Unknown & Unlikely & Unlikely \\
\hline M51/18 & Grey seal & $17 / 01 / 2018$ & Fife & $U$ & Juvenile & Possible & Unlikely \\
\hline M56/18 & Grey seal & $17 / 01 / 2018$ & Highland & $U$ & Juvenile & Unlikely & Unlikely \\
\hline M58/18 & Grey seal & $18 / 01 / 2018$ & Fife & $\mathrm{F}$ & Juvenile & Possible & Possible \\
\hline $\mathrm{M} 61 / 18$ & Harbour Seal & $18 / 01 / 2018$ & Argyll and Bute & $U$ & Juvenile & Possible & Unlikely \\
\hline M62/18 & Seal (indeterminate species) & $21 / 01 / 2018$ & East Lothian & $U$ & Unknown & Possible & Unlikely \\
\hline $\mathrm{M} 63 / 18$ & Grey seal & $21 / 01 / 2018$ & East Lothian & U & Juvenile & Possible & Unlikely \\
\hline $\mathrm{M} 67 / 18$ & Grey seal & $26 / 01 / 2018$ & North Ayrshire & $u$ & Juvenile & Possible & Possible \\
\hline $\mathrm{M74} / 18$ & Seal (indeterminate species) & $27 / 01 / 2018$ & Orkney & $U$ & Unknown & no data & no data \\
\hline $\mathrm{M} 75 / 18$ & Seal (indeterminate species) & $27 / 01 / 2018$ & Orkney & $\mathrm{U}$ & Unknown & no data & no data \\
\hline M76/18 & Seal (indeterminate species) & $27 / 01 / 2018$ & Orkney & $\mathrm{U}$ & Juvenile & no data & no data \\
\hline M97/18 & Grey seal & $09 / 02 / 2018$ & Highland & $\mathrm{U}$ & Juvenile & Likely & Possible \\
\hline $\mathrm{M} 104 / 18$ & Grey seal & $17 / 02 / 2018$ & Aberdeenshire & $\mathrm{U}$ & Juvenile & Possible & Possible \\
\hline M139/18 & Harbour Seal & $25 / 02 / 2018$ & Highland & $\mathrm{U}$ & Juvenile & Possible & Unlikely \\
\hline M154/18 & Harbour Seal & $09 / 03 / 2018$ & Highland & $F$ & Juvenile & Possible & Likely \\
\hline M206/18 & Grey seal & $02 / 04 / 2018$ & Highland & U & Juvenile & Possible & Unlikely \\
\hline M236/18 & Grey seal & $15 / 04 / 2018$ & Aberdeenshire & $\mathrm{U}$ & Juvenile & Likely & Likely \\
\hline
\end{tabular}


Likelihood of

(grey) seal

predation lesions fit

with the

archetypal

'corkscrew'

pattern?

\begin{tabular}{|c|c|c|c|c|c|c|c|}
\hline M324/18 & Harbour Seal & $14 / 06 / 2018$ & Highland & $\mathrm{F}$ & Adult & Likely & Likely \\
\hline M331/18 & Seal (indeterminate species) & $14 / 06 / 2018$ & Highland & $U$ & Unknown & Possible & Likely \\
\hline M347/18 & Harbour Seal & $30 / 06 / 2018$ & Highland & $\mathrm{F}$ & Adult & Probable & Possible \\
\hline M352/18 & Grey seal & $01 / 07 / 2018$ & Fife & $\mathrm{U}$ & Juvenile & Unlikely & Unlikely \\
\hline M358/18 & Harbour Seal & 03/07/2018 & Argyll and Bute & $U$ & Unknown & Possible & Possible \\
\hline M341/18 & Grey seal & $02 / 07 / 2018$ & Moray & $\mathrm{F}$ & Adult & Probable & Unlikely \\
\hline M381/18 & Harbour Seal & $17 / 07 / 2018$ & Argyll and Bute & $\mathrm{U}$ & Juvenile & Possible & Possible \\
\hline M411/18 & Harbour Seal & $31 / 07 / 2018$ & Fife & $\mathrm{U}$ & Juvenile & Probable & Unlikely \\
\hline M420/18 & Grey seal & 08/08/2018 & Fife & $\mathrm{U}$ & Juvenile & Probable & Probable \\
\hline M434/18 & Harbour Seal & $13 / 08 / 2018$ & Argyll and Bute & $\mathrm{U}$ & Juvenile & Possible & Unlikely \\
\hline M450/18 & Harbour Seal & $16 / 08 / 2018$ & North Ayrshire & $U$ & Juvenile & Likely & Likely \\
\hline M460/18 & Harbour Seal & $18 / 08 / 2018$ & Argyll and Bute & $\mathrm{U}$ & Juvenile & Possible & Unlikely \\
\hline M474/18 & Harbour Seal & $18 / 08 / 2018$ & Argyll and Bute & $U$ & Unknown & Possible & Unlikely \\
\hline M639/18 & Grey seal & $16 / 10 / 2018$ & Orkney & $U$ & Juvenile & Likely & Likely \\
\hline M641/18 & Grey seal & $17 / 10 / 2018$ & Orkney & $U$ & Juvenile & Likely & Likely \\
\hline M669/18 & Grey seal & $01 / 11 / 2018$ & Aberdeenshire & $U$ & Unknown & Possible & Possible \\
\hline M671/18 & Grey seal & $01 / 11 / 2018$ & Highland & $U$ & Pup & Likely & Likely \\
\hline M684/18 & Harbour Seal & $05 / 11 / 2018$ & Fife & $U$ & Adult & Possible & Possible \\
\hline M700/18 & Grey seal & $15 / 11 / 2018$ & Western Isles & $U$ & Unknown & Possible & Possible \\
\hline M705/18 & Grey seal & $18 / 11 / 2018$ & Orkney & $\mathrm{U}$ & Pup & Possible & Possible \\
\hline M749/18 & Grey seal & $28 / 11 / 2018$ & East Lothian & $\mathrm{U}$ & Pup & Possible & Possible \\
\hline M772/18 & Grey seal & $04 / 12 / 2018$ & Orkney & $\mathrm{U}$ & Juvenile & Probable & Likely \\
\hline M784/18 & Grey seal & $09 / 12 / 2018$ & Argyll and Bute & U & Juvenile & Probable & Probable \\
\hline M788/18 & Grey seal & $01 / 12 / 2018$ & Orkney & $U$ & Unknown & Possible & Possible \\
\hline M791/18 & Grey seal & $01 / 12 / 2018$ & Orkney & $U$ & Unknown & Probable & Probable \\
\hline M793/18 & Grey seal & $01 / 12 / 2018$ & Orkney & $U$ & Pup & Possible & Possible \\
\hline
\end{tabular}


SMASS

ID

Species

Date

found

Region

Sex

Age

Group

Likelihood of

(grey) seal

predation

lesions fit

with the

archetypal

'corkscrew'

pattern?

\begin{tabular}{|l|l|l|l|l|l|c|c|}
\hline M799/18 & Grey seal & $10 / 12 / 2018$ & Orkney & U & Unknown & Possible & Possible \\
\hline M802/18 & Grey seal & $11 / 12 / 2018$ & Shetland & U & Juvenile & Likely & Probable \\
\hline M809/18 & Grey seal & $16 / 12 / 2018$ & Fife & U & Juvenile & Likely & Probable \\
\hline M813/18 & Grey seal & $16 / 12 / 2018$ & Fife & U & Pup & Possible & Possible \\
\hline M817/18 & Grey seal & $15 / 12 / 2018$ & Fife & F & Juvenile & Likely & Possible \\
\hline M818/18 & Grey seal & $15 / 12 / 2018$ & Fife & M & Juvenile & Probable & Probable \\
\hline M819/18 & Grey seal & $16 / 12 / 2018$ & Orkney & $\mathrm{U}$ & Juvenile & Probable & Likely \\
\hline M827/18 & Grey seal & $17 / 12 / 2018$ & Highland & U & Juvenile & Probable & Probable \\
\hline M839/18 & Grey seal & $18 / 12 / 2018$ & Highland & U & Juvenile & Possible & Possible \\
\hline M866/18 & Grey seal & $14 / 12 / 2018$ & Orkney & $\mathrm{U}$ & Juvenile & Possible & Possible \\
\hline M869/18 & Grey seal & $14 / 12 / 2018$ & Orkney & $\mathrm{U}$ & Juvenile & Possible & Possible \\
\hline M879/18 & Grey seal & $20 / 12 / 2018$ & Orkney & $\mathrm{U}$ & Juvenile & Possible & Possible \\
\hline M880/18 & Grey seal & $20 / 12 / 2018$ & Orkney & $\mathrm{U}$ & Juvenile & Possible & Possible \\
\hline M895/18 & Grey seal & $23 / 12 / 2018$ & Fife & $\mathrm{U}$ & Juvenile & Probable & Possible \\
\hline M906/18 & Grey seal & $26 / 12 / 2018$ & Orkney & $\mathrm{U}$ & Juvenile & Likely & Likely \\
\hline M907/18 & Grey seal & $26 / 12 / 2018$ & Orkney & $\mathrm{U}$ & Juvenile & Possible & Possible \\
\hline M908/18 & Grey seal & $26 / 12 / 2018$ & Orkney & $\mathrm{U}$ & Juvenile & Possible & Possible \\
\hline M917/18 & Grey seal & $30 / 12 / 2018$ & Orkney & $\mathrm{U}$ & Unknown & Possible & Possible \\
\hline
\end{tabular}




\title{
Section 10: Other single pinniped strandings
}

\author{
10.1 M6/18- Harbour seal (Phoca vitulina)
}

This adult male harbour seal was found dead stranded. It was in good body condition but reasonably autolysed at necropsy, it was also subjected to sub-zero temperatures potentially confounding gross examination. The animal had recently fed, with a large amount of, assumed, fish ingesta in the stomach. Some of this material had refluxed into the proximal trachea and sinuses and the lungs were bilaterally congested and exhibited stable foam. There are two possible causes for this- overeating and subsequent regurgitation of thick mucoid ingesta causing respiratory obstruction and suffocation, or bycatch, with anoxic drowning and subsequent agonal or peri-mortem reflux of stomach contents by physical pressure from the net. There is no other evidence for bycatch, such as bruising or claw loss. Bacteriology did not reveal any significant isolates. There is no apparent underlying condition for the gastric reflux. Screening for algal toxin would also be advised in this case. Histology did not reveal any significant lesions. We were unable to determine the cause of death of this animal. There were no typical lesions suggestive of parasitism or infection. Interpretation was however severely hampered by autolysis and freeze/thaw damage.

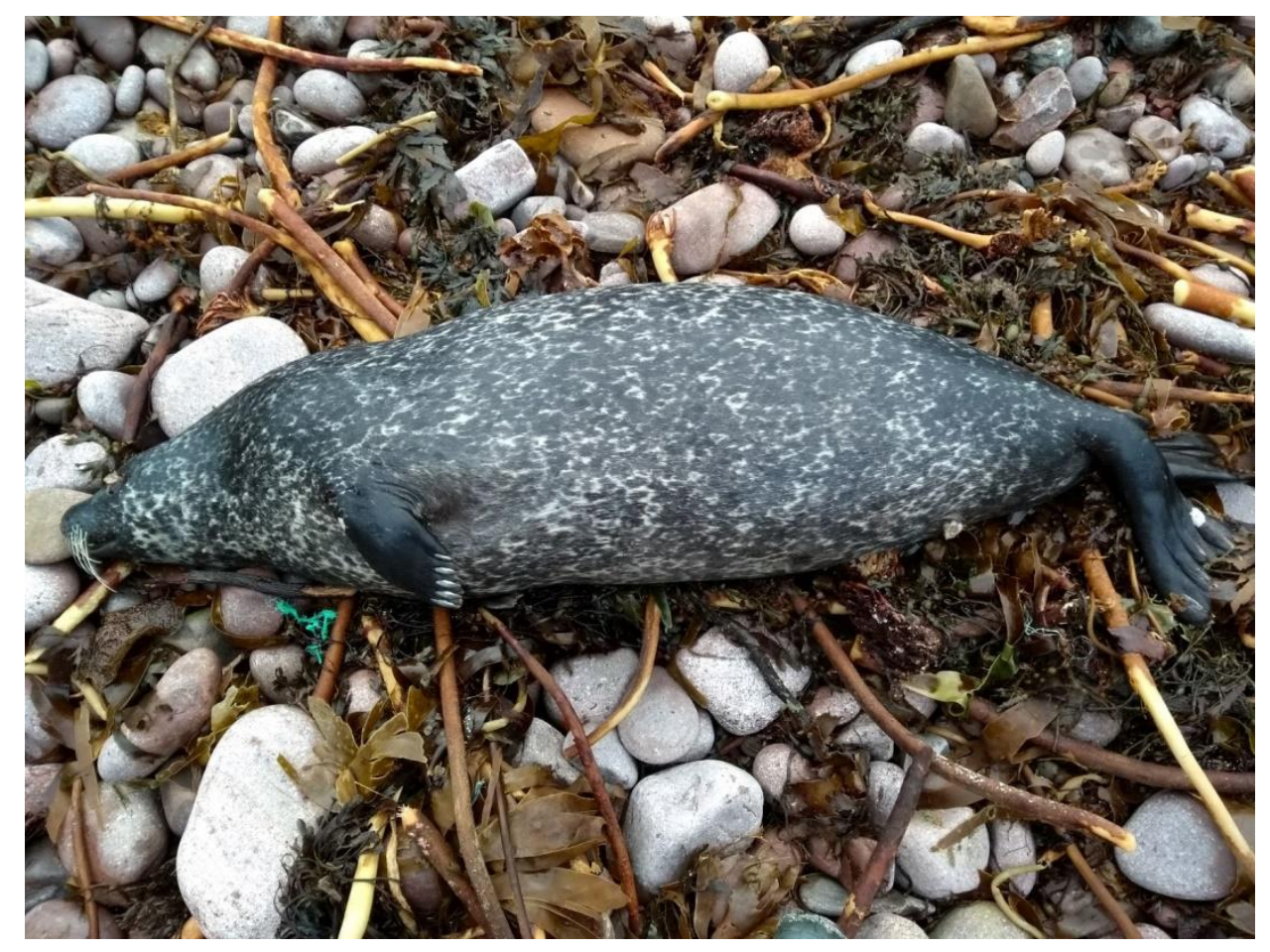

Figure 48: M6/18 harbour seal (Phoca vitulina) from Reiff near Achiltibuie, Highland.

\subsection{M27/18- Harbour seal (Phoca vitulina)}

This juvenile female harbour seal was found dead stranded at Portree, Skye on the $16^{\text {th }}$ of January. It was in thin condition with very poor blubber- and muscle reserves, and had a 
severe verminous pneumonia; of a likely Otostrongylus species. In addition, there was antemortem cranial haemorrhage from unilateral puncture through the skull, but not into the brain, most likely a bird peck. No shot fragments were detected. Of note, was a mature nematode in the pleural cavity, assumed migrated from the bronchial tree? Histology showed a severe, sub-acute to chronic, multifocal, verminous pneumonia. Moderate, sub-acute to chronic, multifocal, mixed cell hepatitis. Severe, sub-acute to chronic, generalised lymphadenopathy. Bacteriology produced Brucella pinnipedialis either in pure or mixed culture from all sites cultured including brain. This is not thought to be significant however. Cause of death is verminous pneumonia.

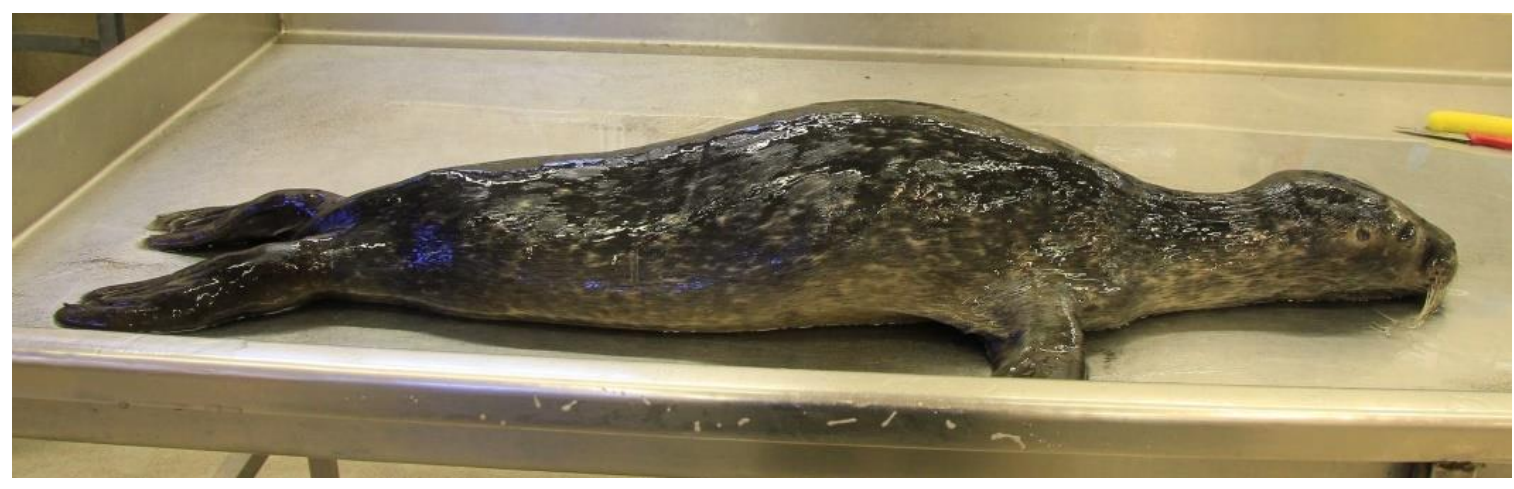

Figure 49: M27/18 harbour seal seal (Phoca vitulina) from Portree, Skye.

\subsection{M263/18- Harbour seal (Phoca vitulina)}

This juvenile female harbour seal was found dead at Fairlie, North Ayrshire on the 25th of April. The animal was in poor body condition with very low blubber reserves and starvation/hypothermia is a likely proximal cause of death. The gross parasite burden was low, but the lungs appeared slightly emphysematous and friable, possibly indicating a verminous pneumonia severe enough to cause haemorrhage. Streptococcus phocae was also isolated from the lung possibly indicating a secondary bacterial pneumonia. This may explain the digested blood in the gastro-intestinal tract, with blood coughed up from the lungs and swallowed. Other organs were grossly unremarkable, and the animal had not successfully fed recently. The isolation of Brucella pinnipedialis from several organs is thought to be incidental. Histology showed a very severe, sub-acute, generalised, verminous, granulocytic, pneumonia with haemorrhage. Severe, sub-acute, generalised, lympho-stimulation. Moderate, subacute, multifocal, verminous hepatic necrosis. This is the most severe case, in terms of number of nematodes per unit area, of verminous pneumonia the histopathologist has seen. Cause of death is verminous pneumonia. 


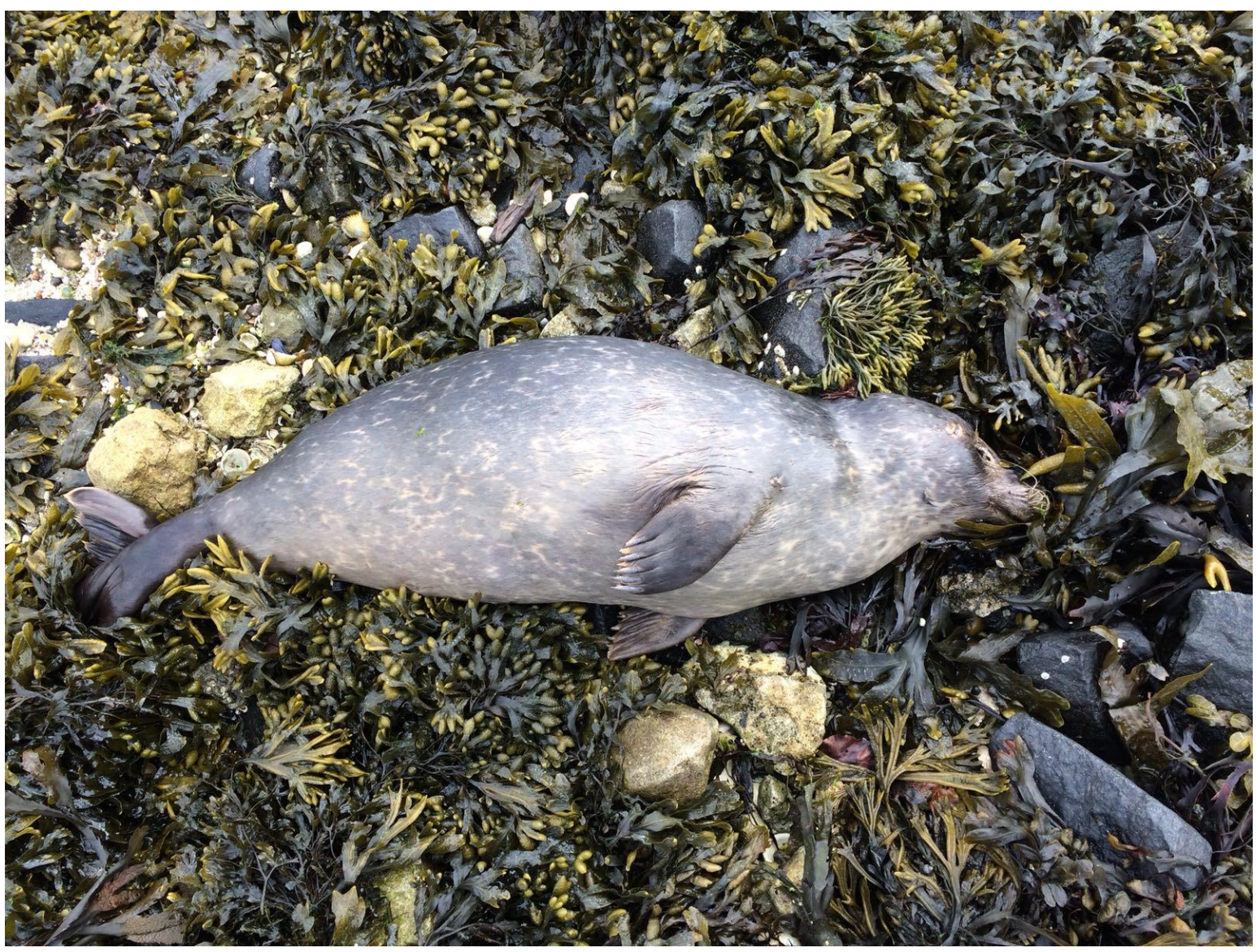

Figure 50: M263/18 harbour seal (Phoca vitulina) from Fairlie, North Ayrshire.

\subsection{M296/18- harp seal (Pagophilus groenlandicus)}

This juvenile female harp seal pup was found dead stranded on Skye on the $28^{\text {th }}$ of May. Scotland is outside the normal range for this ice-associated species, although vagrant animals such as this have been recorded in the UK and even further south in Europe in the past. From the pelage pattern this animal was likely under a year old. The carcase was moderately autolysed, dehydrated and in emaciated condition, although the original cause for the poor condition and failure to thrive was not obvious from gross necropsy. There was no gross indication of trauma or infectious process and the parasite burden was low, so insufficient feeding is likely to have played a role. The stomach was empty of ingesta although of potential significance was a small fragment of compacted plastic, roughly $6 \mathrm{~cm}$ square, occluding the pyloric sphincter. There was mild ulceration around the impaction site, indicating the fragment had been in place for some time and could have potentially compromised gastric emptying. Decomposition hampered detailed assessment of the intestines but the friable, haemorrhagic appearance of the proximal duodenum indicates a degree of enteritis. This could be linked to the foreign body. No other foreign bodies were noted in the GIT. The liver was pale and appeared fatty, indicative of recent blubber catabolism. The brain showed a generalised congestion, indicative of generalised sepsis. Bacteriology recovered possible E.coli from all sites cultured possibly post mortem invaders. Histopathology did not reveal any significant lesions. The granules present in the hepatocytes were haemosiderin, along with severe general depletion of the spleen, then this animal may have had a chronic haemorrhagic 
condition. We will request some special stains to further investigate the tissues but a definitive diagnosis is unlikely to be forthcoming due to the poor state of tissue preservation. This is a likely starvation case.

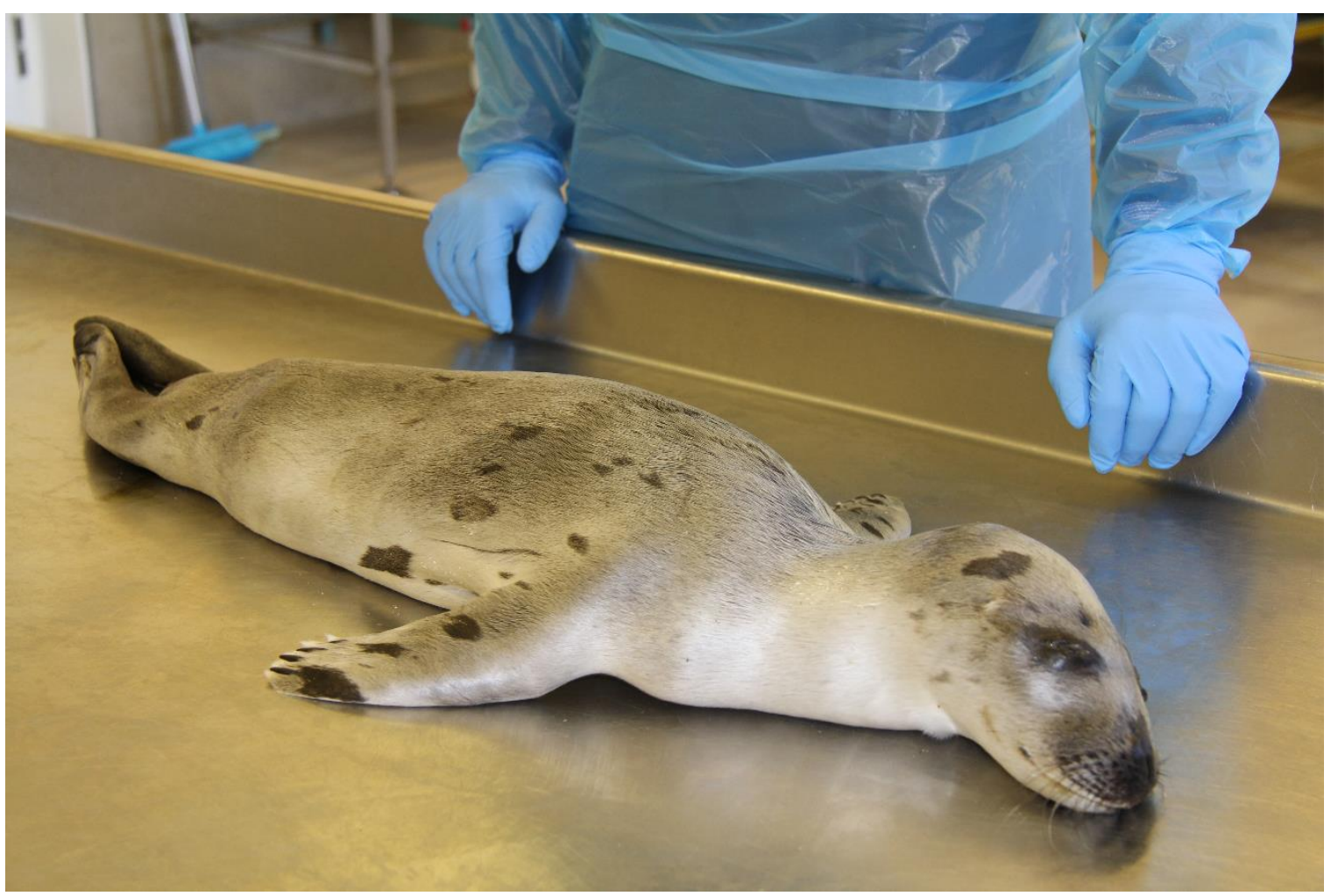

Figure 51: M296/18 harp seal (Pagophilus groenlandicus) from near Halistra, Skye.

10.5 M343/18- grey seal (Halichoerus grypus)

This aged adult male grey seal was observed to be in respiratory distress and die on a beach out of water in Melby, Shetland on the $26^{\text {th }}$ of June. It was immediately recovered for transport to Inverness. However this took four days inn hot weather and consequently the animal was in in condition 3 at examination. The animal was in poor nutritional condition with a mid-sternal blubber thickness of just $12 \mathrm{~mm}$. There was no evidence of recent feeding with the stomach empty apart from a heavy nematode burden. The lungs were very congested with stable foam and fluid in the airways. There was pulmonary interstitial emphysema over the caudal aspects of the lung. The pulmonary lymph nodes were enlarged and the right ventricle of the heart very dilated suggesting some degree of dilated cardiomyopathy. The brain showed some dilated cerebral vasculature with some neovascularisation over cortex and turbid CSF. This was an aged animal and congestive heart failure is a plausible cause of death in this case, however the role of neuropathology is also a possibility. Bacteriology on the brain revealed a mixed culture including Streptococcus equi ssp. zooepidemicus. Histology showed a severe, acute, generalised, mixed inflammatory cell but primarily suppurative, meningitis/ ventriculitis with extension into the adjacent brain tissue. Despite the advanced autolysis of many of the tissues, it is clear that this animal had a severe infectious disease, probably bacterial, and centred on the meninges/brain which would have been highly clinically significant. 


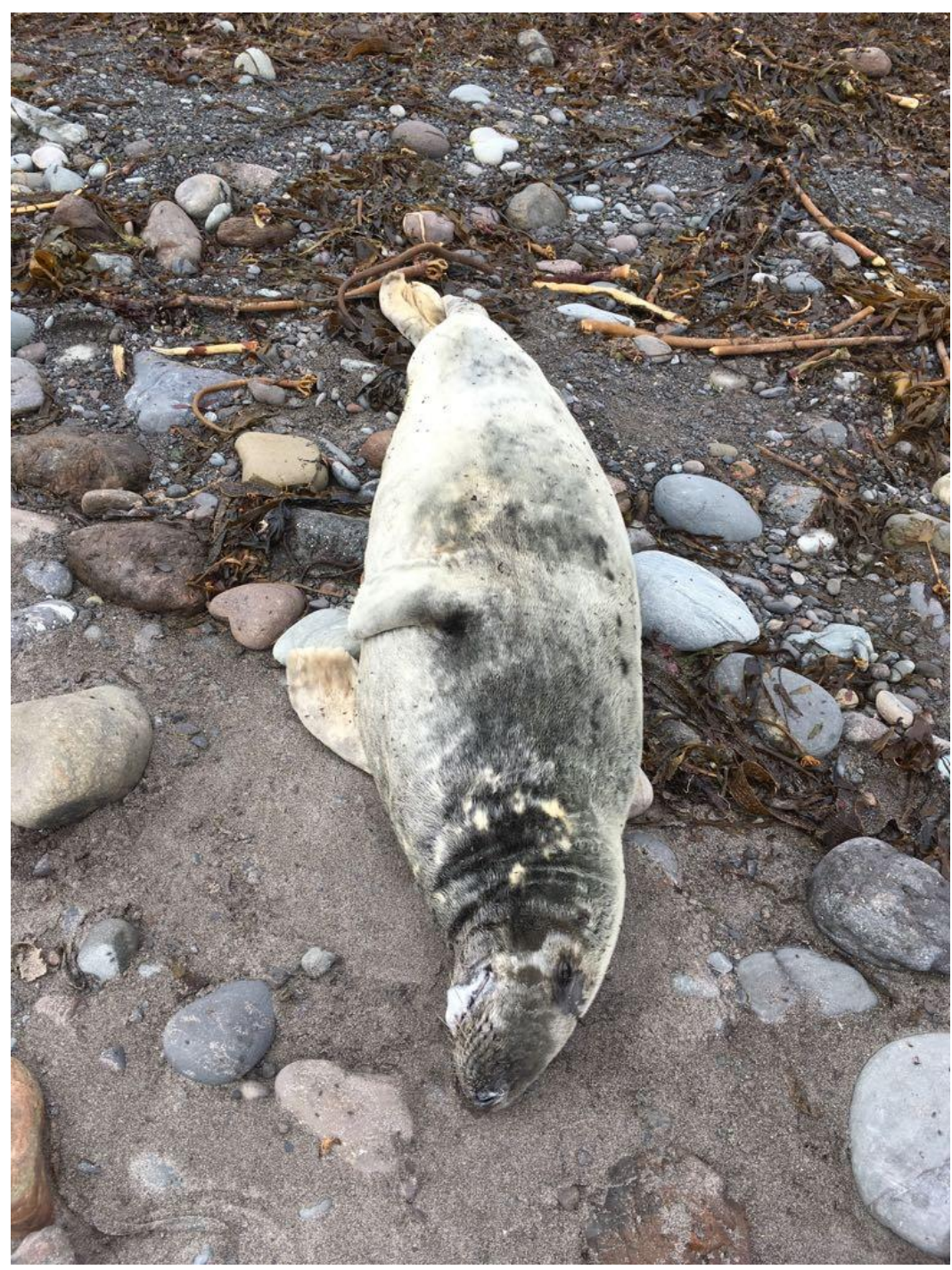

Figure 52: M343/18 grey seal (Halichoerus grypus) from near Melby, Shetland.

\subsection{M429/18- Harbour seal (Phoca vitulina)}

This adult harbour seal was found floating dead in Kylesku narrows, Highland on the $12^{\text {th }}$ of August. The skull was obliterated, with average bone fragment under $3 \mathrm{~cm}^{2}$. Radiographs showed radiodense fragments thoughout, indicating metal fragments and that the animal had been shot. It was not clear if this was under license and the case was reported to police Scotland as a wildlife crime. Otherwise the animal was in moderate body condition and had not recently fed, however the large intestine and colon contained large amounts of normal faecal material. The lungs did not show a significant verminous pneumonia and the airways contained large blood clots, again indicative of acute cranial ballistic trauma. 


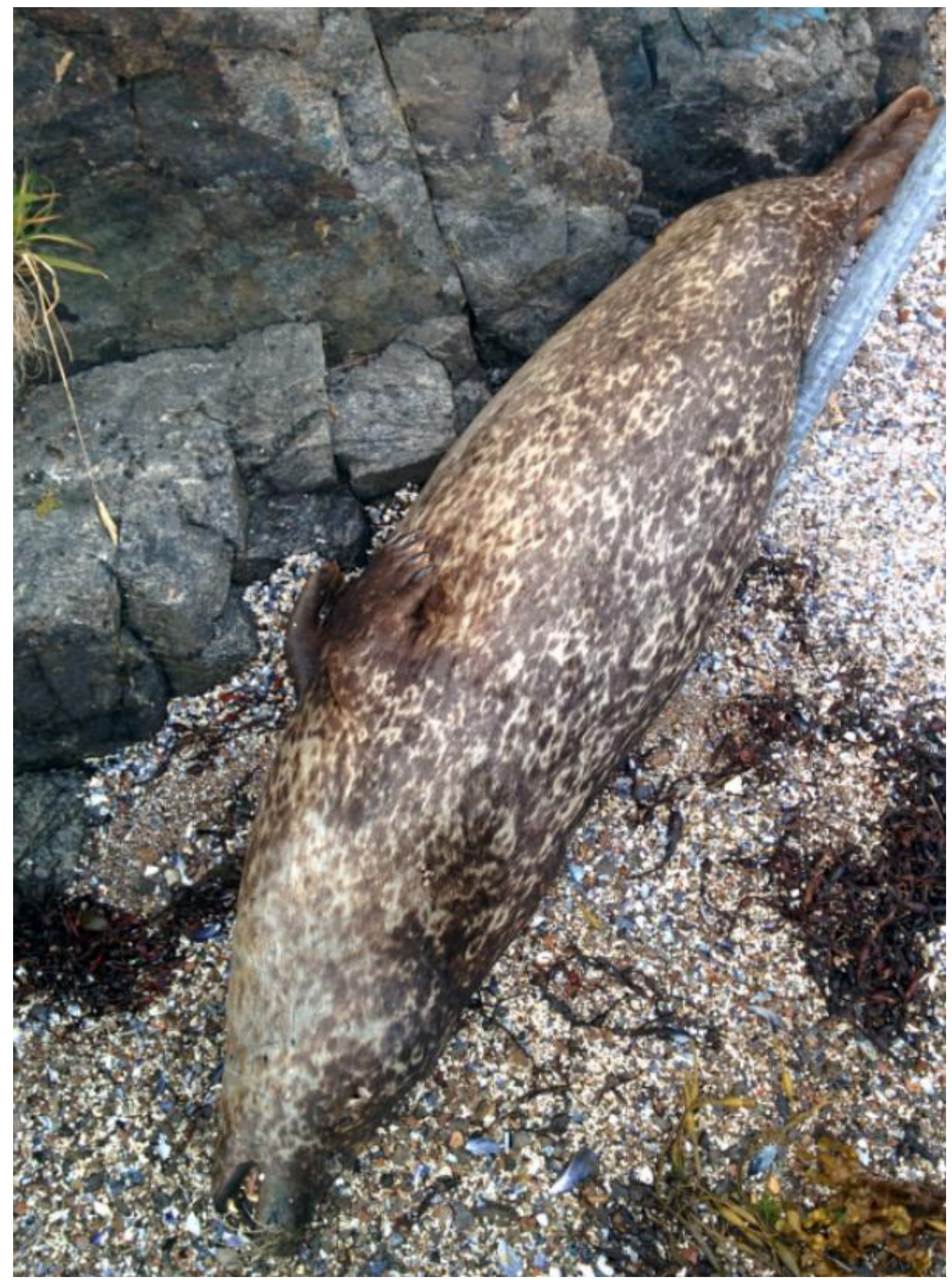

Figure 53: M263/18 harbour seal (Phoca vitulina) from Kylesku, Highland. 
This aged adult male harbour seal was found dead stranded at St. Ninians Isle, Shetland on the $2^{\text {nd }}$ of September. It exhibited severe chronic lung pathology characterised by bilateral emphysema, inflammation of serosal lining to trachea and major airways and hypertrophy of thoracic intercostal muscles, suggesting a chronic respiratory compromise. PDV (chronic) and verminous pneumonia are possible differentials. The brain was very congested, possibly agonal but generalised sepsis needs to be ruled out. Bacteriology produced a mixed growth of Arcanobacterium phocae, Streptococcus phocae, and Hafnia alvei from all sites, the significance of these isolates is uncertain but arte not currently considered to be primary pathogens. Histology showed a severe, acute, generalised, pulmonary congestion and alveolar oedema. Viral screening is underway for this case

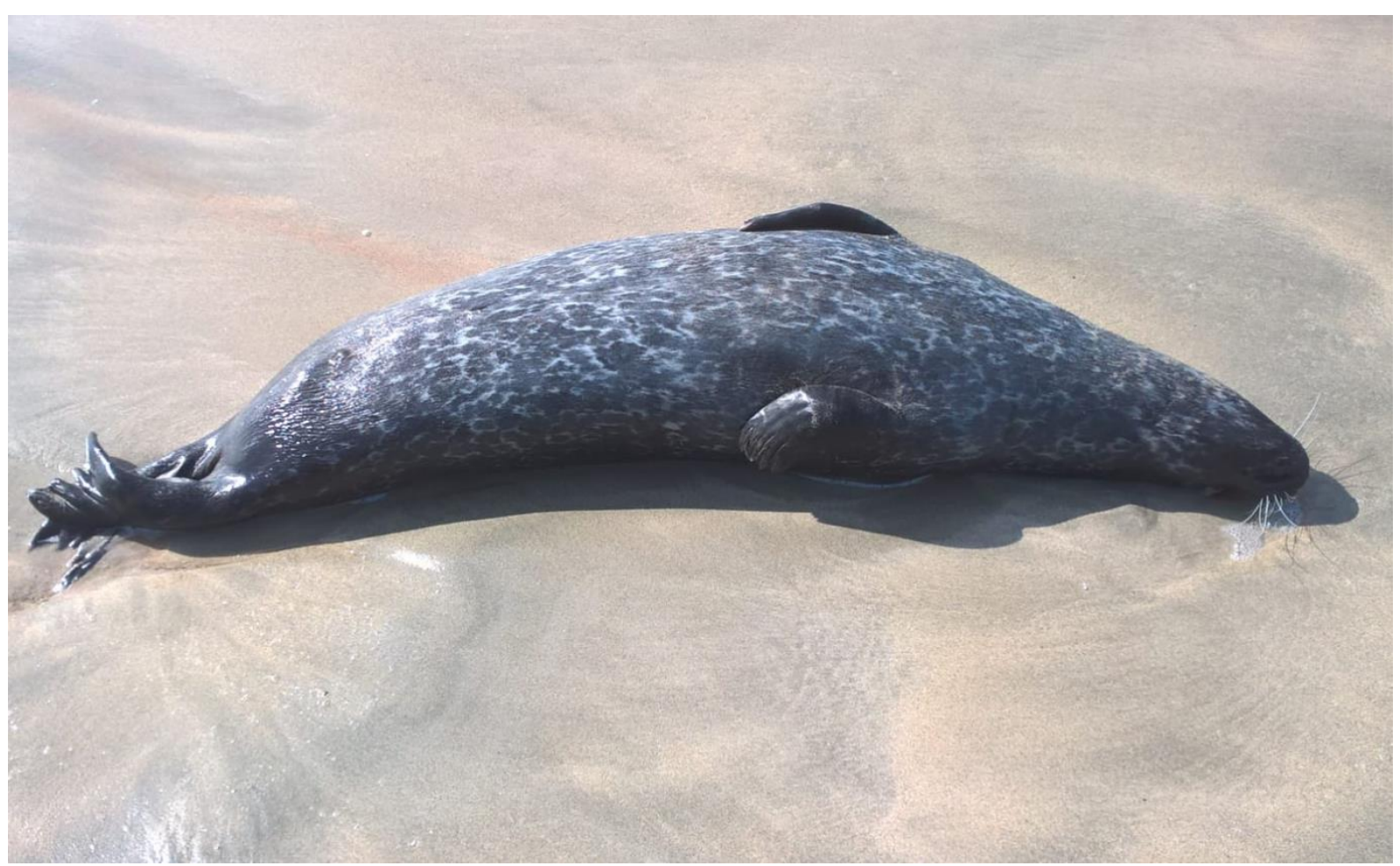

Figure 54: M523/18 harbour seal (Phoca vitulina) from St. Ninians Isle, Shetland. 


\section{Section 11: $\quad$ Basking sharks and marine turtles}

\subsection{Basking sharks (Cetorhinus maximus)}

There were two reports of a basking sharks in 2018, one much decomposed animal at Doonfoot near Ayr on the $29^{\text {th }}$ of July, which was identified from the vertebrae. The second animal was found near Wormhills Elliot beach, Angus on the $22^{\text {nd }}$ of November. This animal vanished after initial reports and was reported again several days later. Although the animal was not recovered for necropsy, samples were taken.

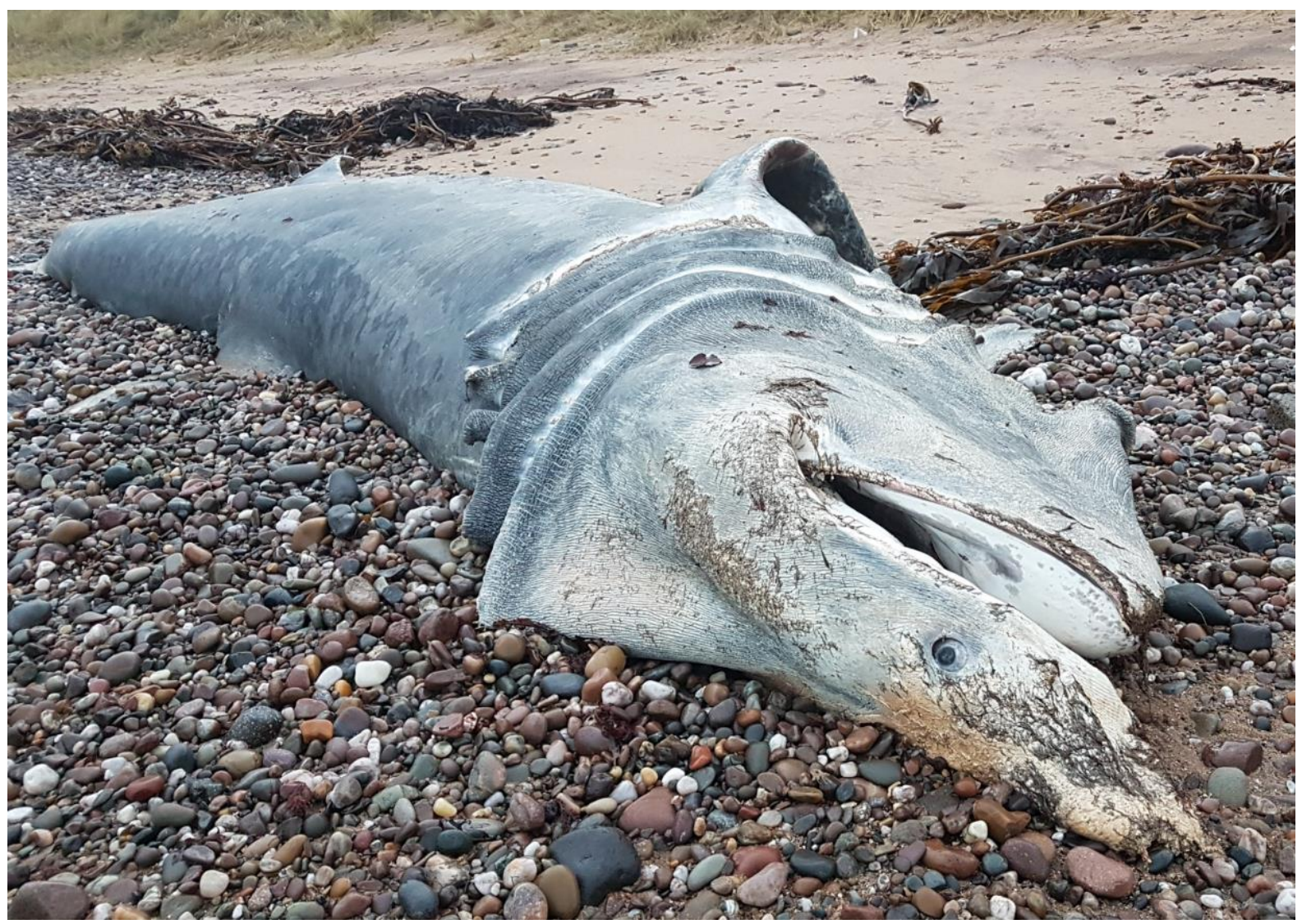

Figure 55: M728/18 Basking shark (Cetorhinus maximus) from Elliot beach, Angus. 
There was a single report of a marine turtle during in 2018. A single leatherback turtle (Dermochelys coriacea), was reported as entangled in creel lines north northeast of Muldoanich near Barra, Western Isles on the $13^{\text {th }}$ of August. It was released alive.

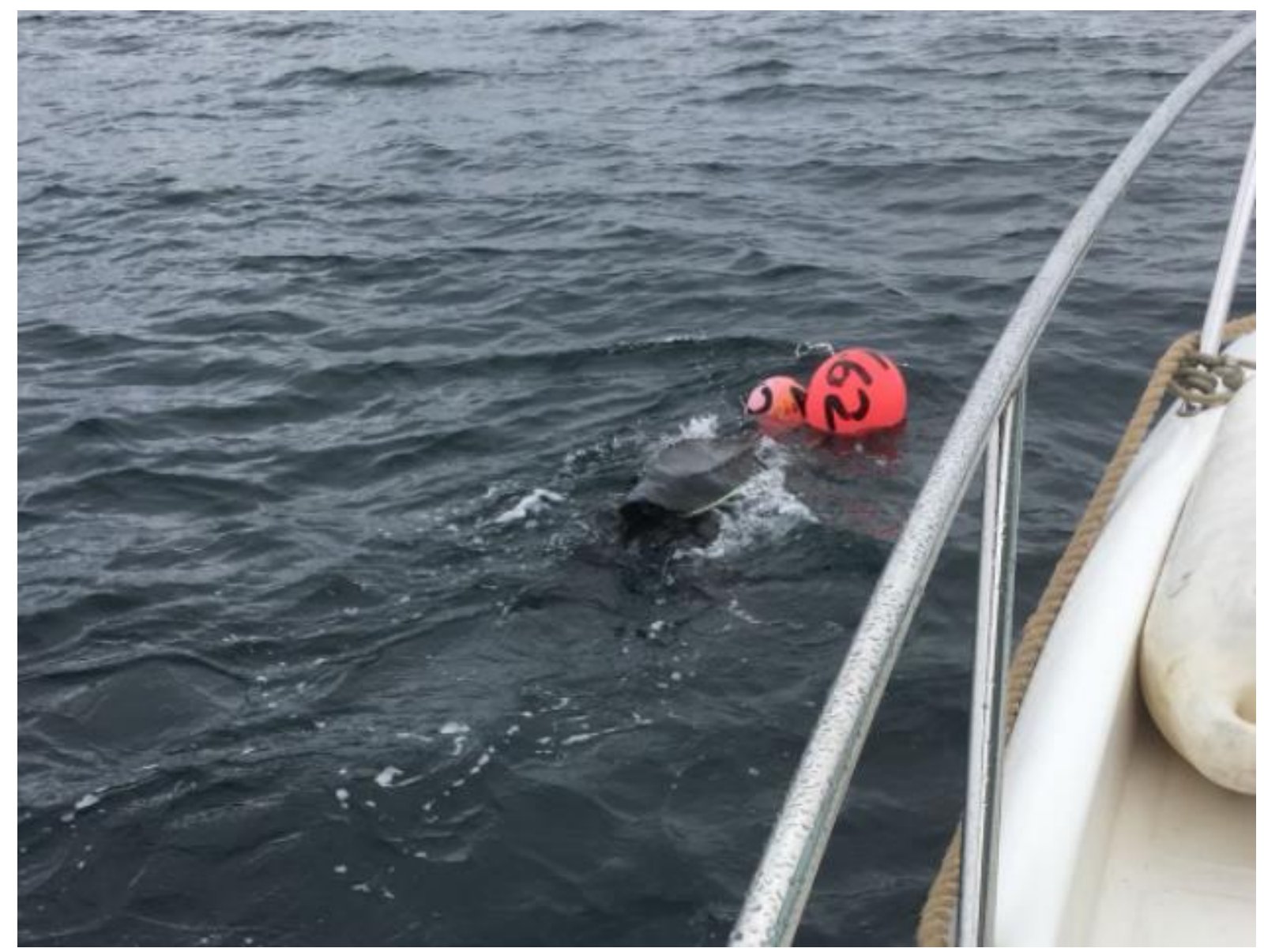

Figure 56: M445/18 leatherback turtle (Dermochelys coriacea), disentangled by fishermen and released alive from creel lines near Barra, Western Isles.

\section{Section 12: Bacteriology}

12.1 Brucella sp.

Brucella ceti was isolated from six cetaceans of five different species during 2018. This is the same number of isolation as the previous year. This includes the second ever case of neurobrucellosis in a beaked whale.

B. ceti was from the cerebrospinal fluid (CSF) of an Atlantic white-sided dolphin diagnosed with neurobrucellosis (see section 7).

B. ceti was isolated from the brain, lung, placenta and bite wounds of a harbour porpoise that died due to a Neisseria anamaloris sepsis (see section 6), the B.ceti isolate was thought incidental in this case. 
B.ceti was isolated from the spleen of a harbour porpoise it was not thought a significant finding in this animal which was a starvation case.

B. ceti was from the cerebrospinal fluid (CSF) of a Sowerby's beaked whale diagnosed with neurobrucellosis (see section 7).

B. ceti was from the cerebrospinal fluid (CSF) and brain of a striped dolphin diagnosed with neurobrucellosis (see section 7).

B.ceti was isolated from the cerebrospinal fluid (CSF), lung, liver, spleen and kidney of a shortbeaked dolphin, suggesting a sepsis, histology is pending.

Brucella pinnipedialis was isolated from six seals in 2018. They were all harbour seals.

B. pinnipedialis was isolated from the brain, lung, liver spleen and kidney of one seal that was diagnosed with verminous pneumonia, the Brucella isolate was thought incidental

B. pinnipedialis was isolated from the brain, lung, liver and spleen of another seal with verminous pneumonia, the Brucella isolate was again thought incidental.

B. pinnipedialis was isolated from the lung of another seal, which was diagnosed as dying from starvation, the Brucella isolate was again thought incidental.

\subsection{Streptococcus sp.}

Streptococcus phocae was isolated from lung of one harbour seal and the brain of another both were thought to be incidental findings. This same organism was isolated in mixed culture from an adult grey seal with pneumonia. It was also isolated from the pulmonary associated lymph of another grey seal with verminous pneumonia. S. phocae was also isolated from the lung and liver of a harbour porpoise diagnosed with verminous pneumonia.

A $\alpha$ Haemolytic Streptococcus sp. with a profile that matches an isolate from the liver of a fin whale from Devon was isolated from the brain and CSF of a sperm whale. The significance of this isolate is at present uncertain.

Streptococcus phocae was isolated from suspected bites wounds on a harbour porpoise suggesting an infected seal bite (see section 6).

Streptococcus equi ssp. zooepidemicus was isolated in mixed culture from the brain of an adult male grey seal that was observed to die on a beach. This animal had a severe, acute, generalised, mixed inflammatory cell but primarily suppurative, meningitis and ventriculitis possibly due to this organism.

A Streptococcus sp. with a profile not seen before was isolated from the lung and kidney of a Sowerby's beaked whale. This also was not thought significant.

Streptococcus sp., possibly S. infantius, ssp. coli, was isolated from the liver, kidney and brain of a long-finned pilot whale that live stranded as part of a MSE (Section 4). Its significance is uncertain.

An Enterococcus $s p$. was isolated from all sites cultured of a neonate male sperm whale. 
Actinobacillus delphinicola was isolated from the brain of a harbour porpoise and the spleen a Sowerby's beaked whale neither isolate is significant.

A Pasteurella sp. with a profile not seen before was isolated from the lung and liver of a grey seal this is thought to be an incidental finding.

Another Pasteurella sp. with a profile not seen before was isolated from the lung of a harp seal pup this is thought to be an incidental finding.

\subsection{Vibrio sp.}

Vibrio alginolyticus was isolated in mixed culture from the CSF of a live stranded long-finned pilot whale; it is not thought to be significant. It was also isolated in mixed culture from the brain of two Sowerby's beaked whales and the kidney of a white beaked dolphin.

Vibrio anguillarum was isolated from the lung of an Atlantic white-sided dolphin, this is an incidental finding.

Photobacterium damselae was isolated in mixed culture from the lung of a neonate male sperm whale. The same organism was isolated from the lung and kidney of one Sowerby's beaked whale and the brain of another, and the lung of a neonate Risso's dolphin. It was not thought significant in any of these cases. P. damselae was also isolated from all sites cultured in a white beaked dolphin with a severe broncho-pneumonia. $P$. damselae was also isolated from two of the long-finned pilot whales involved in the MSE (Section 4); from the brain and kidney of one and lung, liver, brain and CSF of another. It was also cultured from the brain a much decomposed Cuvier's beaked whale and the lung of a harbour seal. The significance of these isolates is uncertain.

\subsection{Yersinia sp.}

Yersinia kristensenii was isolated from brain, CSF and skin lesions of a harbour porpoise. The significance of this isolate is uncertain.

\subsection{Bordetella bronchiseptica}

Bordetella bronchiseptica was isolated from lung and liver of a grey seal possibly suggesting pneumonia and sepsis.

\subsection{Mycoplasma sp.}

Mycoplasma phocicerebrale was isolated in mixed culture from the brain of a grey seal, the significance of this isolate is at present uncertain.

A Mycoplasma sp. was isolated from a testicle lesion of a harbour porpoise. Results of $16 \mathrm{~s}$ sequencing on the Mycoplasma sp. would indicate a novel member of family Mycoplasmataceae. 
A single colony of Aspergillus fumigatus was recovered from the lung of a harbour porpoise this was thought to be an incidental finding.

\section{Section 13: Virology}

The role of viral infection in the morbidity and mortality of stranded marine mammals in Scotland is not clear, and although virology screening is conducted as part of epizootic or mass stranding investigations, it has not been undertaken routinely.

Screening for morbillivirus was undertaken on 45 of the Cuvier's beaked whales involved in the UME (see section 4) all proved negative.

Forty-two cases from previous years were sent for virology screening, as histological examination suggested possible viral involvement. Six cases proved positive for Herpesvirus, three odontocetes, one common dolphin, one harbour porpoise and one white-beaked dolphin all from 2017. Additionally three mysticetes all minke whales also proved positive for Herpesvirus. Morbillivirus was detected in two white-beaked dolphins from 2015 and 2016.

\section{Section 14: Volunteer training courses}

Scotland has over 10,000 miles of coastline, including over 800 islands; an enormous area to cover for the SMASS team alone. Consequently, since 2014, we have implemented an initiative to recruit and train collaborators and members of the public in the safe, reliable and accurate measurement and sampling of dead stranded marine animals. This outlines techniques used for encouraging the public to report strandings and assesses how effective this approach has been to add data and samples to the scheme. Coined by one volunteer as a way of training "Whale Detectives", the programme has proved invaluable to SMASS in both providing rapid and reliable information and images about strandings and in many cases measurement and samples from cases too autolysed, or remote, to enable a necropsy.

\subsection{Courses run 2018}

Two courses were run in 2018 both at Inverness, to help fill in gaps in our coverage.

1. $09 / 07 / 18$ training course for new SMASS Volunteers at Inverness SAC.

2. 05/12/18 training course for new SMASS Volunteers at Inverness SAC.

Since beginning this initiative in 2014, we have trained 212 people, of which 210 were considered competent to be issued with a kit and wished to be a volunteer, a single volunteer declined to sample. 


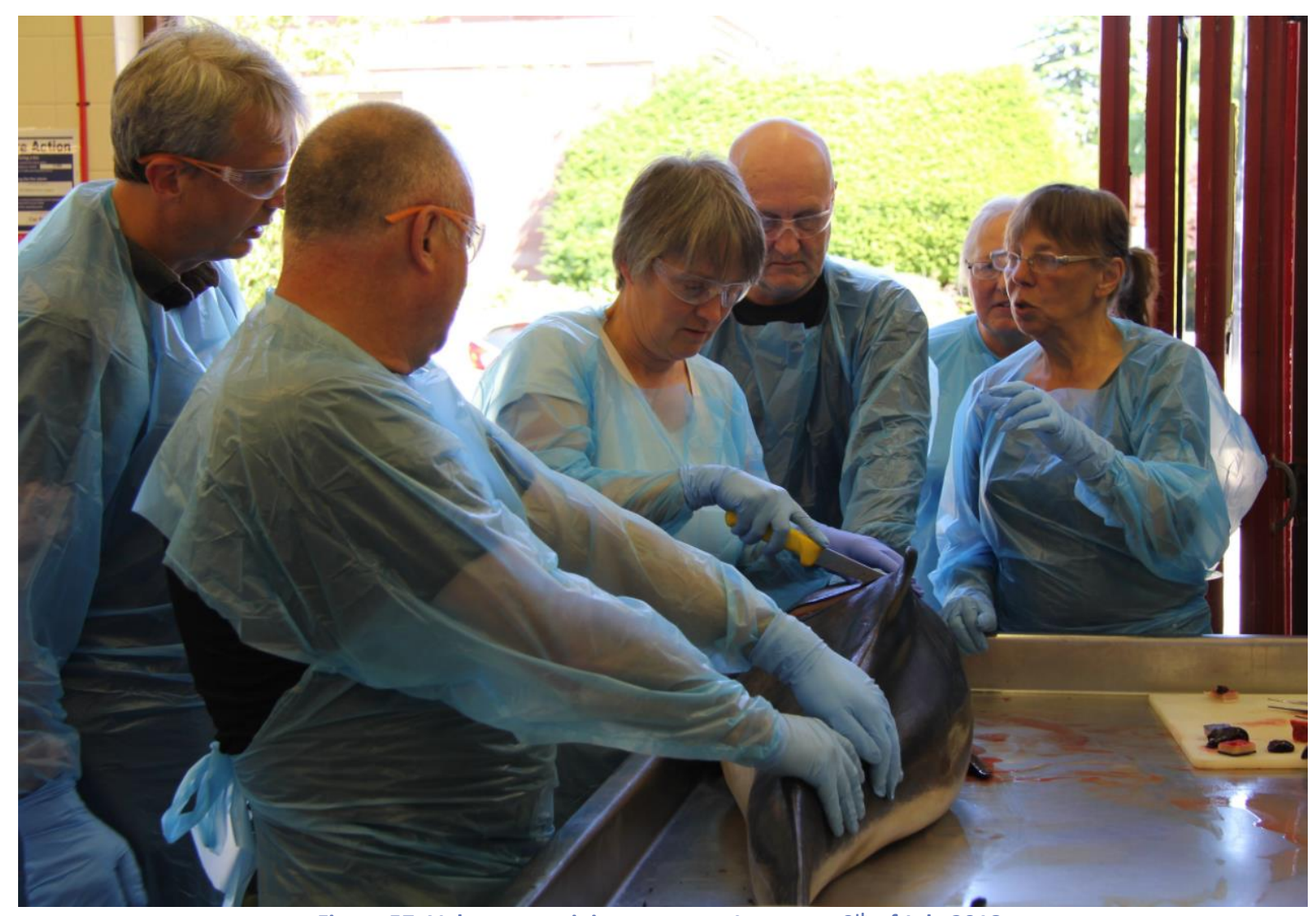

Figure 57: Volunteer training course at Inverness $9^{\text {th }}$ of July 2018.

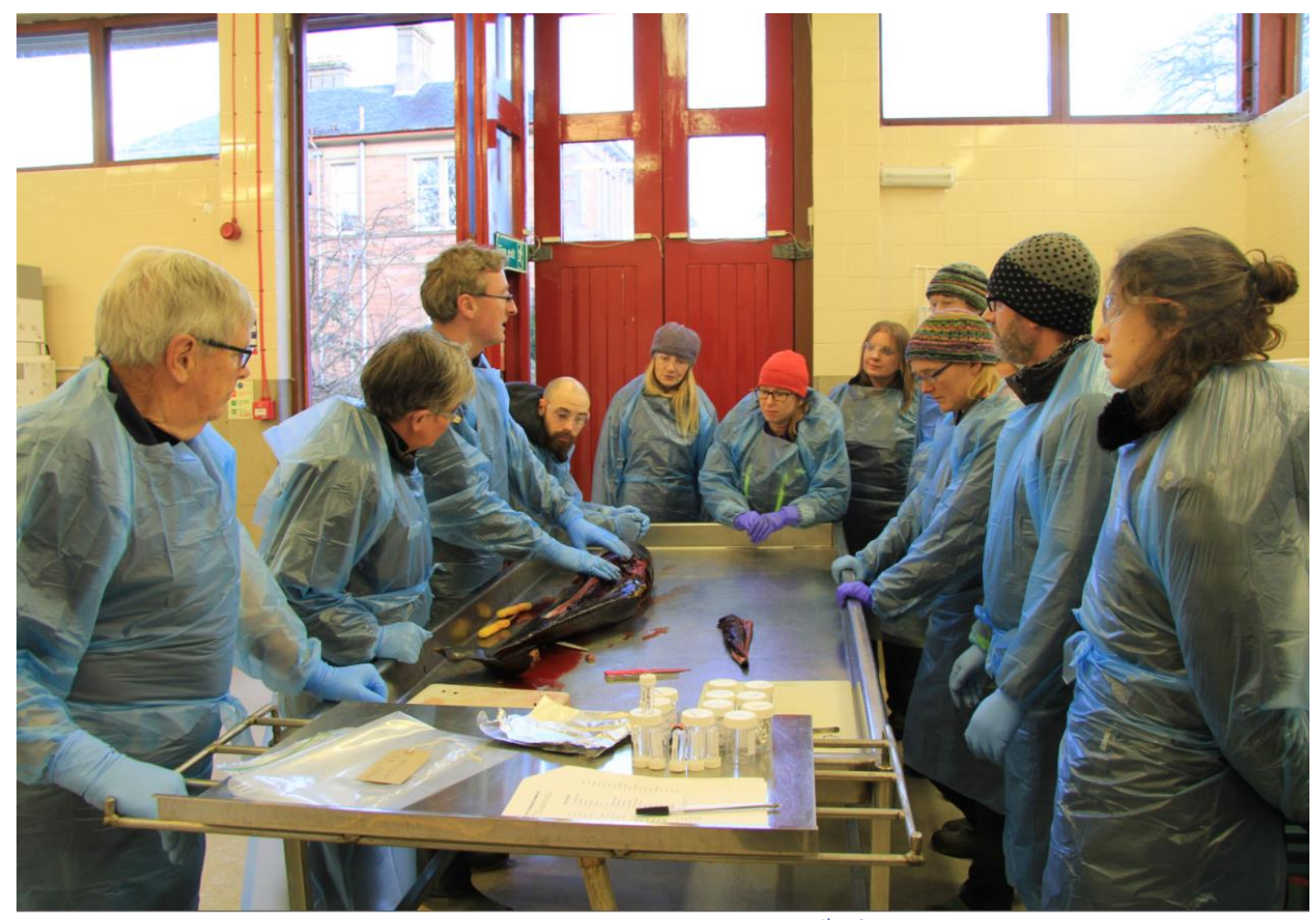

Figure 58: Volunteer training course at Inverness $5^{\text {th }}$ of December 2018. 


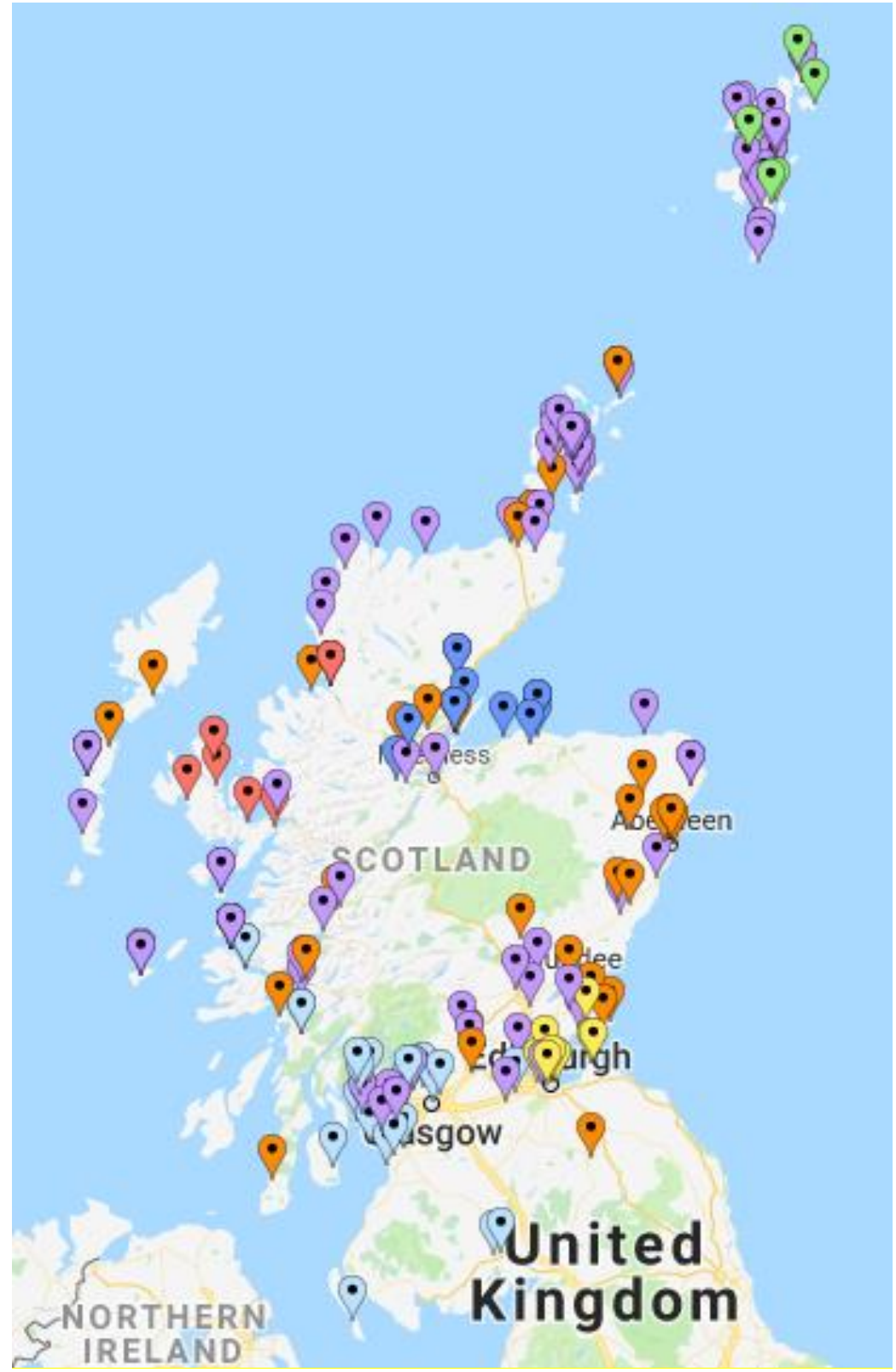

Figure 59: Distribution of stranding volunteers, colours representing the different WhatsApp groups 


\section{Section 15: Necropsy demonstrations and outreach}

\subsection{SMASS Forum}

On the $20^{\text {th }}$ of January, SMASS held the first 'forum' a day of talks and workshops highlighting some of the marine mammal research taking place in Scotland. The event was open to SMASS volunteers and the public held at the Inverness Campus, with capacity being limited to 100 by the lecture theatre on site. It was a ticketed event, with the cost of the ticket covering lunch, and was fully subscribed, with around 20 on a waiting list. Feedback was good, and it is hoped to make this an annual event.

\section{Morning Session}

UHI Campus Inverness,

1 Inverness Campus, IV2 5NB

10:00 - 10:10 Welcome by SMASS

10:10 - 10:40 Dead useful - Andrew Brownlow (SMASS)

10:40 - 11:00 Sounds under the sea - Ben Wilson (UHI/SAMS)

11:00 - 11:20 Harbour Seal Decline Project: Investigating the decline in harbour seal numbers around regions of Scotland - Monica Civil Arso (SMRU)

11:20 - 11:50 In the Company Of Dolphins-Charlie Philips (WDC)

11:50-12:10 A Rubbish Year - Sorcha Cantwell (Scottish beach clean-up project)

12:10 - 12:35 Evidence for change - Lauren Hartny-Mills (HWDT)

12:35 - 12:45 Elevator pitches - Quick description and summary of workshops

\section{Afternoon Session}

An Lochran, UHI Campus Inverness

10 Inverness Campus, IV2 5NB

---- LUNCH ---

provided to all with a valid ticket

$13: 45-14: 15$

Workshop round I

$14: 15-14: 45$

Workshop round II

$14: 45-15: 15$

Workshop round III

\section{---- End of Workshops ----}

15:15 - 16:00 Volunteer feedback session (SMASS volunteers only)

\section{Workshops:}

1. Dolphin photo-ID research - how you can get involved.

Host: Dr Barbara Cheney, Aberdeen University, Cromarty lighthouse field station Description: A practical introduction to the University of Aberdeen's new citizen 
science project and how you can help with their long running bottlenose dolphin photo-identification project.

2. Introduction to Shorewatch; a taster

Host: Katie Dyke, Whale and Dolphin Conservation Description: An interactive taster session to the Shorewatch programme, including species cues and testing your skills on species ID!

3. Get the Picture?! - An Introduction to Marine Mammal Photography

Host: Charlie Phillips, Whale and Dolphin Conservation Description: A workshop on how to take good, safe and respectful photos of marine mammals from the perspective of increasing the quality of images that are not only pretty, but useful to science as well.

4. Mock Mass Stranding Events

Host: Stephen Marsh (British Divers Marine Life Rescue) Description: In recent years, mass strandings of pilot whales around the Scottish coast have become more regular. BDMLR has a good track record on rescues with over $60 \%$ of mass stranded whales returned to the water. But are we missing out on some vital information that could be gathered on the day? Could we learn about strandings by looking a bit closer at the behaviour and patterns of the whales?

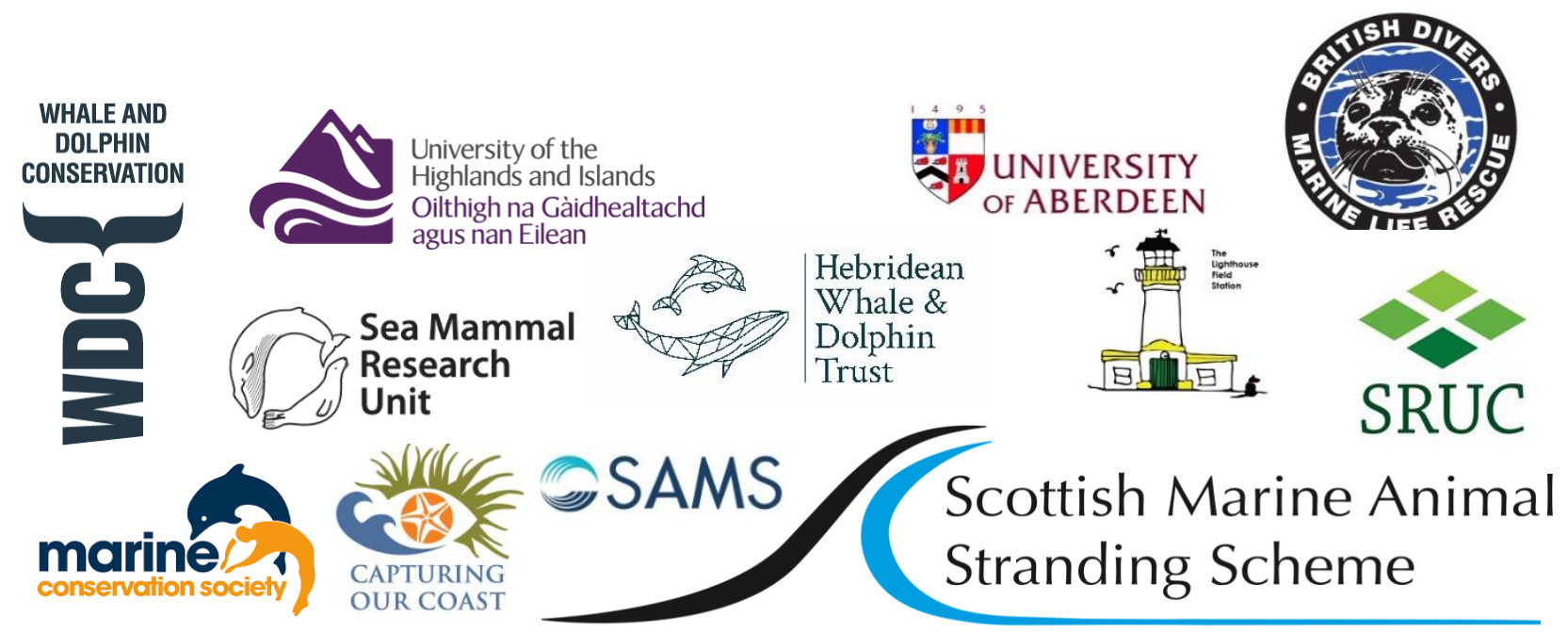




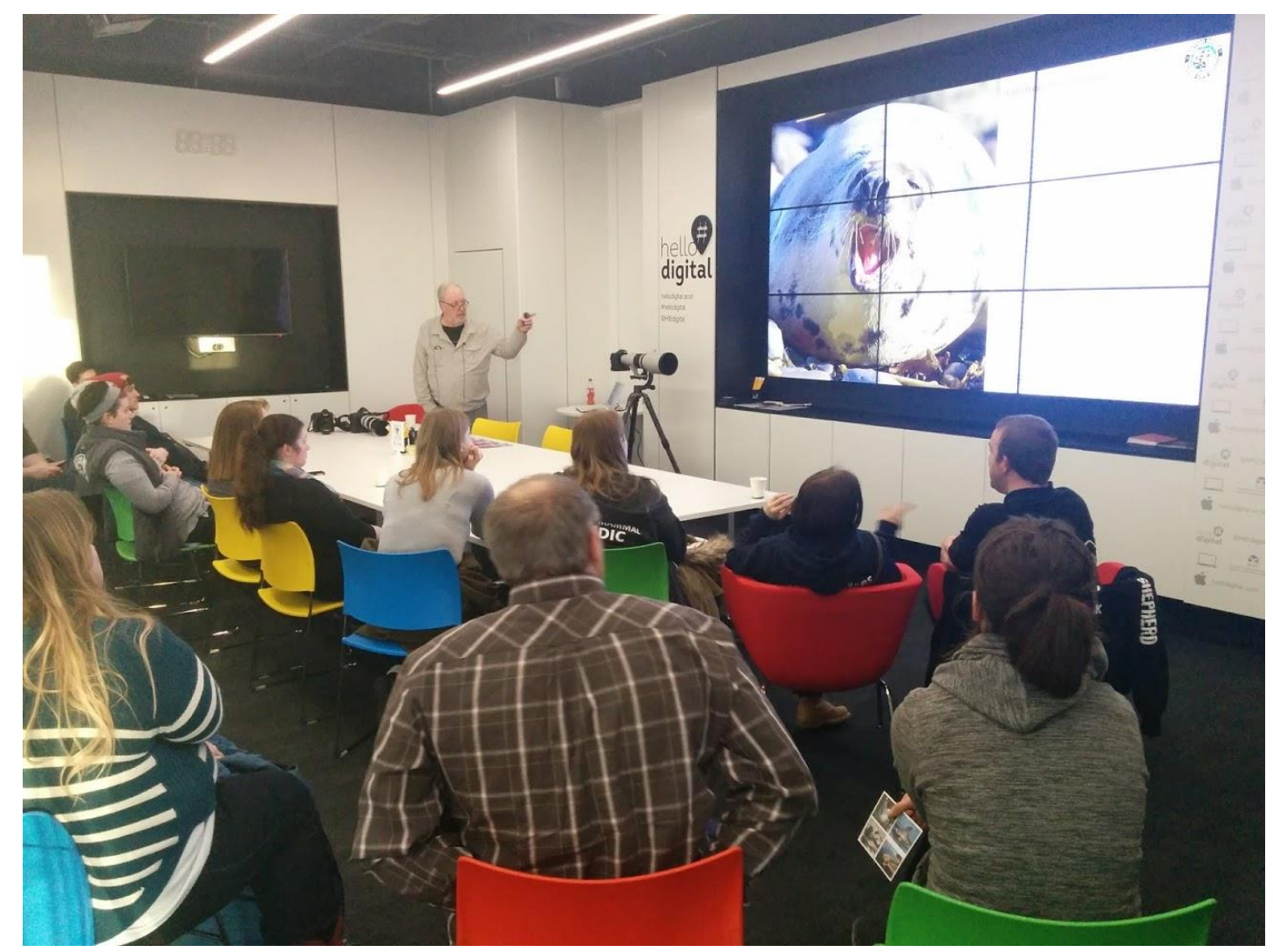

Figure 60: WDC Photographer Charlie Phillips giving a workshop on wildlife photography at the SMASS forum.

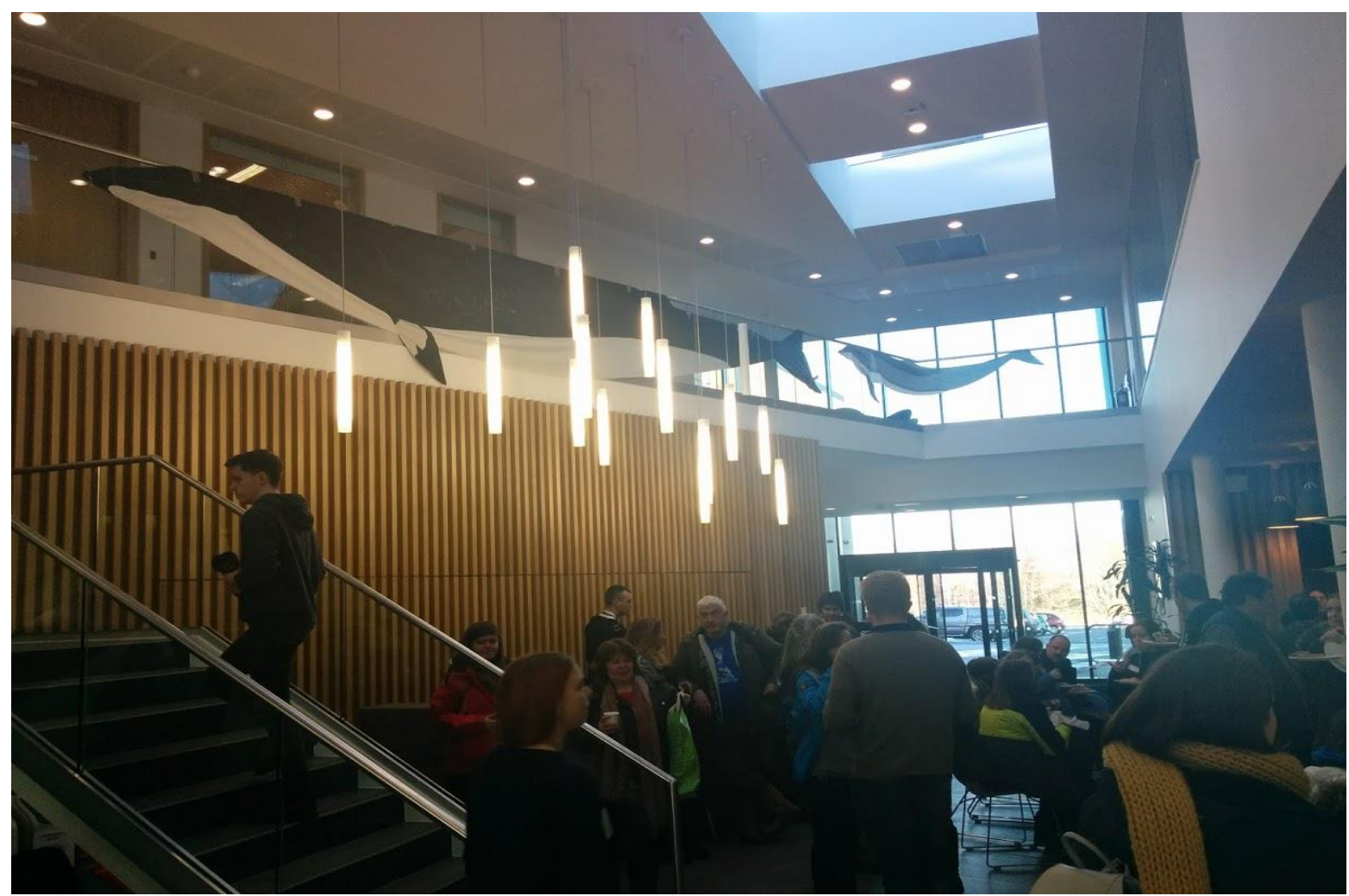

Figure 61: Delegates enjoying lunch at the SMASS forum 


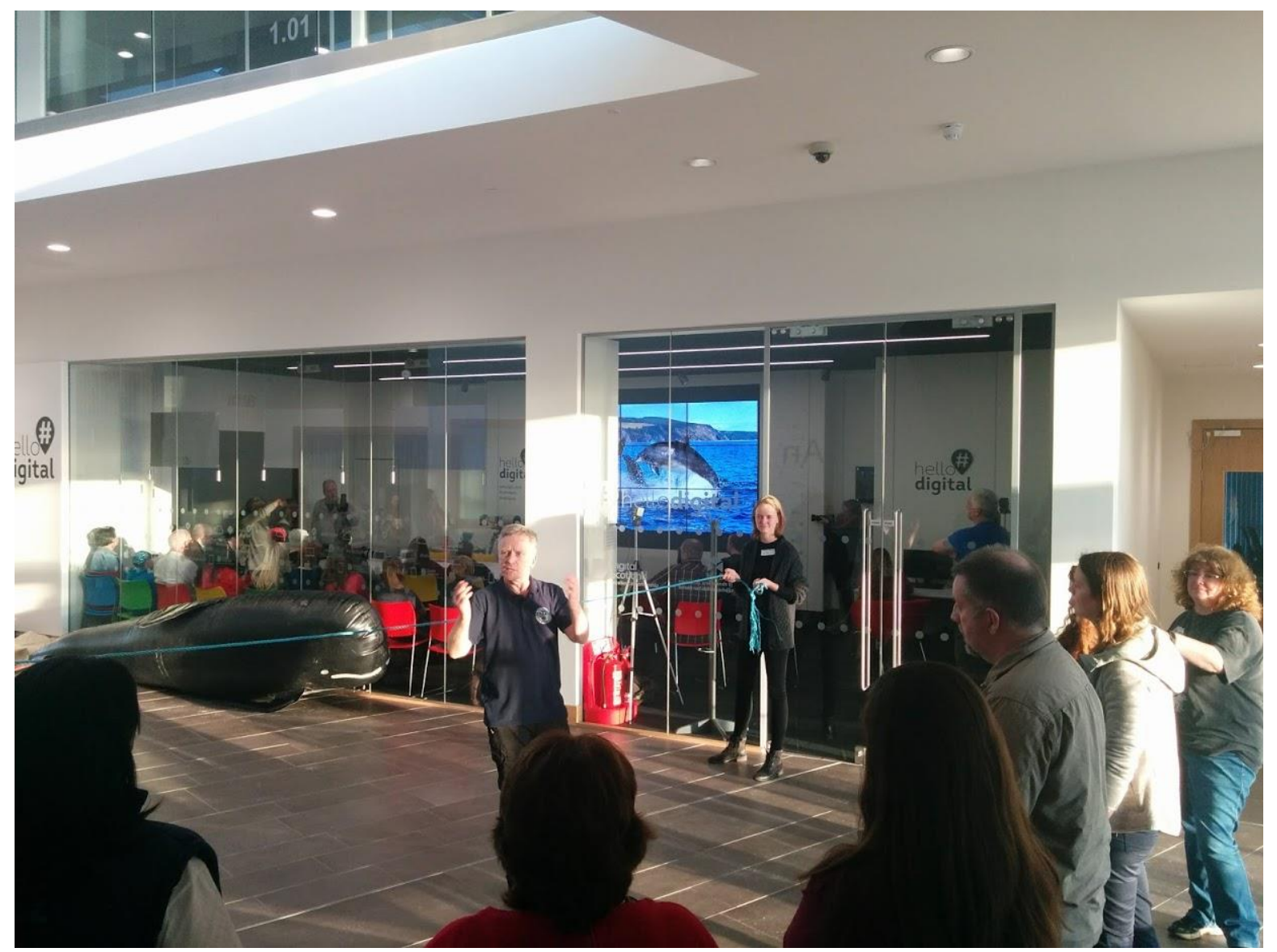

Figure 62: Stephen Marsh Operations Manager for British Diver's Marine Life Rescue (BDMLR) gets volunteers involved in a mock mass stranding workshop at the SMASS forum. 
In addition to the volunteer training courses and the Forum, SMASS have run a single necropsy demonstration to marine science undergraduate students from Scottish Association for Marine Science (SAMS) on the $6^{\text {th }}$ of November.

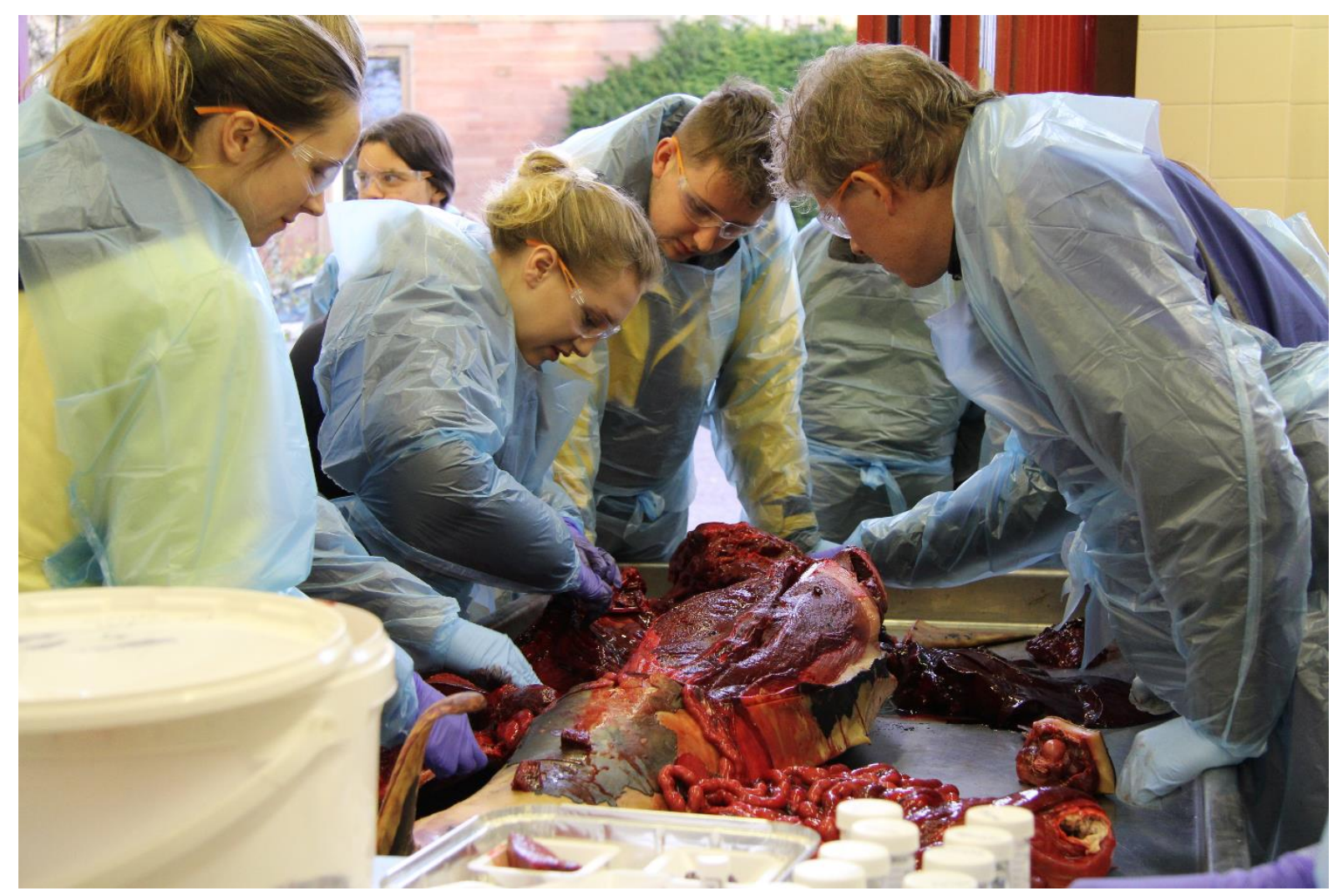

Figure 63: Necropsy Demonstration for Scottish Association for Marine Science (SAMS) undergraduate students at Inverness, $6^{\text {th }}$ of November.

\section{Section 16: Outputs}

16.1 Overview

In 2018, staff at the Scottish Marine Animal Strandings Scheme generated three peer reviewed papers, one book chapter and three conference presentations.

\subsection{Publications}

- Lonneke L. IJsseldijk, Mariel T.I. ten Doeschate, Nicholas J. Davison, Andrea Gröne, Andrew C. Brownlow (2018). Crossing boundaries for cetacean conservation: Setting research priorities to guide management of harbour porpoises. Marine Policy, 95: 7784. https://doi.org/10.1016/j.marpol.2018.07.006

- Lonneke L. IJsseldijk, Abbo van Neer, Rob Deaville, Lineke Begeman, Marco van de Bildt, Judith M.A. van den Brand, Andrew Brownlow, Richard Czec, Willy Dabin, Mariel ten Doeschate, Vanessa Herder, Helena Herr, Jooske IJzer, Thierry Jauniaux, Lasse Fast 
Jensen, Paul D. Jepson, Wendy Karen Jo, Jan Lakemeyer, Kristina Lehnert, Mardik F. Leopold, Albert Osterhaus, Matthew W. Perkins, Uwe Piatkowski, Ellen PrengerBerninghoff, Ralf Pund, Peter Wohlsein, Andrea Gröne, Ursula Siebert. Beached bachelors: An extensive study on the largest recorded sperm whale Physeter macrocephalus mortality event in the North Sea (2018) PLoS ONE 13(8): e0201221. https://doi.org/10.1371/journal.pone.0201221

- Sinéad Murphy, Robin J. Law, Robert Deaville, James Barnett, Matthew W. Perkins, Andrew Brownlow, Rod Penrose, Nicholas J. Davison, Jonathan L. Barber, Paul D. Jepson (2018). Organochlorine Contaminants and Reproductive Implication in Cetaceans. In book: Marine Mammal Ecotoxicology (ISBN: 9780128121443), Editors: Maria Cristina Fossi Cristina Panti, Part 1, Chapter 1.Pages 3-38

- Lonneke L. IJsseldijk, Andrew Brownlow, Nicholas J. Davison, Rob Deaville, Jan Haelters, Guido Keijl, Ursula Siebert \& Mariel T.I. ten Doeschate (2018)

Spatiotemporal trends in white-beaked dolphin strandings along the North Sea coast from 1991-2017 Lutra 61 (1): 153-163

\subsection{Publications (Submitted)}

- S. E. Nelms, J. Barnett, A. Brownlow, N. J. Davison, R. Deaville, T. S. Galloway, P. K. Lindeque, D. Santillo \& B. J. Godley. Microplastics in marine mammals stranded around the British coast: ubiquitous but transitory? Nature Scientific Reports.

- Milaja Nykänen, Kristin Kaschner, Willy Dabin, Andrew Brownlow, Nicholas J. Davison, Rob Deaville, Rod Penrose, Valentina Islas-Villanueva, Nathan Wales, Simon N. Ingram, Emer Rogan, Marie Louis and Andrew D. Foote. Post-glacial Colonisation History of Bottlenose Dolphins at the Northern Extreme of Their Range: A Marine Leading-edge Expansion? Submitted to Journal of Heredity

\subsection{Conference Presentations}

- Andrew Brownlow, Nicholas J Davison, Mariel ten Doeschate, Mark P. Dagleish Emerging pathologies of bacterial infections in Scottish strandings. Presentation for the pathology workshop at ECS in La Spezia, $7^{\text {th }}$ April.

- Andrew Brownlow, Mariel ten Doeschate, Nick Davison, Robert Deaville, Mark Dagleish, James Barnett, Jon Barber, Rod Penrose, Matthew Perkins and Paul D. Jepson. So why do they strand? What we know from 25 years of marine mammal surveillance in the UK. Presentation, European Wildlife Diseases Association (EWDA) in Larissa, Greece $27^{\text {th }}$ to the $31^{\text {st }}$ of August.

- Mariel ten Doeschate, Nicholas J. Davison, Robert Deaville, Mark P. Dagleish, James Barnett, Jon Barber, Rod Penrose, Matthew Perkins, Paul D. Jepson, and Andrew Brownlow, 
Dead useful; Separating the Signal From the Noise through Marine Mammal Strandings Surveillance Presentation, European Wildlife Diseases Association (EWDA) in Larissa, Greece $27^{\text {th }}$ to the $31^{\text {st }}$ of August.

\subsection{Media}

The adult male long-finned pilot whale that live stranded and died on Calgary beach, Mull, on the $19^{\text {th }}$ January received media attention.

https://www.pressandjournal.co.uk/fp/news/islands/1399315/needs-pic-long-finned-pilotwhale-dies-stranding-mull/

The SMASS held on the 20th January received some coverage.

http://www.bbc.co.uk/news/uk-scotland-highlands-islands-42439945

http://www.invernesscampus.co.uk/news/2018/a-first-for-scottish-marine-strandingforum/

A BBC radio Scotland interview with Andrew was recorded on the 19th January, and broadcasted on the 20th January.

The live stranding of a sperm whale at Buddon Ness in Angus on the 21th of March attracted quite a bit of media coverage

https://www.thecourier.co.uk/fp/news/local/angus-mearns/624009/video-watch-ascomplex-operation-to-probe-death-of-and-bury-tay-sperm-whale-gets-under-way/

https://www.scotsman.com/news/environment/autopsy-to-be-performed-on-spermwhale-found-on-scottish-beach-1-4713004

http://www.dailymail.co.uk/news/article-5531375/A-12-metre-sperm-whale-dies-washingScottish-beach.html

https://www.mirror.co.uk/news/uk-news/heartbreaking-drone-footage-shows-body$\underline{12231698}$

https://www.eveningexpress.co.uk/fp/news/scotland/watch-sadness-as-massive-40ftwhale-washed-up-at-scottish-beach-dies/

In April, the unsuccessful re-float of a harbour porpoise at Crammond near Edinburgh attracted some local press interest.

https://www.edinburghnews.scotsman.com/news/porpoise-stranded-on-cramond-islanddies-after-failed-rescue-bid-1-4731222

In May, the rare report of a harp seal pup on Skye and its subsequent necropsy attracted quite a bit of media interest including the National Geographic magazine. http://www.bbc.co.uk/news/uk-scotland-highlands-islands-44314724 https://news.nationalgeographic.com/2018/05/seal-plastic-death-climate-changeanimals/?utm source=Facebook\&utm medium=Social\&utm content=link fb20180531new s-sealpupplastic\&utm campaign=Content $\&$ sf190778010=1 
In August, yet another harp seal turned up this time in Aberdeenshire and attracted some media interest. This actually turned out to be a grey seal pup with patches of alopecia.

https://www.bbc.co.uk/news/uk-scotland-highlands-islands-45127499

https://www.pressandjournal.co.uk/fp/news/aberdeen/1537878/lost-arctic-seal-washesup-dead-on-aberdeenshire-beach/

https://www.eveningexpress.co.uk/fp/news/local/investigation-after-arctic-seal-founddead-on-north-east-beach/

In August and September an unusual mortality event (UME), involving Cuvier's beaked whales attracted a large amount of press coverage.

https://www.bbc.co.uk/news/uk-scotland-highlands-islands-45342576

https://www.bbc.co.uk/news/uk-scotland-highlands-islands-45446869

https://www.bbc.co.uk/news/uk-scotland-highlands-islands-45508188

https://www.thetimes.co.uk/article/deaths-of-40-whales-on-west-coast-prompts-inquiry3j062677r

https://www.thetimes.co.uk/article/suspicion-falls-on-submarines-for-record-number-ofwhale-deaths-vj6lbgl93

https://uk.whales.org/blog/2018/08/why-are-beaked-whales-stranding-on-irish-andscottish-coasts-again

https://www.pressandjournal.co.uk/fp/news/islands/1561124/a-spate-of-whale-strandingsalong-scotlands-west-coast-is-being-linked-to-the-search-for-a-russian-sub/

http://www.thejournal.ie/record-number-of-dead-beaked-whales-washed-ashore-inireland-this-month-4203674-Aug2018/

https://www.pressandjournal.co.uk/fp/news/highlands/1559575/mystery-surroundslargest-number-of-recorded-deep-sea-whale-strandings-on-west-coast-of-scotland/

https://www.sundaypost.com/fp/scientists-investigate-as-dozens-of-whales-wash-up-onscottish-coast/\#r3z-addoor

https://www.stornowaygazette.co.uk/news/mystery-of-the-large-number-of-strandingsacross-the-islands-1-4805658

https://www.obantimes.co.uk/2018/09/11/whale-washes-up-in-mystery-strandings/

https://www.thesun.co.uk/news/7237867/beaked-whale-deaths-scotland-russian-

submarines-uk-coast/

https://www.pressreader.com/uk/the-press-and-journal-inverness-highlands-andislands/20181004/281522227030972

https://www.communitiesforseas.scot/beaked-whales-stranding-again/

https://www.pressandjournal.co.uk/fp/lifestyle/animals/1547143/whale-deaths-alongscottish-and-irish-coasts-may-be-linked-to-military-games/

https://www.campbeltowncourier.co.uk/2018/09/11/whale-washes-up-in-mysterystrandings/ 
https://extra.ie/2018/09/22/news/irish-news/whale-deaths-irish-coast-submarines

https://www.thetimes.co.uk/article/war-games-may-be-killing-whales-say-campaignersrwann9nzp

https://www.galwaydaily.com/news/mystery-mass-whale-deaths-hit-record-high/

In September, the recovery and subsequent necropsy of a minke whale also resulted in some media coverage.

https://www.bbc.co.uk/news/uk-scotland-highlands-islands-45630725

https://www.pressandjournal.co.uk/fp/news/highlands/1566619/minke-whale-dies-afterwashing-up-on-highland-beach/

https://www.bbc.co.uk/news/uk-scotland-highlands-islands-45572528

https://www.inverness-courier.co.uk/News/Rescuers-fail-to-save-beached-minke-whale20092018.htm

https://www.dailyrecord.co.uk/news/scottish-news/massive-21ft-whale-carcass-hauled$\underline{13300057}$

In October, the continuing UME of beaked whales along the West coast of Scotland and Ireland continued to attract attention

https://www.bbc.co.uk/news/uk-scotland-45643374

https://www.pressandjournal.co.uk/fp/news/islands/shetland/1584371/shetwhaless/ https://www.livescience.com/63949-unprecedented-dead-whales-scotland-ireland.html In November a fairly manky minke attracted some media attention.

https://www.thecourier.co.uk/fp/news/local/angus-mearns/771341/whale-discovered-onangus-beach-to-be-buried-today/

A stranded basking shark also in attracted a bit of attention too.

https://www.thecourier.co.uk/fp/news/local/angus-mearns/771136/such-a-magnificentbeast-body-of-20ft-basking-shark-washes-up-on-angus-coast/

https://www.pressreader.com/uk/the-courier-advertiser-perth-and-perthshireedition/20181124/281552291909201

In December, a mass stranding of pilot whales in the Firth of Forth attracted some media interest.

https://www.bbc.co.uk/news/uk-scotland-edinburgh-east-fife-46469948

https://www.thecourier.co.uk/fp/news/local/fife/778409/animals-rescuers-called-afterpod-of-whales-found-stranded-near-fife-village/

https://www.edinburghlive.co.uk/news/edinburgh-news/four-pilot-whales-die-after$\underline{15519040}$

https://www.thecourier.co.uk/fp/news/local/fife/779885/experts-fear-pilot-whalesstranded-near-fife-village-have-perished/ 
https://stv.tv/news/east-central/1433528-three-whales-die-despite-rescue-efforts-afterbeaching/

https://www.dunfermlinepress.com/news/17275506.experts-fear-remaining-whale-maybe-injured-or-ill/

https://www.thecourier.co.uk/fp/news/local/fife/779202/concern-for-whales-after-expertslose-track-of-forth-pod/

https://www.thecourier.co.uk/fp/news/local/fife/780282/sad-end-for-forth-pod-as-twowhales-dead-and-two-likely-to-be-euthanised/

Also in December, the UME also made the news again this time in the Herald despite no one from SMASS actually talking to the paper or releasing any results.

https://www.heraldscotland.com/news/17328433.scientists-point-finger-for-mass-whaledeaths-at-rise-in-submarine-war-games/

\subsection{Conferences/meetings}

- Mariel and Andrew presented talks at the European Cetacean Society (ECS) annual conference in La Spezia, Italy 8th-10th of April

- Mariel and Andrew presented tow talks at the European Wildlife Disease Association (EWDA) in Larissa, Greece 27th to the 31st of August.

- Andrew attended the Agreement on the Conservation of Small Cetaceans of the Baltic and North Seas (ASCOBANS) conference in Vilnius, Lithuania 25th - 26th September.

- Mariel and Andrew presented talks at Marine Alliance for Science and Technology Scotland (MASTS) science conference in Glasgow 31st to 2nd of November.

- Andrew was invited to represent the UK CSIP at a workshop sponsored by Sea Alarm https://www.sea-alarm.org/ aiming to improving preparedness and capability to respond to marine wildlife emergencies. Brest, Oct 8th-11th 2018

\subsection{Other collaborations}

Raquel Puig Lozano from the University of Las Palmas, Grand Canaria, Spain had a week's internship with SMASS in December. 


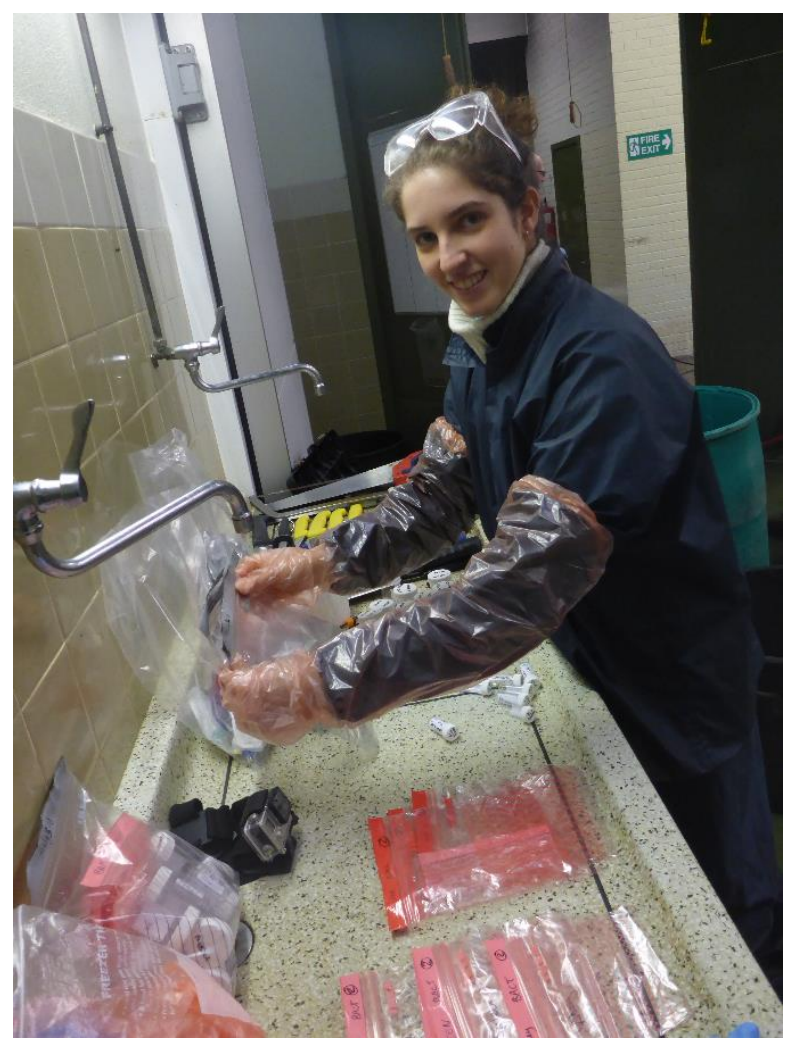

Figure 64: Raquel Puig Lozano from the University of Las Palmas, Grand Canaria during the pilot whale MSE December 2018.

\subsection{Website and digital media}

Facebook and Twitter pages were set up in October 2012. We post regular stranding reports, selected photos and requests for information on strandings on both. Feedback has generally been good and at the end of January 2019 Facebook has over 9300 likes and Twitter has over 1000 followers. Both still prove a valuable resource for the reporting of strandings to the scheme. 


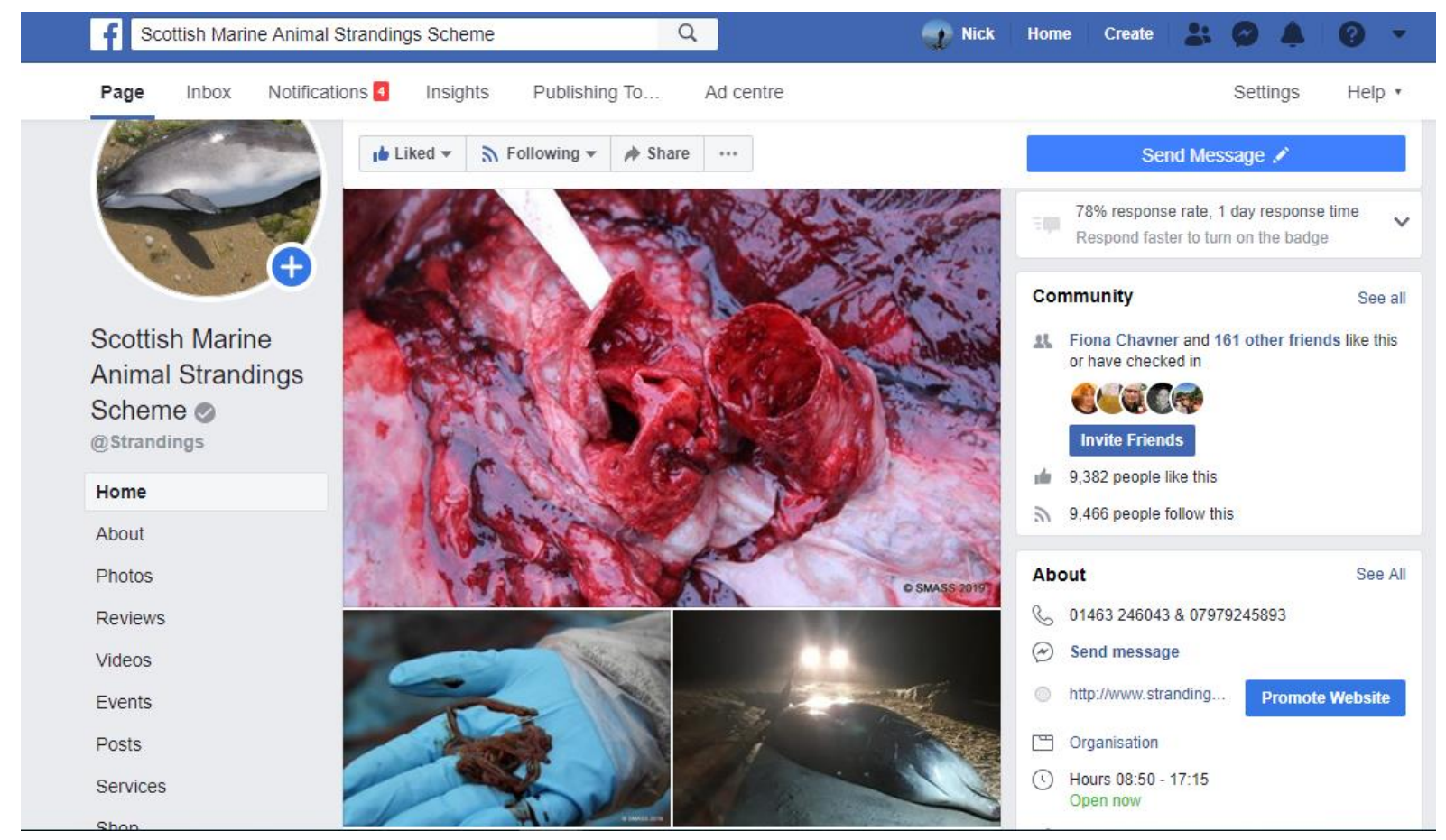

Figure 65: Facebook front page, Jan 2018.

16.9 Data and sample requests

These are either part of on-going collaborations or one off requests for data and or samples.

\subsubsection{Samples sent}

- $24 / 01 / 2018$ skin samples from grey and harbour seals for genetic analysis. Kristina Steinmetz student GMIT Galway, Ireland.

- 06/03/2018 fixed helminths sent for identification. Natalia Fraija-Fernandez NHM London helminth post doc research.

- 07/03/2018 fixed helminths sent for identification. Natalia Fraija-Fernandez NHM London helminth post doc research.

- 13/03/2018 faeces and urine for domoic acid analysis, ongoing collaboration with Ailsa Hall SMRU.

- 13/03/2018 cetacean stomach contents for prey analysis, new collaboration with Simon Northridge SMRU.

- 14/03/2018 fixed helminths sent for identification. Natalia Fraija-Fernandez NHM London helminth post doc research.

- 19/03/2018 fixed helminths sent for identification. Natalia Fraija-Fernandez NHM London helminth post doc research.

- 27/03/2018 fixed helminths sent for identification. Natalia Fraija-Fernandez NHM London helminth post doc research.

- 19/06/2018 Kerri Smith Smithsonian Institution Predoctoral Fellow Wildlife Ecology and Conservation Lab Environmental Science and Engineering Program University of Texas at El Paso Sowerby's beaked whale tissues for stable isotope analysis 
- 26/06/2018 Emma Carroll SMRU skin samples from beaked whales for genetic analysis as part of Morten Olsen's project.

- 10/08/2018 Emma Carroll SMRU skin samples from beaked whales for genetic analysis as part of Morten Olsen's project.

- 16/08/2018 Emma Carroll SMRU skin samples from beaked whales for genetic analysis as part of Morten Olsen's project.

- 08/10/2018 Emma Carroll and Aubrie Onoufriou SMRU muscle samples from beaked whales for genetic analysis as part of UME investigation

- 15/11/2018 Emma Carroll and Aubrie Onoufriou SMRU muscle samples from beaked whales for genetic analysis as part of UME investigation

- 22/11/2018 Mara Rocchi Virus Surveillance Moredun Institute UME beaked whale samples for morbillivirus PCR

\subsubsection{Data sent}

- 25/01/2018 data on skin samples from grey and harbour seals for genetic analysis. Kristina Steinmetz student GMIT Galway, Ireland.

- 22/02/2018 data on Orkney seal strandings, Brian Ribbands Orkney Field Club.

- 26/02/2018 Data on harbour seal strandings 1992-2017 for population model. Monica Arso/ Ailsa Hall SMRU.

- 06/03/2018 data on fixed helminths sent for identification. Natalia Fraija-Fernandez NHM London helminth post doc research.

- 09/03/2018 Data on seal Strandings Skye, Kintyre, Orkney Monica Arso SMRU

- 14/03/2018 data on fixed helminths sent for identification. Natalia Fraija-Fernandez NHM London helminth post doc research.

- 19/03/2018 data on fixed helminths sent for identification. Natalia Fraija-Fernandez NHM London helminth post doc research.

- 19/03/2018 data on turtle strandings for 2017 Rod Penrose MEM Wales

- $27 / 03 / 2018$ data on fixed helminths sent for identification. Natalia Fraija-Fernandez NHM London helminth post doc research.

- 20/04/2018 Georg Hanke National Museum of Scotland data on large cetacean strandings on the Uists 2013-2017.

- 10/05/2018 Alexandra Epple Virginia Aquarium Stranding Response Program, Virginia USA Information on BND attacks on porpoises in particular case $\mathrm{M} 277 / 18$

- 18/05/2018 Zena Timmons National Museum of Scotland Data on particular individuals stranded on the Western Isles for potential collection trip

- 24/05/2018 Emma Milne SMRU MSc student Meta data on faeces/urine samples domoic acid study with Ailsa Hall

- 07/06/2018 Nikki Taylor JNCC Cause of death of UK seals data in 2010-2011 for reporting.

- 19/06/2018 Kerri Smith Smithsonian Institution Predoctoral Fellow Wildlife Ecology and Conservation Lab Environmental Science and Engineering Program University of Texas at El Paso Data on Sowerby's beaked whale tissues for stable isotope analysis

- 26/06/2018 Emma Carroll SMRU Data on skin samples from beaked whales for genetic analysis as part of Morten Olsen's project.

- 12/07/18 Monica Arso Civil, data on seal strandings Skye, Kintyre, Orkney. 
- $10 / 08 / 2018$ Emma Carroll SMRU data on skin samples from beaked whales for genetic analysis as part of Morten Olsen's project.

- 16/08/2018 Emma Carroll SMRU data on skin samples from beaked whales for genetic analysis as part of Morten Olsen's project.

- 09/11/2018 Denise Risch and Steven Benjamins SAMS Data on Minke whale strandings.

- 12/11/2018 Kerri Smith "Smithsonian Institution Predoctoral Fellow Wildlife Ecology and Conservation Lab Environmental Science and Engineering Program University of Texas at EI Paso Data UME and other beaked whale strandings

- 15/11/2018 Aubrie Onoufriou SMRU Data on beaked whale samples

- 13/11/2018 Wojtek Bachara Independent beaked whale specialist Data on Cuviers UME

- 14/11/2018 Nikki Taylor JNCC Data on Minke whale findings

- 22/11/2018 Mara Rocchi Virus Surveillance Moredun Institute Data on UME beaked whale samples for morbillivirus PCR

- $23 / 11 / 2018$ Nicola Hodgins WDC Data on BND strandings in Lewis and Harris

- 18/12/2018 Alex Coram SMRU Data on minke whale entanglements

- 20/12/2018 Mary Harman SMASS volunteer data on beaked whale UME for Western Isles

\subsection{Collaborators}

- Dr Mark Dagleish Moredun Research Institute, Pentlands Science Park, Bush Loan, Penicuik, Midlothian, EH26 OPZ, Scotland. Histopathological studies on cetacean tissues from Scottish cetaceans.

- Dr Andrew Kitchener, Royal Museum of Scotland, Edinburgh, Scotland. Recording all marine mammal stranding events in Scotland. Marine mammal skulls and scapulae are sent to Dr Kitchener for marine mammal morphometric studies.

- Professor Ailsa Hall SMRU. Biotoxin screening for levels of domoic acid

- Dr Eva Krupp, Aberdeen University. Metal residue analysis of tissues collected at necropsy

- Dr Barbara Cheney, Aberdeen University. Bottlenose dolphin necropsy details for comparison with photo-id catalogue.

- Dr Graham Pierce, University of Aberdeen, Oceanlab, Main Street, Newburgh, Aberdeenshire, Scotland, AB41 6AA, UK Collaboration on life history, dietary and toxicological studies of harbour porpoises and other cetaceans stranded in Scotland.

- Dr Fiona Read, University of Aberdeen, Oceanlab, Main Street, Newburgh, Aberdeenshire, Scotland, AB41 6AA, UK Collaboration on life history and teeth aging cetaceans stranded in Scotland.

- Mycoplasma dept., Animal and Plant Health Agency, New Haw, Addlestone, Surrey, KT15 3NB. Identification of Mycoplasma sp. isolates from marine mammals.

- Emma-Jane Dale Brucella Reference Laboratory, Animal and Plant Health Agency, New Haw, Addlestone, Surrey, KT15 3NB. Serological studies to assess exposure to Brucella spp. and typing of Brucella isolates. 
- Dr. Maria Morell, University of British Columbia (UBC), Canada. Examination of ear bones using scanning and transmission electron microscopy for indirect quantification of hearing ability in mass stranded pilot whale.

- Erasmus Medical Centre, Rotterdam, the Netherlands - bacteriological culture of samples collected following necropsy of marine mammals.

- Scottish Salmonella Reference Laboratory - perform typing of Salmonella isolates

- Lesley Hoyles, Department of Food and Nutritional Sciences, University of Reading, Whiteknights, Reading - performs sequencing of bacterial isolates.

- Dr. Catherine S Jones University of Aberdeen, Skin \& muscle from Basking sharks for DNA analysis.

- Milaja Nykanen, PhD Candidate School of BEES University College Cork Ireland for bottlenose dolphin mitogenome work.

- Eileen Harris Senior Curator Parasites \& Vectors Division Department of Life Sciences Natural History Museum Cromwell Road London SW7 5BD

- Natalia Fraija-Fernandez Cetacean helminth post doc research Parasites \& Vectors Division Department of Life Sciences Natural History Museum Cromwell Road London SW7 5BD

- Kristina Steinmetz student grey and harbour seals for genetic analysis GMIT Galway Ireland.

- Kerri Smith Smithsonian Institution Predoctoral Fellow Wildlife Ecology and Conservation Lab Environmental Science and Engineering Program University of Texas at EI Paso Sowerby's beaked whale tissues for stable isotope analysis

- Monica Arso/ Ailsa Hall SMRU harbour seal declines.

- Lonneke L. Ijsseldijk, BSc Project coordinator Cetaceans Faculty of Veterinary Medicine, Department of Pathobiology Utrecht University Yalelaan Utrecht The Netherlands. Bacteriology

- Emma Carroll / Aubrie Onoufriou / Morten Olsen SMRU beaked whale genetic analysis.

\section{Section 17: $\quad$ Staff and facilities}

SMASS currently has four members of staff. Andrew Brownlow the veterinary pathologist and has managed the project since 2009. Nick Davison is the stranding coordinator and undertakes the microbiology for the scheme. He joined the team in October 2012 and has been involved with marine mammal pathological investigation for 33 years. Mariel ten Doeschate joined as a marine strandings administration assistant in September 2014. Ellie MacLennan Harrison joined in April 2018 to run the Scottish Entanglement Alliance (SEA) project.

Since its inception, SMASS has operated from SRUC Veterinary Services Disease Surveillance centre at Drummondhill, Inverness. It continued to do so for the whole of 2018, however the site was closed in June 2019. SMASS staff have relocated to the Inverness campus site, however the future arrangements for necropsy of marine mammals in the region are unclear. 


\section{Section 18: Acknowledgments}

The successful operation of a strandings project over the 10,000 miles comprising Scotland's coastline is only possible with assistance from a large number of individuals and organisations. These volunteers assist SMASS staff in the identification, recovery, storage and transport of stranded animals. We are immensely grateful to all who helped us out so far in 2018 , however particular thanks are due to the staff and students of the Sea Mammal Research Unit, Hessilhead Wildlife Rescue Trust, Karen Hall and the Scottish Natural Heritage team on Shetland, Georg Hantke of the National Museums of Scotland, British Divers Marine Life Rescue medics, the Hebridean Whale and Dolphin Trust and Mark Dagleish at the Moredun Research Institute.

We are also grateful to all our trained stranding volunteers who have ventured out in all weathers to collect photographs, data and samples from some much decomposed animals. Particular thanks to Sorcha Cantwell, Marc Herridge, Sue Edwards and SMRU for collecting animals. Thanks also to Lee Watson, Vaila Smith, Corrine Gordon, Laura Howieson, Sarah Dolman, David Nairn, Stephanie Cope, Reuben Brown, Malcolm Ogilvie, Vivi Bolin, Lisa Forsyth, Andrew Ferguson, Jack Lucas, Mary Harman, Bill Neil, Jenny Grant, Sue Pomeroy, George Lees, Peggy Semler, Nikki Taylor, Alice Doyle, Catriona Macintyre, Alex Robertson, Stephen Kirkup, Stephanie Cope, Elaine O'Reilly, Steve and Linda Littlewood, Mary Harris, Nick Moore, Kerry Swanson, Kelly Macleod, Andrew Ferguson and Jenny Stark, Ian Thompson, Lindsey Hanekon, Jen Harland, Walter Innes, Monika Carrie, Monica Arso Civil, Mary Clark, Niall McLeod, Pippa Low, Sara Wood-Kwasniewska, Reuben Brown, Andy Knight, Karl Hurd, Pippa Garrard, Gemma Nowrie, Helene G Marc Herridge, Peter Keiller, Gwen Evans, Janet Marshall, Graeme Skea, Mark Fuller, Sorcha Cantwell Leanne McLardy, Alex Burns, Lynn Waddell, Sarah Dolman, Claire Cook, Laura Howieson, Paul Castle, Lisa Forsyth, Imogen Sawyer, James Mckenzie, Kerry Harris, Paul "Smudger" Smith, Richard and Alison Riley, Russell Neeve, Emma Neave- Webb, Jenni Kakkonan, Pete Beavington for sampling animals. Also to Mary Harris and Ross Flett for their efforts in recovering the Atlantic white-sided dolphin from Hoy, Orkney. Special to those who helped recover animals for necropsy, Pippa Low, Jan and Pete Beavington, Jack Lucas, Corinne Gordon, Mary Harman, Georg Hantke, Penny Martin, Karen Hall, Janie Steele and Jamie Dyer. We are also exceptionally grateful to British Divers Marine Life Rescue HM Coastguard - Highland, the Fort George 3rd Battalion Royal Regiment of Scotland, as well as the Highland council and all the locals who came by to lend a hand recovering the minke whale from Ardesier. 